\title{
Utilização de ontologias para busca em um sistema colaborativo de imagens arquitetônicas
}

\author{
Marisol Solis Yucra \\ DisSERTAÇÃo APRESENTADA \\ $\mathrm{AO}$ \\ Instituto DE MATEMÁtica e Estatística \\ DA \\ Universidade De SÃo PaUlo \\ PARA \\ OBTENÇÃO DO TÍTULO \\ $\mathrm{DE}$ \\ Mestre em CiênCiAs \\ Programa: Ciência da Computação \\ Orientadora: Prof ${ }^{\mathrm{a}}$. Dr ${ }^{\mathrm{a}}$. Renata Wasserman
}

Durante o desenvolvimento deste trabalho o autor recebeu auxílio financeiro do CNPq

Processo individual 134319/2013-3

São Paulo, 21 de dezembro de 2016 


\section{Utilização de ontologias para busca em um sistema colaborativo de imagens arquitetônicas}

Esta dissertação contém as correções e alterações sugeridas pela Comissão Julgadora durante a defesa realizada por Marisol Solis Yucra em 27/10/2016.

O original encontra-se disponível no Instituto de Matemática e Estatística da Universidade de São Paulo.

Comissão Julgadora:

- Prof $^{a}$. Dra ${ }^{\mathrm{a}}$. Renata Wassermann (orientadora) - IME-USP

- Prof. Dr. Marco Aurélio Gerosa - IME-USP

- Profa . Dra . Vânia Mara Alves Lima - EP-USP 


\section{Agradecimentos}

O mestrado foi uma etapa de muitos eventos, que me permitiu não somente expandir meus conhecimentos, mas também a crescer pessoalmente.

Agradeço a Deus por me dar força interior para superar as dificuldades, por me mostrar o caminho nas horas incertas e por possibilitar a realização de nossos planos e sonhos.

Agradeço a meus pais (Eugenio e Silveria) e às minhas irmãs Diana e Tania, pelo encorajamento em ser melhor cada dia, pela confiança que sempre depositaram em mim e pelo incondicional apoio em todos os momentos da minha vida.A Edwin pelas suas recomendações, carinho, paciência, compreensão e força que me deu nesta etapa do mestrado.

Agradeço à minha orientadora Renata, pela sua orientação acadêmica e pelo apoio nos momentos mais difíceis nos anos do meu mestrado, suas palavras foram para mim de valor inestimável; obrigada pelas suas recomendações e incentivo ao longo destes anos. Agradeço aos professores do IME pelos diferentes conhecimentos que deles aprendi, por seus comentários, sugestões e esclarecimentos que ajudaram a avançar no meu trabalho. Também a os professores da banca na qualificação e defesa, Prof. Flávio Soares Corrêa da Silva, Profa. Vânia Mara Alves Lima, Marco Aurelio Gerosa pela suas recomendações ao trabalho de mestrado. E ao professor Artur pelas palavras de motivação.

Também agradeço muito e de coração a meus amigos Amanda, Virginia, Silvia, Viviane Bonadia, Ana, Ricardo Ferreira, Jadson, David e Robson, pelas correções com o português. E a todos meus amigos e colegas do LIAMF, entre eles Viviane Menezes, Paulo de Tarso, Filipe Resina, Ricardo Sekeff, Ricardo Hermann, Luis, Adalberto, Ignasi, Letícia e tantos outros que tiveram um importante papel durante essa etapa. Em especial a Fabiano e Esdras, os quais me deram algumas dicas no inicio de meu trabalho.

Com especial carinho agradeço a todos meus amigos peruanos que estudam no IME Lucy, Erika, Leissi, Mariela, Evelyn, Urpi, Jorge, Miguel, Leandro, Edu e muitos mais, pela amizade e momentos de alegrias que compartilhamos nesta fase da minha vida.

Agradeço a todos aqueles que sempre confiaram em mim, desde sempre, pois direta ou indiretamente, contribuíram para a finalização deste trabalho. Um grande abraço e muito obrigada.

Finalmente agradeço a USP e ao IME, pela oportunidade que me brindaram para a realização do mestrado e agradeço ao CNPq pelo apoio financeiro recebido durante a elaboração deste trabalho. 



\section{Resumo}

A recuperação de informação é ainda um assunto essencial a melhorar nos diferentes tipos de sistemas web. Um tipo de sistema web que é muito utilizado na atualidade, é o sistema colaborativo. Estes sistemas permitem que os usuários estejam mais envolvidos, seja contribuindo com a inserção de textos, imagens ou dados, assim como utilizando etiquetas(tags) para identificar aos elementos existentes no sistema e que serão compartilhados com outros usuários.

Nesta dissertação utilizamos um sistema colaborativo de compartilhamento de imagens arquitetônicas, onde os usuários podem inserir títulos e tags livremente para descrever uma imagem. Contudo as tags podem ter um significado ambíguo, resultando em imagens recuperadas que não são relevantes, quando são utilizadas técnicas tradicionais, como por exemplo busca booleana ou por palavra-chave. Além disso, os usuários podem utilizar consultas mais complexas utilizando uma linguagem livre, e utilizando as técnicas mencionadas podem recuperar informação não relevante.

Assim, esta pesquisa aborda, a construção de uma ontologia no domínio arquitetônico denominada OntoArq, baseada no vocabulário controlado da USP e no tesauro experimental de arquitetura brasileira, a qual possibilitou fortalecer a relação entre as tags e os conceitos estruturados da ontologia, por meio de uso de hierarquias de classes e relações semânticas existentes entre as classes. A ontologia também ajudou a melhorar a recuperação de documentos para consultas complexas que utilizam uma linguagem livre, por meio da adição de termos arquitetônicos relacionados à consulta original dada pelo usuário. E quando a consulta expandida é utilizada em conjunto com o modelo de espaço vetorial existente no sistema de recuperação, auxilia na recuperação de imagens mais relevantes.

A avaliação de nossa abordagem foi realizada através de experimentos que utilizaram os dados do sistema Arquigrafia, dois conjuntos de consultas e medidas de avaliação como precisão, cobertura e medida-F. Os conjuntos eram compostos por 11 consultas dada por especialistas da área de arquitetura e 9 consultas aleatórias extraídas do log de busca do Google Analytics do sistema Arquigrafia, tendo um total de 20 consultas.

Para nossos experimentos utilizamos as 20 consultas que pertenciam aos dois conjuntos de consultas mencionados, dentre os quais obtivemos resultados positivos para 16 consultas, considerando um valor de precisão, cobertura e medida-F maior do que 50\%, com nossa abordagem. Em comparação a outra abordagem, que usa a técnica de busca boolena, obteve-se 1 consulta com resultado positivo, também considerando precisão, cobertura e medida-F maior do que $50 \%$. Assim, podemos concluir que nossa abordagem obteve melhores resultados. 
Além disso, pelos resultados obtidos, consideramos que nossa abordagem, ao utilizar uma ontologia, pode ser um inicio de como empregar as ontologias como ferramenta de apoio para dar um maior significado semântico às tags que existem num sistema colaborativo e como as ontologias permitem a adição de termos na consulta, sendo estes termos relacionados a uma área do conhecimento, que para nosso caso, a área da arquitetura. Desta maneira podemos recuperar os documentos associados às imagens, os quais serão mais relevantes para consulta feita pelo usuário.

Palavras-chave: ontologias, recuperação da informação, sistema colaborativos, vocabulário controlado, Arquigrafia. 


\section{Abstract}

Information retrieval is an essential issue in different web system that needs to be improved. In recent years, collaborative systems have gained popularity. In this thesis, we use a collaborative system of architectural image sharing, that users can add titles and tags freely to describe an image. However, the tags may have an ambiguous meaning, resulting in recovering images that are not relevant when traditional technics are used, such as Boolean and keyword search. In addition, users usually use natural language in their queries and with the mentioned techniques it is less posible to retrieve relevant information.

Our research approach is to construct an ontology for architectural domain, based on the controlled vocabulary of USP and the experimental thesaurus architecture information. The ontology allowed to enhance the relationship between tags and structured concepts of ontology, improving the information retrieval through the expanded terms. And when the expanded query is used in conjunction with the vector space model in the recovery system, it helps retrieve more relevant images. The evaluation of our approach was carried out through experiments that used data of Arquigrafia system, two sets of queries were created and metrics like precision, coverage and measure-F were used. The sets consisted of 11 queries given by architecture experts and 9 random queries extracted from Google Analytics logs of the Arquigrafia system, taking a total of 20 queries.

In our experiments we used the 20 queries from the two sets, among which we obtained positive results for 16 queries, considering precision, coverage and F-measure values greater than $50 \%$, applying our approach. In comparison to another approach, which uses the Boolean search technique, we obtained 1 query with positive result, also considering the same metrics with values greater than $50 \%$. Thus, we can conclude that our approach has achieved better results.

In addition, from the results obtained, we consider that our approach using an ontology can be a beginning of how to use ontologies as a support tool to give a greater semantic meaning to tags that exist in a collaborative system, and how Ontologies allow the addition of semantic terms in queries, like terms related to a knowledge area, in our case the area of architecture. In this way we can retrieve documents associated with images, which will be more relevant to the user's query.

Keywords: ontologies, information retrieval, collaborative systems, vocabulary controlled, Arquigrafia. 



\section{Sumário}

Resumo $\quad$ iii

$\begin{array}{lc}\text { Lista de Figuras } & \text { ix }\end{array}$

Lista de Algoritmos $\quad$ xi

1 Introdução 1

1.1 Motivação . . . . . . . . . . . . . . . . . . . . . . 3

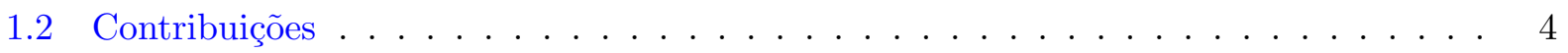

1.3 Organização do trabalho . . . . . . . . . . . . . . . . . . . . 5

2 Fundamentos $\quad 7$

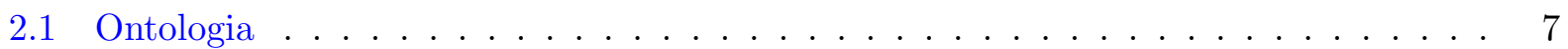

2.2 Tipos de Ontologia . . . . . . . . . . . . . . . . . . . . 8

2.3 Linguagens de representação . . . . . . . . . . . . . . . . . . . . . . . . . . . . . .

2.3.1 RDF (Resource Description Framework) _ . . . . . . . . . . . . . 9

2.3.2 RDFS (Resource Description Framework Schema) . . . . . . . . . . . . 9

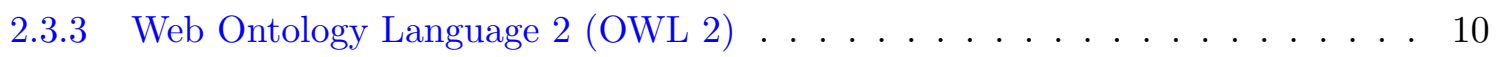

2.3.4 Componentes e elementos da Ontologia em OWL $2 \ldots \ldots$. . . . . . . 11

2.4 Ferramentas para ontologias . . . . . . . . . . . . . . . . . . 14

2.4 .1 Ferramenta para Construção . . . . . . . . . . . . . . . . . . . . 14

2.4.2 Ferramenta para Manipulação . . . . . . . . . . . . . . . . . . 15

2.5 Metodologia para o desenvolvimento de ontologias . . . . . . . . . . . 15

2.6 Vocabulário controlado . . . . . . . . . . . . . . . . . . . . 17

2.7 Tesauros . . . . . . . . . . . . . . . . . . . . . 17

2.8 Folksonomia . . . . . . . . . . . . . . . . . . . . 18

2.9 Recuperação da informação . . . . . . . . . . . . . . . . . . . . . . . 19

2.9 .1 Processo de Indexação . . . . . . . . . . . . . . . . . . . . . . . 20

2.9.1.1 Palavras de parada . . . . . . . . . . . . . . . 21

2.9.1.2 Texto em minúsculas . . . . . . . . . . . . . . . . 21

2.9.1.3 Normalização de termos . . . . . . . . . . . . . . . . . . . . . . . 21

2.9.1.4 Consulta expandida . . . . . . . . . . . . . . . . 22 
2.9.1.5 Pesos dostermos . . . . . . . . . . . . . . . 22

2.9.2 Processo de medida de similaridade na recuperação da informação . . . . . . 22

2.9.2.1 Abordagem OSS (Ontology Structure based Similarity ) . . . . . . 22

2.9.2.2 Teorema similaridade de Dekang Lin . . . . . . . . . . . . . . . 23

2.9 .3 Processo de Recuperação . . . . . . . . . . . . . . . . . . . 23

2.9.3.1 Modelo booleano . . . . . . . . . . . . . . . . . 23

2.9.3.2 Modelo de Espaço Vetorial . . . . . . . . . . . . . . . . . 24

2.10 Avaliação em sistemas de recuperação de informação . . . . . . . . . . . . . . . 28

2.11 Considerações finais . . . . . . . . . . . . . . . . . . . . . 29

3 Recuperação de imagens baseada em ontologias para sistemas colaborativos 31

3.1 Trabalhos relacionados . . . . . . . . . . . . . . . . . . . . . 31

3.2 Visão geral da abordagem proposta . . . . . . . . . . . . . . . . . . . . . . . . . . . . . . . . . . .

3.3 Fase da construção da ontologia . . . . . . . . . . . . . . . . . . . 34

3.3 .1 Propósito e especificação de requisitos . . . . . . . . . . . . . . . . . . . . . . . . . . . . . . . .

3.3 .2 Captura da ontologia . . . . . . . . . . . . . . . . . 36

3.3 .3 Formalização da ontologia . . . . . . . . . . . . . . . . . . . 47

3.3.4 Integração com ontologias existentes . . . . . . . . . . . . . . 51

3.3 .5 Avaliação . . . . . . . . . . . . . . . . . . . . 5 52

3.3 .6 Documentação . . . . . . . . . . . . . . . . . . . 53

3.4 Fase de Indexação e Pré-processamento . . . . . . . . . . . . . . . . . . . 62

3.4 .1 Indexação e pré-processamento . . . . . . . . . . . . . . . . . 63

3.5 Fase de processamento e similaridade de termos . . . . . . . . . . . . . 65

3.6 Expansão de consulta e recuperação de imagens . . . . . . . . . . . . . . . . . 66

3.6.1 Expansão de consulta . . . . . . . . . . . . . . . . . 66

3.6 .2 Recuperação de imagens . . . . . . . . . . . . . . . . . . . . . . . . . . . . . . . . . 69

3.6 .3 Considerações finais . . . . . . . . . . . . . . . . . . . . 69

4 Experimentos e Resultados $\quad 71$

4.1 Conjunto de dados . . . . . . . . . . . . . . . . . . . . . . . 71

4.1 .1 Conjunto de dados para a ontologia . . . . . . . . . . . . . 71

4.1.2 Conjunto de dados para o sistema de recuperação . . . . . . . . . . . . . . 72

4.2 Avaliação de resultados e discussão . . . . . . . . . . . . . . . . . . . 73

4.3 Comparação de resultados . . . . . . . . . . . . . . . . . . . . 77

4.4 Discussão . . . . . . . . . . . . . . . . . . . . . . 86

5 Conclusões $\quad 89$

5.1 Análise dos resultados . . . . . . . . . . . . . . . . . . . . . 91

5.2 Contribuições do trabalho . . . . . . . . . . . . . . . . . . . . . 93

5.3 Trabalhos futuros . . . . . . . . . . . . . . . . . . 93 
$\begin{array}{ll}\text { A Fonte de dados associadas } & 95\end{array}$

A.1 Dicionário de termos arquitetônicos . . . . . . . . . . . . . . . 95

$\begin{array}{ll}\text { B Sistema OntoArq } & 101\end{array}$

$\begin{array}{ll}\text { Referências Bibliográficas } & 105\end{array}$ 


\section{Lista de Figuras}

1.1 Sistema colaborativo de compartilhamento de imagens Arquitetônicas. . . . . . . . . 3

2.1 Tipo de ontologia segundo o seu nível de dependência sobre uma tarefa ou ponto de vista específica, as setas representam relações de especialização [22]. . . . . . . . . . 8

2.2 Grafo em RDF para a tripla $<$ Oscar_niemeyer,type,Autor_da_obra $>\ldots \ldots$

2.3 Exemplo de um grafo em RDFs e RDF . . . . . . . . . . . . . . . . . . . . 10

2.4 Exemplo de propriedade funcional. . . . . . . . . . . . . . . . . . 12

2.5 Exemplo de propriedade funcional inversa. . . . . . . . . . . . . . . . . 13

2.6 Exemplo de propriedade transitiva. . . . . . . . . . . . . . . . 13

2.7 Exemplo de propriedade simétrica $\ldots \ldots \ldots \ldots$

2.8 Passos para o desenvolvimento da ontologia. . . . . . . . . . . . . . 16

2.9 Lista de assuntos de vocabulário controlado da USP . . . . . . . . . . . . . . . 17

2.10 Lista do vocabulário controlado da USP na área da arquitetura. . . . . . . . . . . . 18

2.11 Material de construção no Tesauro Experimental de Arquitetura [16] . . . . . . . . . 19

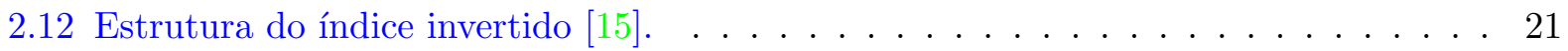

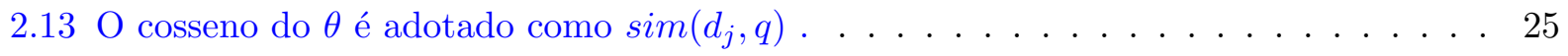

2.14 Documentos relevantes do conjunto de resultados. . . . . . . . . . . . . . . 28

3.1 As quatro fases que são parte de nossa abordagem. . . . . . . . . . . . . . . 34

3.2 Primeira parte da categorização de termos do Tesauro Experimental da arquitetura. 37

3.3 Primeira parte da hierarquia de classes da ontologia. . . . . . . . . . . . . 37

3.4 Segunda parte analisada do Tesauro Experimental da arquitetura. . . . . . . . . . 38

3.5 Segunda parte da hierarquia de classes na ontologia. . . . . . . . . . . . 38

3.6 Terceira parte para a categorização de termos no Vocabulário controlado da USP. . . 39

3.7 Hierarquia de classes para Construcao_arquitetonica com suas subclasses diretas. . . 39

3.8 Hierarquia para a classe "Construcao_arquitetonica" . . . . . . . . . . . . . . . . 40

3.9 Continuação da hierarquia para a classe "Construcao_arquitetonica" . . . . . . . . . . 41

3.10 Parte da hierarquia de classes obtida da análise dos dados do sistema Arquigrafia. 41

3.11 Hierarquia de classes da ontologia. . . . . . . . . . . . . . . . . . . 42

3.12 Relação existente entre as classes "Construcao_arquitetonica" e "Ambiente" . . . . . 44

3.13 Relação existente entre as classes "Construcao_arquitetonica" e "Elemento_sustentante". 45

3.14 Relação existente entre as classes "Construcao_arquitetonica" e "Material_construcao". 45 
3.15 Propriedades existentes que relacionam as classes "Construcao_arquitetonica", "autor_da_obra", "objeto_geografico" e "espaço". . . . . . . . . . . . . . 46

3.16 Classes criadas na ontologia pelo Protégé. ～. . . . . . . . . . . . . . . . . 49

3.17 Lista dos indivíduos criados para a classe "Museu". . . . . . . . . . . . . . . . 49

3.18 Lista de propriedades de objeto criadas para a ontologia no Protégé. . . . . . . . . 50

3.19 Propriedades de tipo de dado criada para a ontologia no Protégé. . . . . . . . . . . 50

3.20 Propriedade "tem_autor_da_obra" para relacionar a instância "Museu_de_arte_moderna" e a instância "Reidy_Affonso_Eduardo" no Protégé. . . . . . . . . . . . . . . 51

3.21 Exemplo de uma consulta "Onde encontro casas de madeira no Pará" realizada em

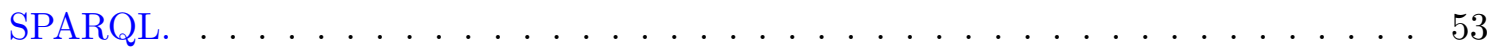

3.22 Relações principais na ontologia utilizada para o sistema Arquigrafia. . . . . . . . . . 54

3.23 Resultado da questão "Onde se localizam as construções de taipa remanescentes em São Paulo?". . . . . . . . . . . . . . . . . . . . . 54

3.24 Resultado da questão "Quem é o autor do projeto da Praça do Relógio?". . . . . . 55

3.25 Resultado da questão "Quais eram os principais arquitetos em atividade em São Paulo entre as décadas de 30 e 60?". . . . . . . . . . . . . . . . . . 56

3.26 Resultado da questão "Quais eram os principais arquitetos em atividade no Rio de Janeiro entre as décadas de 30 e 60?". . . . . . . . . . . . . . . . . . . 56

3.27 Resultado da questão "Qual a data da obra do Conjunto Habitacional Prefeito Mendes de Moraes?". . . . . . . . . . . . . . . . . . . . . . . . 57

3.28 Resultado da questão "Quais são os principais edifícios residenciais no interior do Rio de Janeiro?". . . . . . . . . . . . . . . . . . . . . . . . . . . . . . 58

3.29 Resultado para a questão "Existem edifícios em vidro construídos no Brasil?". . . . 59

3.30 Resultado da questão "Quais são os edifícios projetados por Macedo Silvio Soares em São Paulo?". . . . . . . . . . . . . . . . . . . . . . . 59

3.31 Resultado da questão "Quem projetou a Biblioteca Brasiliana?". . . . . . . . . . . . 60

3.32 Resultado da questão "Quais edifícios foram projetados por Gian Carlo Gasperini no Brasil?". . . . . . . . . . . . . . . . . . . . . . . 6 61

3.33 Resultado da questão "Quais são os exemplares de arquiteturas do primeiro século (séc. XVI) do Brasil que ainda existem e podem ser visitados?". . . . . . . . . . . . 62

3.34 Resultado da questão "As palafitas típicas da habitação ribeirinha no Norte do Brasil, podem ser vistas em que lugares da Amazônia?". . . . . . . . . . . . . . . . . . . . .

4.1 Passos para determinar os conjuntos de documentos relevantes para cada questão de

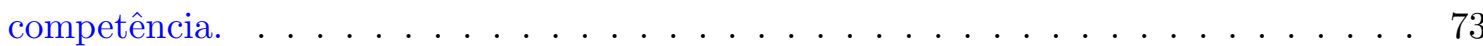

4.2 Precisão e cobertura para a consulta "Quem é o autor do projeto da Praça do

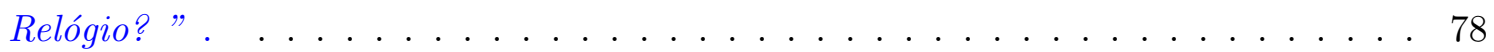

4.3 Medida-F para "Quem é o autor do projeto da Praça do Relógio?" . . . . . . . . . 79

4.4 Precisão e cobertura para "Onde encontro casas de madeira no Pará??" . . . . . . 80

4.5 Medida-F para "Onde encontro casas de madeira no Pará.?" . . . . . . . . . . . 81 
4.6 Resultado comparativo da consulta "Quem projetou a rodoviária de Jaú?" . . . . . 82

4.7 Resultado comparativo para "Onde encontro casas de madeira no Pará." . . . . . 83

4.8 Resultado comparativo para "Edifícios de educação". . . . . . . . . . . . . . 85

4.9 Resultado comparativo para "Residência do arquiteto Joaquim Guedes". . . . . . . 86

B.1 Resultados para a consulta "Quem é autor da praça do relógio". . . . . . . . . . . . 102

B.2 Resultados para a consulta "Quem projetou a biblioteca brasiliana". . . . . . . . . 103

B.3 Resultados para a consulta "Onde encontro casas de madeira no Pará". . . . . . . . 104 


\section{Lista de algoritmos}

1 Criacao_Indice_Expandido (colecao,ontologia,stemmer $) \ldots \ldots . \ldots$. . . . . . 65

2 EstruturaSimilaridadeTermos(ontologia,indice) . . . . . . . . . . . 70 


\section{Capítulo 1}

\section{Introdução}

Os sistemas web em ambientes colaborativos tem ganhado popularidade nos últimos anos, eles permitem que os usuários possam participar e colaborar descrevendo os elementos do sistema por meio de tags ou pela inserção de conteúdo em linguagem natural. As tags criadas pelos próprios usuários são consideradas relevantes para descrever, recuperar e compartilhar o conteúdo que está sendo armazenado. Essa característica particular é conhecida como "Folksonomia" [13].

Nos sistemas colaborativos baseados em folksonomia, não existe uma instrução simples de uso de definições de conceitos ou das palavras-chaves a serem usadas como tags, e a maioria dos usuários não tem uma orientação terminológica. Um exemplo disso é a criação de uma tag composta por termos com significado genérico como "Edifícios de educação". Consequentemente, o conteúdo inserido neste tipo de sistema é não controlado.

Para Macgregor [32], nos referidos sistemas não existe controle das tags definidas pelos usuários, em consequência, nos dados podem existir sinônimos, homônimos e anomalias lexicais, que podem produzir ruído no processo de recuperação. Um sinônimo é uma palavra que tem significado idêntico ou muito semelhante ao de outra, por exemplo, caminho e via. Os homônimos são palavras que possuem a mesma pronúncia ou a mesma grafia, mas significados diferentes, por exemplo banco, pode ser uma instituição financeira ou um assento no qual se podem sentar várias pessoas. A anomalia lexical refere-se ao uso de palavras de maneira incorreta.

A área da web semântica usa ontologias para atribuir sentido e significado ao conteúdo dos documentos e atuar como uma ferramenta de representação do conhecimento [40]. Por outro lado, a área de recuperação de informação tem trabalhado em várias técnicas nas últimas décadas; sendo a busca booleana uma técnica fortemente usada pela maioria dos sistemas web, e que usa os operadores booleanos $A N D, O R$ e $N O T$ que combinados com as palavras-chave, conseguem recuperar documentos ou textos que contenham as palavras buscadas [48]. Outra técnica desta área é a indexação de termos e recuperação de informação baseada nos pesos dos termos para comparar a similaridade existente entre a consulta e os documentos a recuperar [4]. Estas técnicas ainda têm limitações. A busca por palavras-chave é limitada porque não consegue recuperar informações relevantes quando o usuário faz consultas mais complexas. 
Na literatura existem pesquisas que propõem resolver as limitações da busca por palavras-chave ou por indexação com o uso de ontologias em conjunto com a técnica do modelo de espaço vetorial da recuperação de informação, para conseguir expandir termos relacionados à consulta original usando os conceitos da ontologia, para logo utilizar o peso dos termos e a similaridade entre a consulta dada e os documentos existentes a serem recuperados. Essa abordagem tem sido aplicada em vários sistemas web como pode ser visto na literatura [34], [9] , [46], com a característica de que a informação que é inserida nestes sistemas é controlada, isto é, que a informação adicionada no banco de dados é feita por especialistas, gerenciadores ou responsáveis por conteúdo, no qual os usuários não podem acrescentar conteúdo. A este tipo de sistema web, o denominaremos como sistema web tradicional. Um exemplo disso é o sistema de informação de saúde do Hospital Universitário (HU) da USP ou o sistema Dedalus da USP.

O Arquigrafia ${ }^{1}$ é um sistema colaborativo de compartilhamento de imagens arquitetônicas, no qual existe a colaboração de usuários, tanto para adicionar imagens quanto para descrevê-las por meio de tags, títulos entre outros descritores.

Neste ambiente colaborativo, o uso de tags e títulos não é controlado, diferentemente de sistemas web tradicionais, trazendo vários problemas na recuperação de imagens, pois podem existir tags com palavras que não representam uma informação clara, podendo provocar ambiguidade. Outro problema nas tags é o uso de sinônimos sem o estabelecimento de uma relação de equivalência, ocasionando que muitas imagens não sejam recuperadas ao realizar uma consulta. Por exemplo, se a consulta do usuário fosse pau a pique seriam recuperadas todas as imagens associadas a os termos da consulta, porém não seriam recuperadas as imagens associadas aos termos taipa de mão, quem é sinônimo de pau a pique.

Além disso, quando o usuário faz uma busca mais complexa no sistema colaborativo, por exemplo, "casas de madeira no Pará", podem existir algumas imagens que tenham a tag "madeira" e outras com a tag "casa", porém com pouca ou nenhuma relação com a busca. A técnica de busca booleana devolve todas imagens que contenham a palavra "casa" ou a palavra "madeira", diminuindo assim a precisão na recuperação de informação.

Neste trabalho, descrevemos a construção de uma ontologia do domínio arquitetônico, denominada OntoArq, e que é utilizada em conjunto com a técnica de espaço vetorial da área de recuperação de informação para recuperação de imagens no Arquigrafia. Assim, ao aplicar a ontologia construída, conseguimos expandir os termos relacionados à consulta original usando a hierarquia de classes ou adicionando relações semânticas existentes na ontologia, obtendo a partir disso uma consulta expandida para, então, recuperar documentos relevantes para a consulta. Por exemplo, para a consulta "casas de madeira no Pará" , são adicionados termos relacionados a casas e madeira. Para casas adiciona-se o termo "residência" e para madeira adicionam-se as construções que possuam a relação semântica "eh_material" associada com madeira. Dessa maneira conseguimos a

\footnotetext{
${ }^{1}$ Arquigrafia: http://www . arquigrafia.org.br/
} 

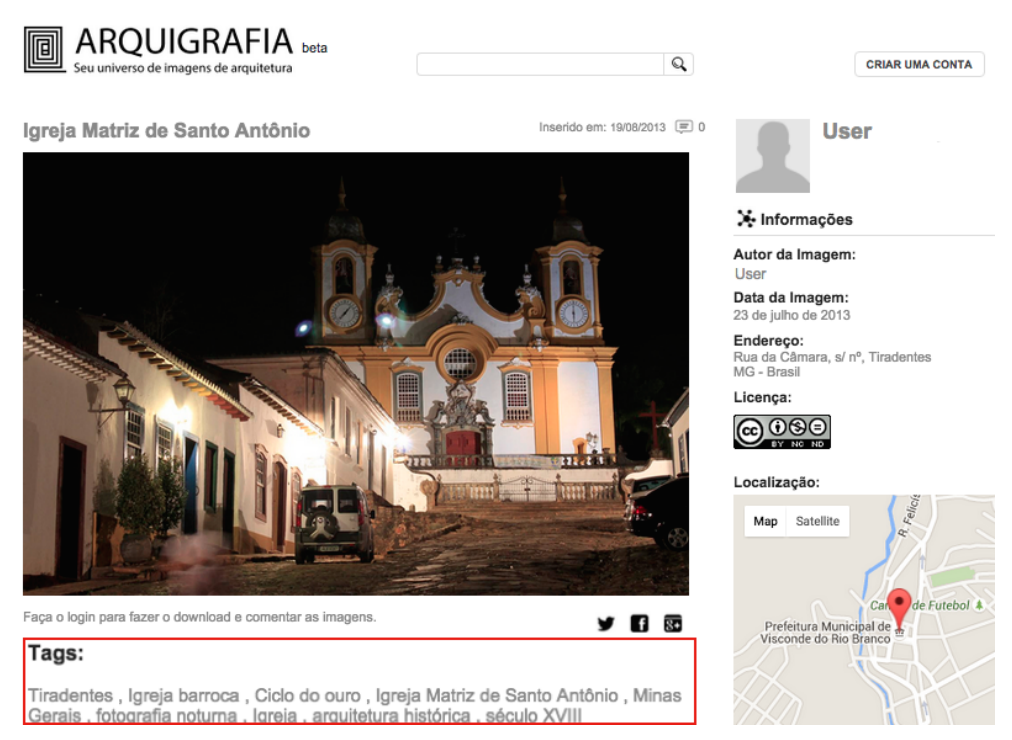

Figura 1.1: Sistema colaborativo de compartilhamento de imagens Arquitetônicas.

consulta expandida para depois calcular a similaridade entre ela e os documentos relacionados às imagens. Antes de avaliar os resultados de nossa abordagem, foi necessário questionar-nos se o uso da ontologia utilizada em conjunto com o sistema de recuperação de imagens desenvolvido ajudava a melhorar a precisão na recuperação de imagens. Para isso, foi necessário utilizar as questões de competência dada pelos especialistas da área da arquitetura. Estas questões de competência foram consideradas como consultas, e o sistema de recuperação deveria retornar resultados relevantes. Para cada questão de competência foi necessário selecionar os documentos que estavam totalmente relacionados a elas. Cada documento pertence a uma imagem arquitetônica específica.

A seleção de documentos originou a criação de vários conjuntos relacionados a cada questão de competência ou consulta. Após este processo, pode-se utilizar as métricas de avaliação, como precisão, cobertura e medida-F. O resultado da utilização dessas métricas para cada tipo de consulta dada pelo especialista, permitiu saber que a ontologia, em comparação com a busca boolena, ajudava a melhorar a precisão de resultados.

\subsection{Motivação}

O uso da folksonomia nos sistemas colaborativos permite a participação dos usuários, os quais cumprem um papel fundamental no compartilhamento do conhecimento, como por exemplo, ao descrever uma imagem, um vídeo, etc. Tal descrição se dá por meio de linguagem natural ou pelo uso de tags criadas pelos usuários. Contudo, vale ressaltar, essas descrições não possuem orientação terminológica e pode ocorrer, por isso, de serem empregadas palavras demasiado genéricas e com pouco significado semântico, sobretudo nas tags. Assim, a informação armazenada nos traz algumas dificuldades no momento da recuperação da informação, uma vez que o conteúdo não pode ser controlado. 
Esse problema, que em geral ocorre em sistemas colaborativos, é encontrado também no Arquigrafia, visto que ele permite a colaboração e compartilhamento de imagens arquitetônicas elaboradas pelos usuários. Esses, ao compartilharem a imagem de uma edificação específica, produzem tags baseadas no seu próprio conhecimento ou percepção pessoal. Desse modo, as imagens relacionadas a uma dada edificação podem possuir tags com o mesmo significado semântico (ou sinônimos). Por exemplo: uma imagem que contém a tag "sopapo" e uma semelhante que contém a tag "taipa de mão" podem não ser reconhecidas pela consulta quando o usuário realiza a busca apenas pelo termo "sopapo", sendo retornado pelo motor de busca apenas uma das duas imagens, quando ele deveria retornar ambas.

Por outro lado, se o usuário utilizar uma linguagem livre e mais complexa em sua busca, como "Edifícios projetados por Macedo Silvio", pela técnica de busca booleana - a qual emprega operadores lógicos -, os documentos a serem devolvidos serão todos aqueles que contiverem ao menos algum termo da consulta. Por consequência, muitos documentos desnecessários serão também devolvidos ao usuário. Da mesma forma, quando o usuário cria palavras genéricas para uma tag relacionada a uma imagem, como por exemplo "janela", esse termo sozinho pode não ser recuperado em consultas mais complexas, como por exemplo na busca "quais são os materiais da biblioteca brasiliana".

Em razão de tais problemas, nossa abordagem tenta aprimorar a recuperação de documentos para as imagens mais relevantes da consulta do usuário por meio da construção de uma ontologia no domínio arquitetônico OntoArq. Esta auxilia na atribuição de um sentido e significado mais específicos aos termos ou palavras pertencentes às tags e na adição de novos termos à consulta original, os quais serão relacionados ao domínio arquitetônico. Dessa maneira, quando o usuário realizar consultas, seja utilizando palavras-chaves ou utilizando uma linguagem livre, a ontologia integrada ao sistema de recuperação poderá retornar documentos mais relevantes ao usuário.

\subsection{Contribuições}

As principais contribuições do presente trabalho são:

- A construção de uma ontologia baseada em um vocabulário controlado da área da arquitetura, com a finalidade de que ela possa ser estendida e reutilizada.

- Implementação e reutilização de um sistema de recuperação de imagens indexadas por conceitos para o domínio da arquitetura, que permite processar consultas em linguagem livre ou palavras chaves, através do uso da hierarquia de classes e relações semânticas da ontologia.

- Integração da ontologia construída com o sistema de recuperação de imagens de ambientes colaborativos.

- Utilização da ontologia para obter consultas expandidas para serem utilizadas por um sistema de recuperação de imagens em ambientes colaborativos. 
- Análise comparativa do sistema com e sem a ontologia para verificar se a ontologia construída junto com o sistema de recuperação de imagens de ambientes colaborativos melhora a recuperação de documentos relevantes.

Partes deste trabalho foram publicadas como:

- Leliane Nunes de Barros, Marisol Solis Yucra, Ricardo Teixeira de Souza, Renata Wassermann e Marco Aurelio Gerosa, Da Folksonomia para formatos da Web Semântica: Um estudo exploratório no Sistema Arquigrafia, XII Simpósio Brasileiro de Sistemas Colaborativos (SBSC 2015).

- Marisol Solis Y, Renata Wassermann e Vânia Mara Alves Lima, On the use of ontologies for search in a collaborative system for architectural images, International Society for Knowledge Organization (ISKO 2016).

\subsection{Organização do trabalho}

Esta dissertação está organizada da seguinte forma:

O Capítulo 2 apresenta conceitos e definições básicos relacionados às ontologias, vocabulário controlado e técnicas de recuperação de informação que são utilizados neste trabalho.

Em seguida, no Capítulo 3, descrevemos as fases da abordagem aplicada para a recuperação de imagens relevantes.

No Capítulo 4 são apresentados os resultados obtidos após a aplicação da ontologia e técnicas de recuperação de informação.

No Capítulo 5 são apresentadas as conclusões desta pesquisa. 


\section{Capítulo 2}

\section{Fundamentos}

Neste capítulo são apresentadas algumas definições e conceitos fundamentais como as definições de ontologias, além de ferramentas, linguagens para descrição de ontologia, métodos de recuperação de informação e técnicas de similaridade utilizadas ao longo do trabalho.

\subsection{Ontologia}

Existem diversas definições para ontologias. Segundo Gruber [19], uma ontologia é uma especificação explicita de uma conceitualização, e ela pode ser descrita pela definição de um conjunto de termos que a representam. Assim, uma ontologia tem definições associadas aos nomes das entidades do universo de discurso como, por exemplo, as classes, relações, funções ou outros objetos com textos explicando o significado dos nomes e a criação de axiomas formais que restringem a interpretação e o uso correto dos termos bem formados.

Para Borst [7], uma ontologia é definida como uma especificação formal e explícita de uma conceitualização compartilhada.

Segundo Guarino [23], em ciência da computação, uma ontologia é um tipo especial de objeto de informação ou artefato computacional. Além disso, as ontologias computacionais são meios para formalmente modelar a estrutura de um sistema, utilizando as entidades relevantes e relações que surgem da observação, os quais são úteis para um propósito específico. Estas entidades são analisadas e organizadas em conceitos e relações, os quais são representados por predicados unários e binários.

Na área de inteligência artificial, uma ontologia é vista como a um artefato de engenharia, constituído por um vocabulário especifico usado para descrever uma determinada realidade. A ontologia descreve uma hierarquia de conceitos relacionados pela especificidade, e os axiomas são adicionados para expressar outras relações entre conceitos e restringir sua interpretação [22].

Os componentes básicos de uma ontologia são: conceitos, relações, axiomas e instâncias. Os conceitos descrevem classes de objetos, que por sua vez são organizados em uma taxonomia, enquanto que as relações são representadas por um predicado binário que associa duas instâncias. Quanto aos axiomas, estes podem ser escritos afirmando se uma propriedade é simétrica, transitiva, irreflexiva, funcional ou se algumas classes são disjuntas de outras. E por fim, as instâncias são objetos ou indivíduos que pertencem a uma classe [23]. 
As ontologias permitem o compartilhamento e reutilização do conhecimento, porém é importante que os conceitos tenham uma especificação formal.

Os conceitos sugeridos por Gruber e Guarino [19], [23], foram considerados importantes para compreender a definição e os elementos que compõem uma ontologia.

\subsection{Tipos de Ontologia}

Existem muitas maneiras de classificar as ontologias, para este trabalho é utilizada a classificação baseada no seu conteúdo [21], [22] e [24].

Ontologias Genéricas: descrevem conceitos bem amplos e gerais, como por exemplo, matéria, objeto, evento, ação entre outros, estes conceitos são independentes de um problema ou domínio específico.

Ontologias de Domínio: apresentam conceitos e conjuntos de palavras relacionadas a um domínio específico, descrevendo o vocabulário relacionado a um domínio genérico, como por exemplo, domínio de arquitetura, arte, etc.

Ontologias de Tarefas: possuem conceitos que contribuem na solução de problemas, sem depender de um domínio específico, ou seja, os conceitos e conjuntos de palavras relacionadas descrevem o vocabulário relacionado a uma atividade ou tarefa genérica, como por exemplo, pedidos ou vendas.

Ontologias de Aplicação: descrevem conceitos dependentes do domínio e da tarefa específica. Estes conceitos estão relacionados com frequência aos papeis desempenhado por entidades de domínio para a realização de uma determinada atividade.

A figura 2.1 esquematiza os tipos de ontologia existentes.

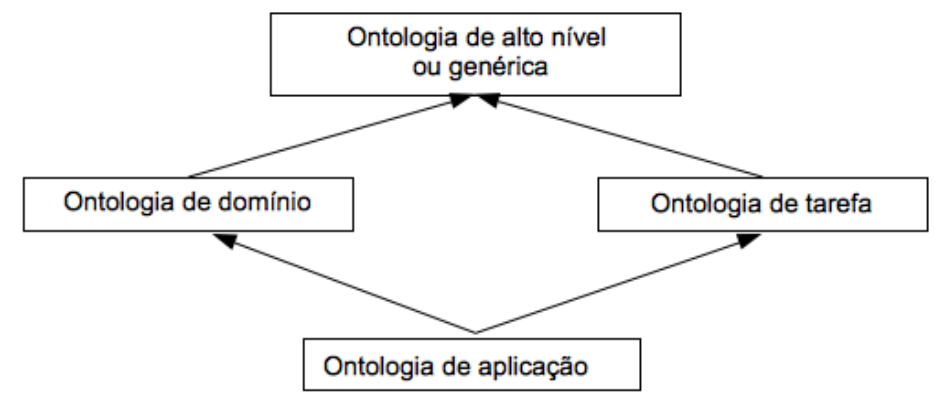

Figura 2.1: Tipo de ontologia segundo o seu nível de dependência sobre uma tarefa ou ponto de vista específica, as setas representam relações de especialização [22]. 


\subsection{Linguagens de representação}

Existem diversas linguagens de representação de ontologias, as quais estão baseadas na sintaxe do XML (Extensible Markup Language):

\subsubsection{RDF (Resource Description Framework)}

$\mathrm{O} \mathrm{RDF}^{1}$ é uma recomendação da W3C que define uma linguagem que foi projetada para descrever recursos web tais como páginas web [35].

Em RDF, URIs ${ }^{2}$ (Uniform Resource Identifiers) são utilizadas para dar nome a entidades e relações entre elas formando triplas.

Cada tripla pode ser vista como uma estrutura definindo uma relação entre dois recursos. Esta estrutura de ligação forma um grafo dirigido e etiquetado, no qual as arestas representam o nome da ligação entre dois recursos, que são representados pelos nós do grafo. A estrutura de um grafo de $\mathrm{RDF}^{3}$ é um conjunto de triplas, que consiste de um sujeito, predicado e objeto. E pode ser visualizado como um diagrama de nós e um arco direcionado.

A figura 2.2 mostra um exemplo de uma tripla em RDF.

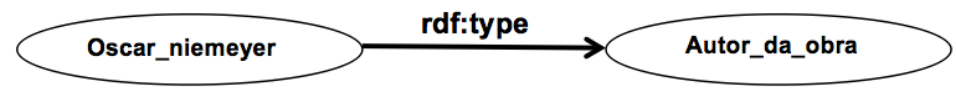

Figura 2.2: Grafo em RDF para a tripla < Oscar_niemeyer,type,Autor_da_obra>

E o fragmento de código em RDF:

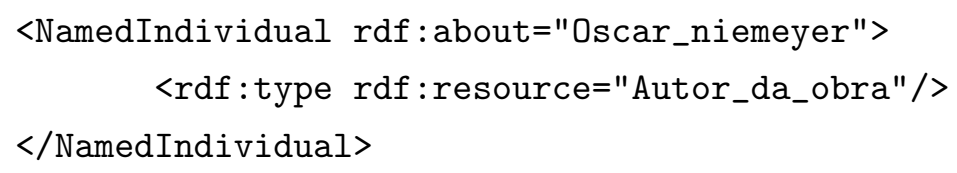

\subsubsection{RDFS (Resource Description Framework Schema)}

RDF Schema (RDFS) ${ }^{4}$ é uma extensão semântica de RDF que introduz os conceitos de classe, propriedade, subclasse, sub-propriedade.

RDF Schema fornece um vocabulário de modelagem de dados para dados RDF e descreve as propriedades em termos da classe e qual é o tipo para o respectivo valor da propriedade, para a qual se aplicam os mecanismos do domínio e imagem.

\footnotetext{
${ }^{1}$ RDF:https://www.w3.org/TR/2014/REC-rdf-schema-20140225/\#ch_introduction

${ }^{2}$ URIs:https : //www.w3.org/Addressing/\#background

${ }^{3}$ Grafo de RDF: http://www.w3.org/TR/rdf11-concepts/

${ }^{4}$ RDFs: http://www.w3.org/TR/rdf-schema/
} 
Por exemplo a figura 2.3 mostra um grafo em RDF e em RDFS.

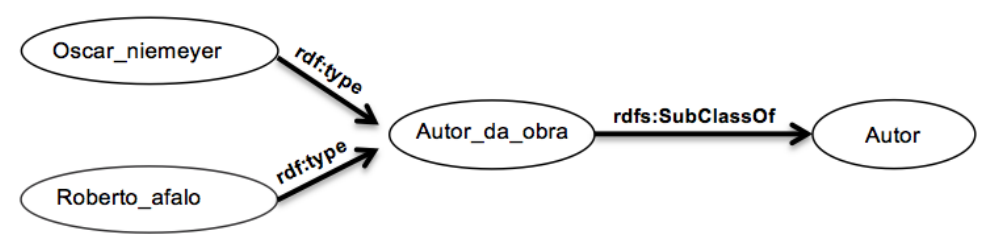

Figura 2.3: Exemplo de um grafo em RDFs e RDF

Fragmento de código para o grafo mostrado na figura 2.3 :

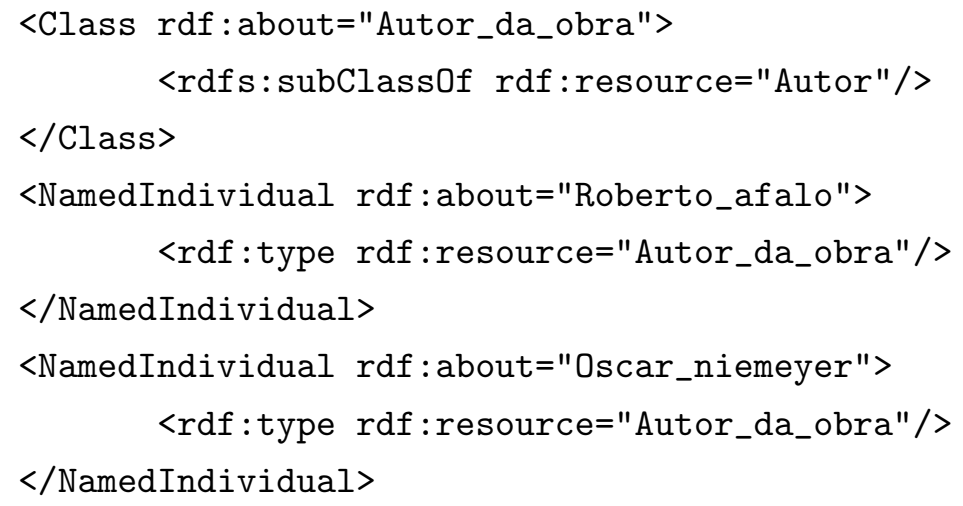

\subsubsection{Web Ontology Language 2 (OWL 2)}

OWL $2^{5}$ é uma linguagem de representação de conhecimento desenvolvida no âmbito do W3C - World Wide Web Consortium que descreve ontologias de uma maneira lógica. Esta linguagem é projetada para formular e raciocinar com o conhecimento a respeito de um domínio de interesse. Algumas noções são explicadas para entender como o conhecimento é representado em OWL 2:

- Entidades: São elementos usados para referenciar objetos do mundo real.

- Axiomas: São enunciados básicos que uma ontologia em OWL expressa.

- Expressões: São as combinações de entidades para formar descrições complexas.

OWL 2 fornece três perfis ${ }^{6}$, que têm fragmentos lógicos com a capacidade expressiva adequada para tarefas distintas e raciocínio eficiente.

- OWL 2 EL: Trabalha com aplicações que utilizam grandes ontologias que têm grande número de classes ou propriedades. Possui verificação de consistência e de instâncias em tempo polinomial.

\footnotetext{
${ }^{5}$ OWL 2: http://www.w3.org/TR/ow12-primer/\#What_is_OWL_2.3F

${ }^{6}$ Perfis OWL 2: http://www.w3.org/TR/ow12-primer/\#OWL_2_Profiles
} 
- OWL 2 QL: Direcionada para consultas conjuntivas utiliza a tecnologia padrão de bancos de dados relacionais. Também captura muitas características utilizadas em RDFS das propriedades inversas e das sub-propriedades hierárquicas.

- OWL 2 RL: É dirigida para aplicações que exigem raciocínio escalável sem sacrificar muito o poder expressivo. Esta linguagem é ideal para enriquecer dados RDF, especialmente quando os dados deveriam ser manipulados por regras adicionais.

\subsubsection{Componentes e elementos da Ontologia em OWL 2}

Todos os componentes da ontologia podem ser representados por diferentes sintaxes mas, para entender estes componentes, serão apresentados exemplos na sintaxe RDF/XML.

Uma ontologia OWL 2 é composta pelos seguintes elementos:

1. Classes: Também denominadas como conceitos, são consideradas como o núcleo para a maioria das ontologias, estas classes pertencem a um dado domínio, e podem representar um conjunto de indivíduos, os quais compartilham características em comum. Os conceitos podem ter subconceitos ou subclasses [30]. Além disso, existe uma relação "é um" entre as classes, que permite a formação de hierarquias.

No seguinte exemplo definimos a classe "Edificio_religioso" como subclasse da classe "Construcao_arquitetonica".

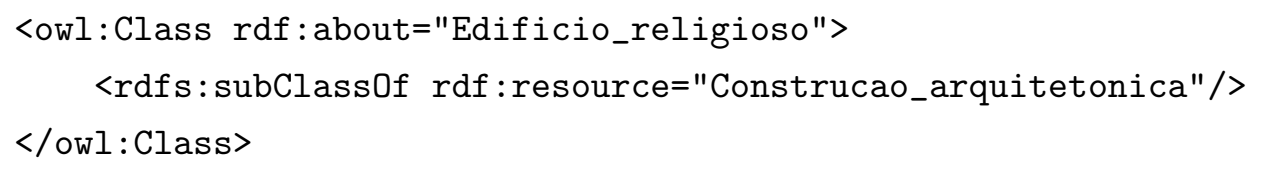

Outro exemplo é a classe "Igreja" como subclasse de "Edificio_religioso"

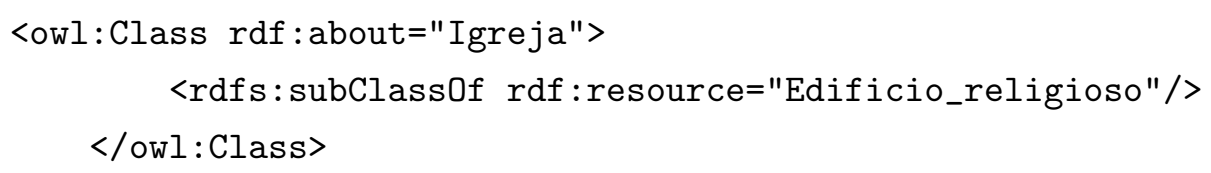

2. Propriedade: É a relação que existe entre dois objetos da ontologia OWL 2. Existem dois tipos de propriedades e o comportamento delas é restringido pela especificação do domínio (origem) e imagem (escopo).

2.1 Propriedade de tipo de dados: Conecta indivíduos ou instâncias de uma classe a um literal [37].

Por exemplo temos a propriedade "tem_data_da_obra" que relaciona um recurso a um literal "dateTime". 


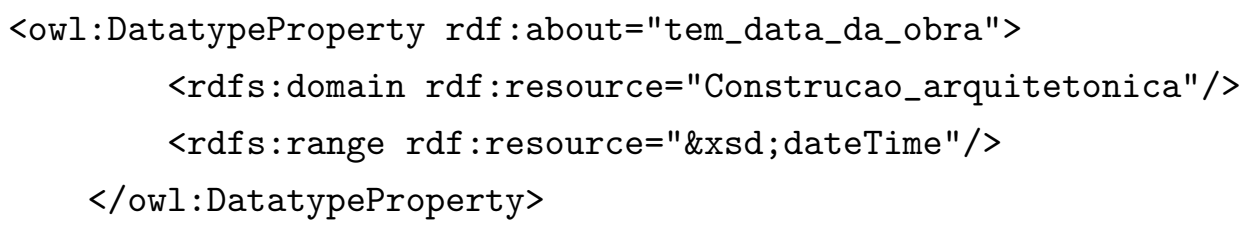

2.2 Propriedade de objeto: É uma relação binária entre instâncias de duas classes [37]. Por exemplo temos a propriedade "feito_de" que relaciona a instância da classe "Edificio_saude" que é o domínio, com a instância da classe "Concreto" que é a imagem.

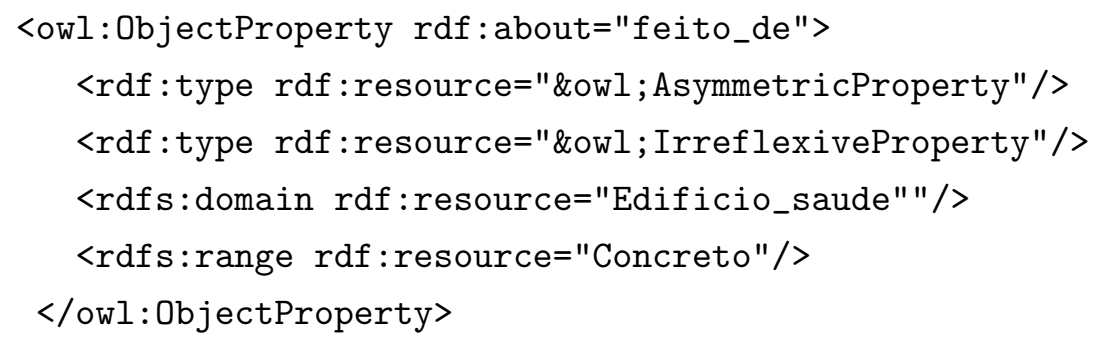

Além disso, todas as propriedades podem ter as seguintes características ${ }^{7}$ :

- Propriedade funcional: Se uma propriedade é funcional, para um indivíduo $X$, pode existir até no máximo um indivíduo $Y$ que está relacionado ao indivíduo $X$ através dessa propriedade [26]. No exemplo da figura 2.4 se "temMãeBiológica" é declarada como funcional, temos que $Y$ e $Z$ são a mesma pessoa.

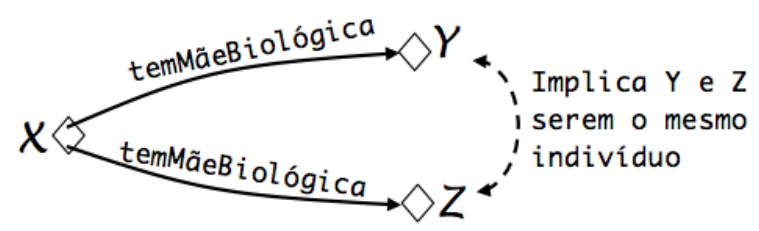

Figura 2.4: Exemplo de propriedade funcional.

- Propriedade funcional inversa: Se a propriedade $\mathrm{P}$ é identificada como uma relação funcional inversa, e se $\mathrm{P}$ relaciona $Y$ e $X$ e também relaciona $Z$ e $X$, isto implica que $Y=Z$.

Por exemplo, na figura 2.5 o indivíduo $Y$ éMarido do indivíduo $X$ e o indivíduo $Z$ éMarido do indivíduo $X$, então podermos inferir que o indivíduo $Y$ e o indivíduo $Z$ são o mesmo indivíduo.

- Propriedade transitiva: Se a propriedade $P$ é transitiva e relaciona o indivíduo $x$ ao indivíduo $y$, e também o indivíduo $y$ ao indivíduo $z$, então podemos inferir que o indivíduo $x$ está relacionado ao indivíduo $z$ através da propriedade $P$.

Por exemplo, na figura 2.6 tem-se a propriedade transitiva "temAncestral".

\footnotetext{
${ }^{7}$ Propriedades: https://www.w3.org/TR/ow12-primer/\#Property_Characteristics
} 


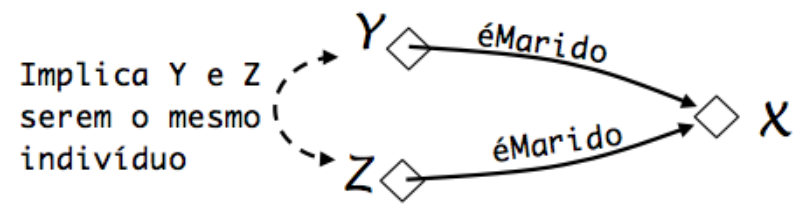

Figura 2.5: Exemplo de propriedade funcional inversa.

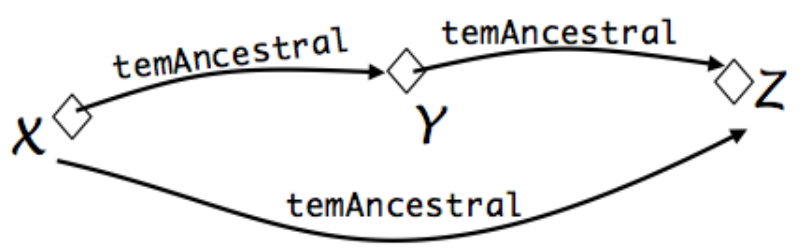

Figura 2.6: Exemplo de propriedade transitiva.

- Propriedade simétrica: Se a propriedade $P$ é simétrica e relaciona o indivíduo $X$ ao indivíduo $Y$, então o indivíduo $Y$ também está relacionado com o indivíduo $X$ através da propriedade $P$. Por Exemplo, na figura 2.7 tem-se a propriedade "temIrmão" que é simétrica.

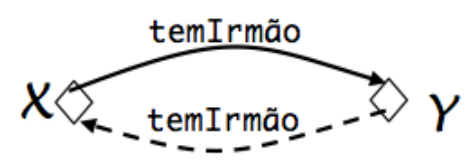

Figura 2.7: Exemplo de propriedade simétrica

- Propriedade assimétrica: Se a propriedade $P$ é identificada como assimétrica, se $P$ relaciona $X$ e $Y$, então não relaciona $Y$ e $X$.

- Propriedade reflexiva: Se a propriedade $P$ é reflexiva, todo indivíduo $X$ relaciona-se com ele mesmo.

- Propriedade irreflexiva: Se a propriedade $P$ é irreflexiva, e relaciona um indivíduo $X$ ao indivíduo $Y$ então $Y$ é diferente de $X$.

3. Indivíduos: São as instâncias de uma classe, representam objetos de um domínio e podem pertencer a mais de uma classe [37].

No seguinte exemplo, temos a instância da classe "Catedral", identificada por "Catedral_Sao_Francisco_Xavier'.

<owl:NamedIndividual rdf:about="Catedral_Sao_Francisco_Xavier $\backslash ">$

<rdf:type rdf:resource="Catedral"/>

$</ o w l$ : NamedIndividual> 
Em outro exemplo temos a instância da classe "Material_litoide", identificada por "Pedra".

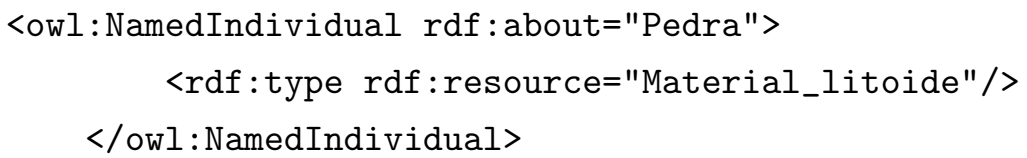

\subsection{Ferramentas para ontologias}

Existem diversas ferramentas disponíveis para a construção de ontologias, que diminuem a complexidade no seu desenvolvimento. Também existem APIs para obter informação da ontologia, estas ferramentas permitem manipular e realizar consultas com a finalidade de simplificar e permitir a integração com outras aplicações.

\subsubsection{Ferramenta para Construção}

- OntoEdit é um editor livre para o desenvolvimento de ontologias criado pela Universidade de Karlsruhe. Ele permite que os usuários possam criar, buscar, manter e gerenciar ontologias. Também permite fazer uso abrangente de inferência. E manipula ontologias em vários formatos de representação, como RDF, RDFS, OWL. Além disso, ele apoia o desenvolvimento colaborativo de ontologias [2] [45].

- TopBraid Composer é um ambiente para o desenvolvimento de ontologias e construção de aplicações semânticas. Ele fornece apoio abrangente para desenvolver e gerenciar ontologias. Permite manipular ontologias em vários formatos de representação, como RDF, RDFS, OWL. Porém precisa de uma licença comercial [2] [45].

- Neon Toolkit é livre e fornece suporte completo para o ciclo de vida da engenharia de ontologias. Ele fornece um amplo conjunto de plugins para fornecer recursos adicionais, tais como anotação, documentação, raciocínio, interface e reutilização de ontologias. Seu conjunto de ferramentas pode ser estendido com plugins poderosos para melhorar a sua funcionalidade [2].

- Protégé ${ }^{8}$ é um editor livre de ontologias criado na Universidade de Stanford. Ele é popular e mais usado no campo da Web Semântica. Ele fornece uma interface gráfica fácil de usar para criar e editar ontologias em vários formatos de representação, como RDF, RDFS, OWL, etc. Também é reconhecido por sua capacidade para trabalhar com grandes ontologias. Além disso, ele utiliza vários plugins para fornecer muitas funcionalidades, tais como apoio multimídia, motores de consulta e raciocínio entre outros serviços adicionais [2] [45]. Os raciocinadores acoplados ao Protégé são HermiT ${ }^{9}$ e $\mathrm{FaCT}++^{10}$.

As ferramentas descritas acima têm características em comum, devido ao fato de que oferecem uma interface gráfica de edição para a elaboração e construção de ontologias. Eles permitem a

\footnotetext{
${ }^{8}$ Protégé: http://protege.stanford.edu/

${ }^{9}$ Hermit:http://www .hermit-reasoner.com/

${ }^{10} \mathrm{FaCT}++$ :http://owl.cs.manchester.ac.uk/tools/fact/
} 
criação de classes, propriedades e instâncias. Utilizam plugins para fornecer serviços de visualização de elementos criados por meio de diagramas, manutenção de ontologias, raciocinadores, importação e exportação nos formatos RDF, RDFS, OWL. Permitem a extensibilidade de serviços via plugins [2] [45]. Todas essas ferramentas podem ser utilizadas como apoio para o desenvolvimento de ontologias, assim neste trabalho optamos pelo editor Protégé porque ele é livre, fácil de usar e flexível.

\subsubsection{Ferramenta para Manipulação}

Apache Jena ${ }^{11}$ é um framework Java de código aberto para o gerenciamento de ontologias. O framework é composto de diferentes APIs (Application Programming Interface | Interface de Programação de Aplicativos) que interagem em conjunto para processar dados RDF.

Entre as APIs disponíveis temos:

1. RDF API, tem funcionalidades para escrever e ler grafos RDF, utilizando o formato do $\mathrm{RDF} / \mathrm{XML}$.

2. Ontology API, trabalha com modelos, RDFs e OWL para a adição de semântica extra aos dados RDF.

3. Inference API, utiliza os raciocinadores sobre os dados existentes para checar e inferir novas triplas RDF.

4. SPARQL API, permite formular consultas sobre os dados RDF e obter informação da ontologia.

SPARQL $^{12}$ é uma linguagem recomendada pelo W3C para realizar consultas às ontologias.

\subsection{Metodologia para o desenvolvimento de ontologias}

Atualmente existem muitas metodologias para a construção de ontologias, porém optamos pela abordagem sistemática de Falbo, Menezes e Rocha [14] para o desenvolvimento da ontologia. Esta abordagem é exibida na figura 2.8, na qual pode se observar a constante interação representada pelas linhas pontilhadas entre os passos associados. As linhas cheias representam o fluxo do trabalho principal no processo de construção da ontologia. As caixas representam os passos de captura e formalização e existe uma forte interação entre eles.

A metodologia dada por Falbo [14] tem as seguintes atividades:

1. Identificação de propósitos e especificação de requisitos:

Tem como finalidade reconhecer qual será o uso e o propósito da ontologia, assim como identificar o escopo da ontologia, mediante a delimitação do que é relevante para a ontologia e mediante a definição das questões de competência, que a ontologia deve ser capaz de responder [20].

\footnotetext{
${ }^{11}$ Jena: https://jena.apache.org/

${ }^{12}$ SPARQL: http://sparql.org/
} 


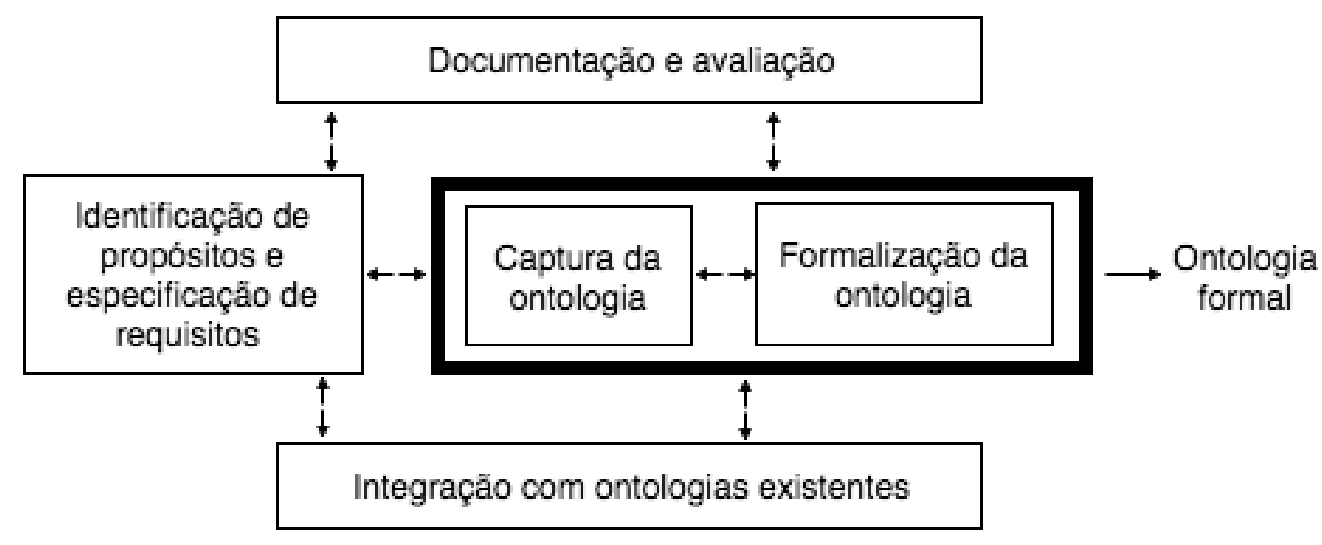

Figura 2.8: Passos para o desenvolvimento da ontologia.

Neste passo pode-se também identificar os potenciais usuários da ontologia [17], [36].

As questões de competência podem também ser usadas para avaliar a ontologia.

2. Captura da ontologia: Baseada no escopo definido, esta atividade identifica e organiza as entidades relevantes do domínio determinado, como por exemplo os conceitos, as relações, as propriedades. Também é recomendada a criação de um dicionário de termos, para auxiliar no entendimento dos elementos criados, evitar ambiguidades e facilitar a comunicação. Neste passo pode-se criar a taxonomia de classes [14].

3. Formalização da ontologia: O objetivo da formalização é representar a conceitualização capturada numa linguagem formal. Esta linguagem deve ser capaz de representar numa forma precisa e não ambígua as entidades de domínio pertencentes à ontologia. Além disso, podese escrever axiomas formais que restringem a interpretação da estrutura formada por estas entidades [14].

4. Integração com ontologias existentes: Na elaboração de captura e formalização, pode ser necessário a integração de outras ontologias existentes com a ontologia em questão para a reutilização de conceitualizações já estabelecidas. Uma boa prática é desenvolver módulos de ontologias, para facilitar sua integração com outras ontologias e sua reutilização [14].

5. Avaliação: Permite saber se a ontologia satisfaz a especificação de requisitos, esta pode ser avaliada utilizando as questões de competência formuladas na fase de Identificação de propósitos e especificação de requisitos. Pode-se observar que as questões de competência têm um papel essencial na avaliação de completude de uma ontologia, especialmente quando se considera seus axiomas [14].

6. Documentação: O desenvolvimento da ontologia deve ser documentado. Deve-se incluir os propósitos, as descrições textuais da conceitualização e a ontologia formal [14]. 


\subsection{Vocabulário controlado}

Um vocabulário controlado é uma lista de termos organizados de maneira explícita. Os termos no vocabulário controlado devem ter uma definição precisa e não redundante, além disso, toda inclusão precisa ser controlada e avaliada por uma autoridade registrada [39].

O vocabulário controlado da $\mathrm{USP}^{13}$ é uma lista de termos que serve como um catálogo de terminologia padronizada da linguagem documentária da Universidade de São Paulo. Serve para controlar sinônimos e facilitar a indexação e recuperação da informação. Este vocabulário mostra uma lista de vários assuntos das diferentes áreas de conhecimento (ver figura 2.9). Ao escolher a área de Arquitetura a qual nos interessa, obteremos uma lista hierárquica como vemos na figura 2.10.

O Vocabulário Controlado USP é utilizado para a indexação de recursos de informação no Banco de Dados Bibliográficos da USP DEDALUS. O Vocabulário abrange as áreas do conhecimento inerentes às atividades de ensino, pesquisa e extensão da Universidade de São Paulo.

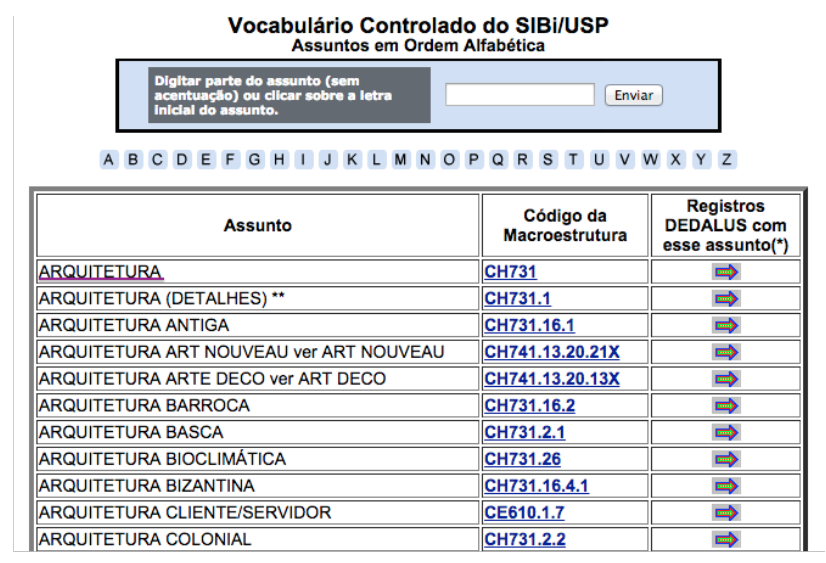

Figura 2.9: Lista de assuntos de vocabulário controlado da USP.

\subsection{Tesauros}

O tesauro é um vocabulário controlado classificado em uma ordem preestabelecida e estruturado de forma que as várias relações (gênero-espécie, equivalência, hierarquia e associação) entre os termos sejam exibidas de forma clara e identificadas por indicadores de relacionamento padronizados. O indicador de relacionamento é uma palavra, frase, sigla ou símbolo usado para identificar uma relação semântica entre os termos [39]. Por exemplo, TG (termo genérico), TE (termo específico), TS (termo sinônimo) e TC (termo correlato).

O Tesauro Experimental de Arquitetura destina-se a ser aplicado ao acervo de arquitetura brasileira e planejamento territorial no Brasil, sob a forma de vários tipos de documentos da Biblioteca da Faculdade de Arquitetura e Urbanismo da Universidade de São Paulo. Sua organização parte de uma definição de arquitetura para obtenção dos grandes campos semânticos, os quais são por sua

\footnotetext{
${ }^{13}$ Vocabulário: http://143.107.154.62/Vocab/
} 


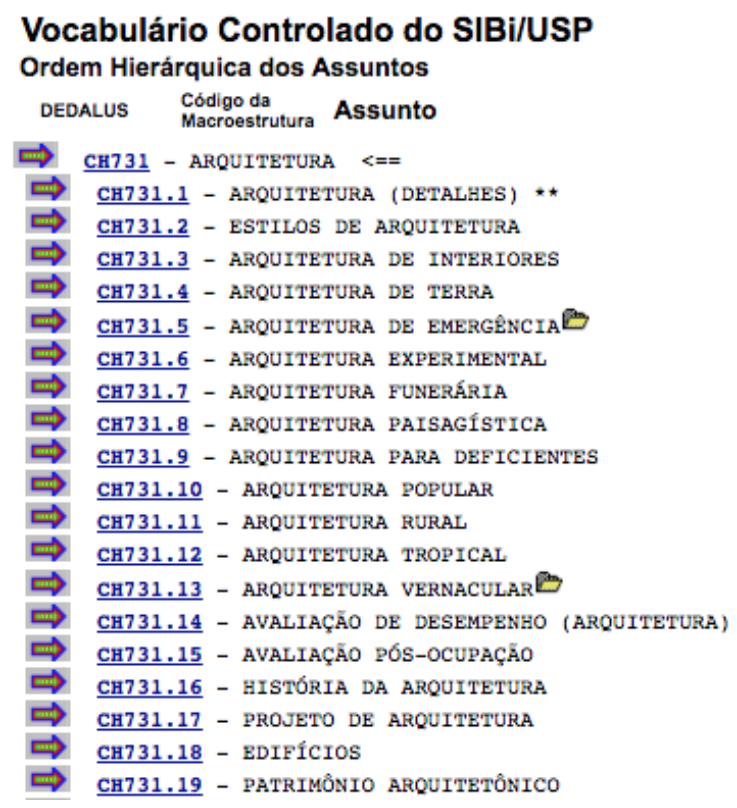

Figura 2.10: Lista do vocabulário controlado da USP na área da arquitetura.

vez, subdivididos em diversos níveis [16]. Segue um exemplo do termo "Material de construção" e da estrutura do termo apresentada na figura 2.11, ambos pertencentes ao Tesauro Experimental de Arquitetura.

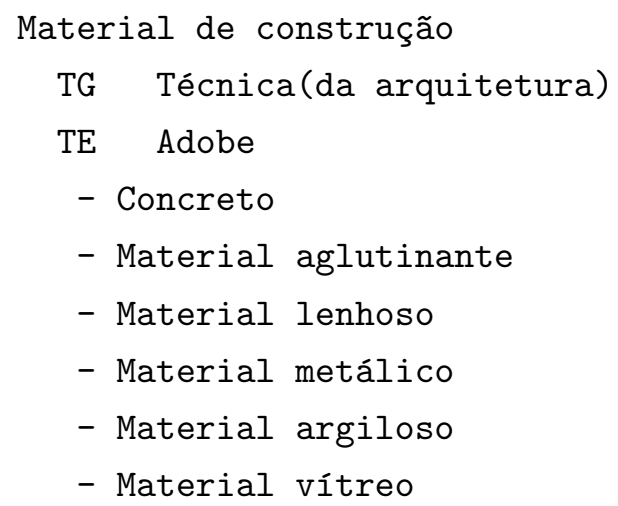

\subsection{Folksonomia}

Este termo criado por Thomas Vander Wal, designa o fenômeno de atribuição livre e pessoal de etiquetas aos conteúdos informacionais disponibilizados na web, a fim de facilitar a recuperação da informação [44].

Folksonomia surge quando um grande número de pessoas estão interessadas em informações particulares e são incentivadas a descrevê-las, ou etiquetá-las. Estas pessoas talvez possam criar uma tag procurando seu próprio beneficio ou podem criar tags pensando em ajudar aos outros. Os usuários tendem a atribuir palavras-chave para documentos ou outras fontes de informação [43].

Tagging é o processo de descrever um objeto utilizando uma tag (etiqueta descritiva). Na 


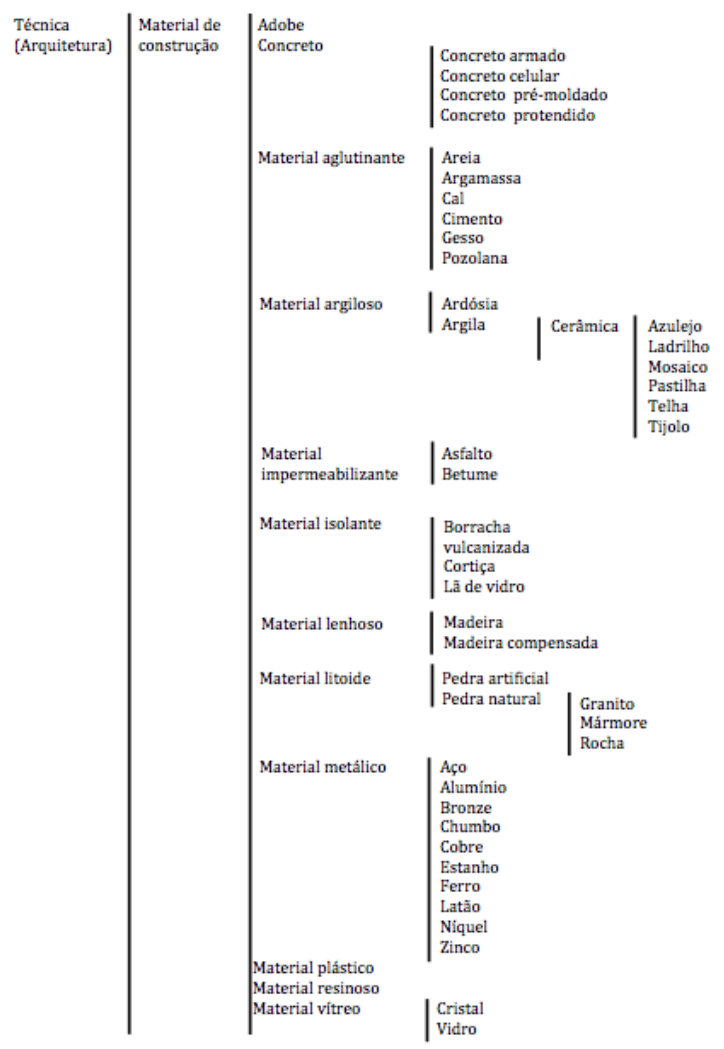

Figura 2.11: Material de construção no Tesauro Experimental de Arquitetura [16].

tendência atual da Web 2.0, tagging é realizada pelos observadores do conteúdo. Essas tags podem ser compartilhadas e utilizadas por todos os membros de uma comunidade [10].

Para nosso trabalho, as etiquetas são definidas como metadados textuais que são atribuídos às imagens.

\subsection{Recuperação da informação}

A recuperação da informação trata da representação, armazenamento, organização e acesso a itens de informação, como documentos, paginas web, catálogos, registros estruturados e semiestruturados, objetos multimídia, etc. A representação e a organização dos itens de informação devem fornecer aos usuários facilidade de acesso às informações de seu interesse [48]. A recuperação da informação de uma coleção de documentos usualmente acontece através de consultas formatadas como um conjunto de palavras chaves [4].

Neste trabalho, foi utilizada uma coleção de documentos e um índice invertido para o processo de indexação. Para o processo de medida de similaridade, foi empregado um arquivo que contém o valor de similaridade de termos. Por fim, para o processo de recuperação, utilizou-se o modelo de espaço vetorial para recuperar os documentos relacionados à consulta. A seguir explicamos sobre os arquivos utilizados em cada processo. 


\subsubsection{Processo de Indexação}

Para a indexação dos termos pertencentes aos documentos é necessário construir o arquivo de índice invertido para uma coleção de documentos.

a) A coleção de documentos é um grupo de documentos selecionados e que contêm a informação que se deseja recuperar.

b) O índice invertido é o mecanismo que utiliza as palavras pertencentes aos documentos de uma coleção para armazenar as frequências de cada palavra e indexar cada uma delas a fim de acelerar a tarefa de busca. A estrutura do índice invertido é composta por dois elementos importantes: o dicionário ou vocabulário e as ocorrências [48].

- O dicionário é uma estrutura de dados composta pelo conjunto de termos ordenados e pertencentes aos documento. E para cada termo do dicionário, o índice armazena os documentos que contêm esta palavra. A estrutura do vocabulário contém os seguintes elementos [48]:

- Token: É uma sequência de caracteres que muitas vezes são indicados como termos ou palavras. Os termos podem ser normalizados [33].

- Frequência de documentos: É o número de documentos na coleção que contém o termo $t$. [33]

- Frequência na coleção: A quantidade total de vezes que o termo aparece na coleção de documentos [33].

- As ocorrências consistem de uma lista de documentos que estão associados a cada termo do dicionário, também conhecido como "posting file" [48].

- Documentos são unidades que registram informação que desejamos recuperar. Para este trabalho serão textos relacionadas às imagens.

- Frequência de termos: Número de vezes que o termo ocorre no documento [33].

- Posição do termo: Número da posição do termo no documento [33].

A figura 2.12 mostra a estrutura do índice invertido.

Para que os tokens sejam armazenados no índice invertido é preciso que eles passem por alguns processos linguísticos. 


\begin{tabular}{|l|c|c|}
\hline Termo & $\begin{array}{c}\text { Freq. Doc } \\
\text { (Num docs) }\end{array}$ & $\begin{array}{c}\text { Col. Freq. } \\
\text { (Total Freq.) }\end{array}$ \\
\hline Ferro & 3 & 9 \\
\hline Madeira & 1 & 7 \\
\hline Marquise & 8 & 16 \\
\hline$\vdots$ & $\vdots$ & $\vdots$ \\
\hline
\end{tabular}

Figura 2.12: Estrutura do índice invertido [15].

\subsubsection{Palavras de parada}

Existem palavras muito comuns que têm pouco valor para ajudar na indexação entre termos e documentos, por isso essas palavras são ignoradas e excluídas do vocabulário e são adicionadas a uma lista de palavras de parada. Estas palavras podem ser: do, por, para, dela, etc. [33].

\subsubsection{Texto em minúsculas}

A técnica conhecida em inglês como CaseFolding, é bastante utilizada na indexação de tokens, ela consiste na transformação de todas as letras em minúsculas. Na fonte original dos dados deste trabalho, os nomes das imagens das edificações, os nomes dos autores, as descrições, as localizações e os tags inseridos pelos usuários estão em diferentes formas incluindo maiúsculas e minúsculas, dessa forma é importante a utilização desta técnica. Um exemplo é a palavra Madeira $\longrightarrow$ madeira.

\subsubsection{Normalização de termos}

Existem duas técnicas para normalizar termos como "stemming" e "lematização" que reduzem em forma flexional ou derivacional das palavras para transformá-las numa forma de base comum. Neste trabalho só se fez uso do "stemming", que consiste em remover os afixos derivacionais com o fim de encontrar as raízes das palavras [33]. A lematização não foi utilizada pois a fonte de dados que contém o título, descrição, autor, cidade e estado possuíam principalmente nomes próprios, como por exemplo "Praça do Relógio", "Vista da praça do relógio", "Macedo Silvio", "São Paulo". Também a maioria das tag possuíam termos técnicos da arquitetura relacionados aos materiais de construção e elementos arquitetônicos, como por exemplo madeira, concreto, pilar. Além disso, como o usuário é livre de inserir conteúdo no sistema colaborativo, a fonte de dados está sujeita a conter termos com erros de escrita, assim o uso da lematização não poderá garantir a correta morfologia flexional para este tipo de termos.

Esta técnica de normalização é necessária para evitar que palavras que se referem ao mesmo conceito, mas que aparecem em formas diferentes como singular e plural (exemplo: construção, construções) gerem entradas distintas no índice invertido.

A utilização de "stemming" permite armazenar as raízes das palavras no índice invertido e associar a ela todos os documentos que possuam esta raiz, como por exemplo as palavras construções, construção serão associados a um radical "construc". Desta maneira, quando o usuário faz uma consulta que possua qualquer dessas palavras, poderá recuperar os documentos associados ao radical construc [33]. Para este trabalho foi utilizado o algoritmo de remoção de afixos desenvolvido 
por Paz Trilho [46], utilizando as regras propostas por Orengo e Huyck [38].

\subsubsection{Consulta expandida}

Se refere à adição dos termos relacionados aos tokens pertencentes à consulta do usuário. Estes termos adicionais são extraídos da ontologia explorando as hierarquias das classes e as relações semânticas entre os termos. A consulta expandida é um dos objetivos deste trabalho e é apresentada na seção 3 da metodologia do mesmo. Por exemplo, para a consulta "Edifícios religiosos", os termos a serem adicionados seriam igreja, catedral, capela, templo que são obtidos da ontologia. Assim, a consulta expandida seria "Edifícios religiosos igreja catedral capela templo".

\subsubsection{Pesos dos termos}

A cada termo de cada documento são atribuídos valores, que são utilizados no índice invertido e representam uma relação de ocorrência entre o termo e o documento. Para aqueles termos que também existem na ontologia o peso será maior, o que influirá diretamente na consulta ao recuperar os documentos relevantes para o usuário.

\subsubsection{Processo de medida de similaridade na recuperação da informação}

A similaridade de termos é importante para a recuperação de informação que, junto com a ontologia, permite recuperar conteúdo relacionado aos termos ou termos similares pertencentes à consulta feita pelo usuário.

Esta similaridade entre termos é importante porque permite recuperar documentos, que podem não conter a palavra utilizada na consulta realizada mas sim uma palavra similar. Desta maneira pode-se recuperar os documentos relevantes para a busca do usuário.

Existem várias abordagens que utilizam a medida de similaridade, utilizando os termos pertencentes aos conceitos de uma hierarquia de uma ontologia.

\subsubsection{Abordagem OSS (Ontology Structure based Similarity )}

No trabalho de Schickel-Zuber e Faltings [42], define-se a medida OSS (Similaridade baseada na estrutura da ontologia). A ontologia usualmente reflete a informação contida entre os conceitos por meio da sua hierarquia.

O cálculo da pontuação a priori (APS) é o principal componente da OSS. O cálculo do APS captura a informação na estrutura da ontologia. A seguir, define-se o APS de um conceito $c$ com $n$ descendentes:

$$
A P S(c)=\frac{1}{n+2}
$$

A partir da fórmula, observa-se que as folhas da ontologia terão um APS igual a 1/2. Adicionalmente, o menor valor será encontrado na raiz, pois quando percorremos a ontologia em direção à raiz encontramos conceitos mais gerais e um maior número de descendentes, desse modo o APS tende a diminuir.

Para encontrar a similaridade entre dois conceitos $x$ e $z$ existentes na hierarquia da ontologia, é necessário identificar o menor ancestral comum (LCA), o qual passa por um conceito y. Assim, para 
encontrar a similaridade, utilizamos o valor de distância $D(x, z)$, demonstrado matematicamente no trabalho de Schickel-Zuber e Faltings [42], e que é definido como:

$$
D(x, z)=\frac{\log (1+2 \widehat{\beta}(z, y))-\log (\widehat{\alpha}(x, y))}{\max D}
$$

Onde max $D$ é a maior distância entre qualquer par de conceitos na ontologia, e $\widehat{\beta}(z, y)$ é o coeficiente de especialização, este sendo estimado utilizando o cálculo a priori APS:

$$
\widehat{\beta}(z, y)=A P S(z)-A P S(y)
$$

E $\widehat{\alpha}(x, y)$ é o coeficiente de generalização, $\alpha$ pode ser estimado utilizando também o cálculo a priori APS:

$$
\widehat{\alpha}(x, y)=A P S(y) / A P S(x) .
$$

\subsubsection{Teorema similaridade de Dekang Lin}

O teorema de similaridade proposto por Dekang Lin [28] define a similaridade entre dois conceitos $C_{1}$ e $C_{2}$ em uma taxonomia. Ele assume que a taxonomia é uma árvore, se $x_{1} \in C_{1}$ e $x_{2} \in C_{2}$, a parte comum entre $x_{1}$ e $x_{2}$ é que $x_{1} \in C_{0}$ e $x_{2} \in C_{0}$, onde $C_{0}$ é a classe que inclui ambos conceitos. Portanto, temos:

$$
\operatorname{Sim}\left(x_{1}, x_{2}\right)=\frac{2 \log \left(P\left(C_{0}\right)\right)}{\log \left(P\left(C_{1}\right)\right)+\log \left(P\left(C_{2}\right)\right)}
$$

Onde $P\left(C_{0}\right), P\left(C_{1}\right)$ e $P\left(C_{2}\right)$ são as probabilidades de ocorrência para cada objeto da taxonomia. Por exemplo, a similaridade entre Escola_estadual e Instituto_central_de_ciencias é:

$$
\operatorname{Sim}(\text { Escola_estadual, Instituto_central_de_ciencias })=\frac{2 \log (P(\text { Edificio_educacao })}{\log (P(\text { Escola }))+\log (P(\text { Instituto }))}
$$

Onde Edificio_educacao é uma super-classe de Escola e Instituto. P(Edificio_educacao), P(Escola) e $P$ (Instituto) são as probabilidade de ocorrência. Este teorema foi utilizado para calcular a similaridade entre termos baseada na taxonomia da ontologia e na distribuição de probabilidade que foi obtida a partir da contagem da frequência dos termos na coleção. Além disso, utilizou-se um segundo fator que usa as relações semânticas entre conceitos. Isto permite encontrar um grau de similaridade maior do que obteria-se só pela taxonomia. Na seção 3.5 descreveremos como foi utilizada a similaridade.

\subsubsection{Processo de Recuperação}

Existem vários modelos de recuperação de informação clássicos, como o modelo booleano, e o modelo de espaço vetorial.

\subsubsection{Modelo booleano}

O modelo de recuperação booleana está baseado na álgebra booleana. Neste modelo pode-se representar qualquer consulta na forma de uma expressão booleana de termos, na qual os termos 
são combinados com os operadores booleanos AND, OR, NOT [33].

Este modelo tem duas principais desvantagens. A primeira é relacionada à sua estrategia, que é baseada no critério de decisão binária que traz como resultado documentos relevantes e não relevantes, sem dar uma ordem de relevância a eles. A segunda é transformar a informação necessária em uma expressão booleana, como no caso das consultas inseridas pelos usuários. Para o modelo booleano, o peso do termo do índice é binário, onde 1 indica presença e 0 indica ausência. Temos como exemplo a consulta "praça OR parque" em que serão recuperados todos os documentos que possuam o termo praça adicionando também os documentos que possuam o termo parque; e se usarmos "praça AND parque" serão recuperados todos os documentos que possuam os dois termos. Este modelo é o mais usado em sistemas com base de dados devido à sua simplicidade.

\subsubsection{Modelo de Espaço Vetorial}

Também conhecido como modelo de vetor, este modelo atribui pesos não binários aos termos que serão indexados. Neste modelo pode-se representar consultas e documentos como vetores de termos para calcular depois a similaridade entre eles [41].

Segundo Baeza-Yates [4], os pesos dos termos são utilizados para calcular o grau de similaridade entre um documento pertencente ao sistema de recuperação e a consulta do usuário.

Os documentos retornados estão ordenados em forma decrescente segundo o grau de similaridade, mesmo se o documento só coincide de maneira parcial com a consulta. O resultado deste modelo em comparação com o modelo booleano é mais exato.

No modelo vetorial tem-se $t$ que é o número de termos no índice, $k_{i}$ um termo genérico no índice e $K=\left\{k_{1}, \ldots, k_{t}\right\}$ é o conjunto de todos os termos do índice. Um peso $w_{i, j}>0$ é associado a cada termo do índice $k_{i}$ de um documento $d_{j}$. Para um termo que não parece estar no documento de texto, $w_{i, j}=0$.

O documento $d_{j}$ está representado por $\vec{d}_{j}=\left(w_{1, j}, w_{2, j}, \cdots, w_{t, j}\right)$. E o peso $w_{i, q} \geq 0$ que está associado a cada termo $k_{i}$ de uma consulta $q$. O vetor de consulta é definido como $\vec{q}=\left(w_{1, q}, w_{2, q}, \cdots, w_{t, q}\right)$.

O documento $d_{j}$ e a consulta $q$ dada pelo usuário são representados como vetores t-dimensionais. A proposta deste modelo é calcular o grau de similaridade do documento $d_{j}$ e a consulta $q$ como a correlação entre os vetores $\vec{d}_{j}$ e $\vec{q}$, sendo quantificada pelo cosseno do ângulo entre esses vetores. Isto é:

$$
\operatorname{sim}\left(d_{j}, q\right)=\cos \left(d_{j}, q\right)=\frac{\vec{d}_{j} \bullet \vec{q}}{\left|\overrightarrow{d_{j}}\right| \times|\vec{q}|}=\frac{\sum_{i=1}^{t} w_{i, j} \times w_{i, q}}{\sqrt{\sum_{i=1}^{t} w_{i, j}^{2}} \times \sqrt{\sum_{i=1}^{t} w_{i, q}^{2}}}
$$

A figura 2.13 mostra o vetor de consulta $q$ e o vetor de documento $d_{j}$

O fator $|\vec{q}|$ não influencia no posicionamento, porque o valor dele é o mesmo para todos os 


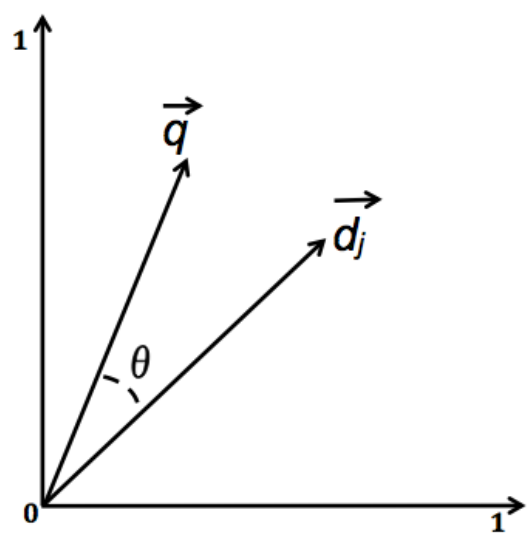

Figura 2.13: O cosseno do $\theta$ é adotado como $\operatorname{sim}\left(d_{j}, q\right)$.

documentos. O fator $\left|\vec{d}_{j}\right|$ proporciona uma normalização no espaço de documentos. A similaridade $\operatorname{sim}\left(d_{j}, q\right)$ pode ter valores entre 0 e 1 desde que $w_{i, j} \geq 0$ e $w_{i, q} \geq 0$. Pode-se estabelecer um limiar para os resultados da similaridade com o fim de recuperar os documentos acima desse limiar.

Para poder calcular a similaridade é necessário antes calcular os pesos dos termos indexados. Um dos modelos mais comuns para a ponderação de termos é Frequência de termo, frequência de documento inverso(TF-IDF), o qual atribui ao termo $i$ um peso no documento $j w_{i, j}$ é definido na equação 2.5 .

$$
w_{i, j}=t f_{i, j} \times i d f_{i}
$$

A frequência dos termos $t f_{i, j}$ baseada no peso do termo $i$ o qual é o número de ocorrências do termo $i$ no documento $d_{j}$. Um problema da frequência dos termos é que todos os termos são considerados igualmente importantes quando trata-se de avaliar a relevância na consulta. Por exemplo, se uma coleção de documentos contém informação sobre material de construção concreto então é provável que a maioria dos documentos possuam o termo "concreto". Por isso, é necessário atenuar o efeito desses termos que ocorrem tão frequentemente na coleção. Uma solução é usar a frequência de documento.

A frequência de documento $d f_{i}$ do termo $i$, que é o número de documentos na coleção que possuem o termo $i$.

Calculamos a frequência de documento inversa $i d f$. Na equação 2.6 temos $N$ que é o número total de documentos na coleção, e o logaritmo ajuda a moderar o efeito do valor da frequência do termo no documento $d f_{t}$; desta maneira, os termos muito repetitivos ou frequentes terão um $i d f$ 
baixo enquanto os termos pouco comuns terão um idf alto.

$$
i d f_{t}=\log \frac{N}{d f_{t}}
$$

A seguir mostra-se um exemplo para o modelo de espaço de vetorial. Suponha uma coleção de dois documentos que contêm os termos: "vista", "aérea", "da", "praça", "do", "relógio", "superior", "parque", "juventude" que representam as dimensões de 1 a 9 do espaço dimensional. Os documentos são:

$d_{1}$ : Vista aérea da praça do relógio.

$d_{2}$ : Vista superior do parque da juventude.

Se a consulta do usuário fosse "praça do relógio", seria buscado sobre os documentos da coleção. A seguir, calcularemos o $t f$, idf e a similaridade entre os documentos e a consulta.

\begin{tabular}{lllllll}
\hline$d_{1}$ & vista & aérea & da & praça & do & relógio \\
\hline$f t$ & 1 & 1 & 1 & 1 & 1 & 1 \\
\hline
\end{tabular}

\begin{tabular}{lllllll}
\hline$d_{2}$ & vista & superior & do & parque & da & juventude \\
\hline$f t$ & 1 & 1 & 1 & 1 & 1 & 1 \\
\hline
\end{tabular}

A seguir tem-se o "idf" para todos os termos que ocorrem nos documentos.

\begin{tabular}{|l|l|}
\hline \multicolumn{1}{|c|}{ Termos } & \multicolumn{1}{c|}{ idf } \\
\hline vista & 0 \\
\hline aérea & 0.301 \\
\hline da & 0 \\
\hline praça & 0.301 \\
\hline do & 0 \\
\hline relógio & 0.301 \\
\hline superior & 0.301 \\
\hline parque & 0.301 \\
\hline juventude & 0.301 \\
\hline
\end{tabular}

A seguir calcula-se o peso $w_{i, j}$ que é o "TF-IDF" de cada termo. 


\begin{tabular}{|c|c|c|c|c|c|c|c|c|c|c|c|c|}
\hline \multirow[t]{2}{*}{ Termo } & \multirow[b]{2}{*}{$i d f$} & \multicolumn{3}{|c|}{$q$} & \multicolumn{3}{|c|}{$d_{1}$} & \multicolumn{3}{|c|}{$d_{2}$} & \multirow[b]{2}{*}{$w_{i, 1} \times w_{i, q}$} & \multirow[b]{2}{*}{$w_{i, 2} \times w_{i, q}$} \\
\hline & & $t f$ & $w_{i, q}$ & $w_{i, q}^{2}$ & $t f$ & $w_{i, 1}$ & $w_{i, 1}^{2}$ & $t f$ & $w_{i, 2}$ & $w_{i, 2}^{2}$ & & \\
\hline vista & 0 & 0 & 0 & 0 & 1 & 0 & 0 & 1 & 0 & 0 & 0 & 0 \\
\hline aérea & 0.301 & 0 & 0 & 0 & 1 & 0.301 & 0.091 & 0 & 0 & 0 & 0 & 0 \\
\hline da & 0 & 0 & 0 & 0 & 1 & 0 & 0 & 1 & 0 & 0 & 0 & 0 \\
\hline praça & 0.301 & 1 & 0.301 & 0.091 & 1 & 0.301 & 0.091 & 0 & 0 & 0 & 0.091 & 0 \\
\hline do & 0 & 1 & 0 & 0 & 1 & 0 & 0 & 1 & 0 & 0 & 0 & 0 \\
\hline relógio & 0.301 & 1 & 0.301 & 0.091 & 1 & 0.301 & 0.091 & 0 & 0 & 0 & 0.091 & 0 \\
\hline superior & 0.301 & 0 & 0 & 0 & 0 & 0 & 0 & 1 & 0.301 & 0.091 & 0 & 0 \\
\hline parque & 0.301 & 0 & 0 & 0 & 0 & 0 & 0 & 1 & 0.301 & 0.091 & 0 & 0 \\
\hline juventude & 0.301 & 0 & 0 & 0 & 0 & 0 & 0 & 1 & 0.301 & 0.091 & 0 & 0 \\
\hline
\end{tabular}

Logo calcula-se $\left|\overrightarrow{d_{1}}\right|,\left|\overrightarrow{d_{2}}\right|$ e $|\vec{q}|$ que são as normas de $\overrightarrow{d_{1}}, \overrightarrow{d_{2}}$ e $\vec{q}$ :

$$
\begin{aligned}
& \left|\overrightarrow{d_{1}}\right|=\sqrt{\sum_{i=1}^{t} w_{i, 1}^{2}}=\sqrt{0+0.091+0+0.091+0+0.091+0+0+0}=1.427 \\
& \left|\overrightarrow{d_{2}}\right|=\sqrt{\sum_{i=1}^{t} w_{i, 2}^{2}}=\sqrt{0+0+0+0+0+0+0.091+0.091+0.091}=1.427 \\
& |\vec{q}|=\sqrt{\sum_{i=1}^{t} w_{i, q}^{2}}=\sqrt{0+0+0+0.091+0+0.091+0+0+0}=0.427
\end{aligned}
$$

Por último utilizamos a equação de similaridade para a consulta e o documento $d_{1}$ :

$$
\operatorname{sim}\left(d_{1}, q\right)=\frac{\sum_{i=1}^{t} w_{i, 1} \times w_{i, q}}{\sqrt{\sum_{i=1}^{t} w_{i, 1}^{2}} \times \sqrt{\sum_{i=1}^{t} w_{i, q}^{2}}}=\frac{0+0+0+0.091+0+0.091+0+0+0}{1.427 \times 0.427}=0.299
$$

E para a consulta e o documento $d_{2}$ temos:

$$
\operatorname{sim}\left(d_{2}, q\right)=\frac{\sum_{i=1}^{t} w_{i, 2} \times w_{i, q}}{\sqrt{\sum_{i=1}^{t} w_{i, 2}^{2}} \times \sqrt{\sum_{i=1}^{t} w_{i, q}^{2}}}=\frac{0+0+0+0+0+0+0+0+0}{1.427 \times 0.427}=0
$$

Pelos cálculos realizados vemos que o $d_{1}$ tem a pontuação mais alta. Portanto, $d_{1}$ é o documento mais relevante para a consulta $q$. 


\subsection{Avaliação em sistemas de recuperação de informação}

Segundo Baeza-Yates [4], as avaliações nos sistemas de recuperação de informação são usualmente baseadas em um conjunto de documentos para testes e em uma medida de avaliação. A coleção de teste de referência consiste de uma coleção de documentos, um conjunto de exemplos de requerimentos de informação e um conjunto de documentos relevantes por cada exemplo de informação solicitada.

Para estas avaliações é necessário considerar a tarefa de recuperação que será avaliada, que pode consistir simplesmente de uma consulta dada pelo usuário e os documentos recuperados.

A relevância está relacionada a quanto uma informação é necessária para o usuário. Assim, um documento pertencente a um conjunto de documentos para teste é classificado como relevante ou não relevante.

Considera-se um exemplo de informação requerida $I$ (pertencente ao conjunto de documentos para testes) e seu conjunto $R$ de documentos relevantes, sendo $|R|$ o número de documentos relevantes na coleção. E assume-se que para uma dada estratégia que está sendo avaliada processa-se a informação requerida $I$ e gera um conjunto de documentos recuperados $A$. Logo, $|A|$ é o número total de documentos recuperados desse conjunto. Além disso, $|R a|$ é o número de documentos pertencentes à interseção dos conjuntos $R$ e $A$, isto é, o número de documentos relevantes recuperados. A figura 2.14 exibe os conjuntos mencionados acima.

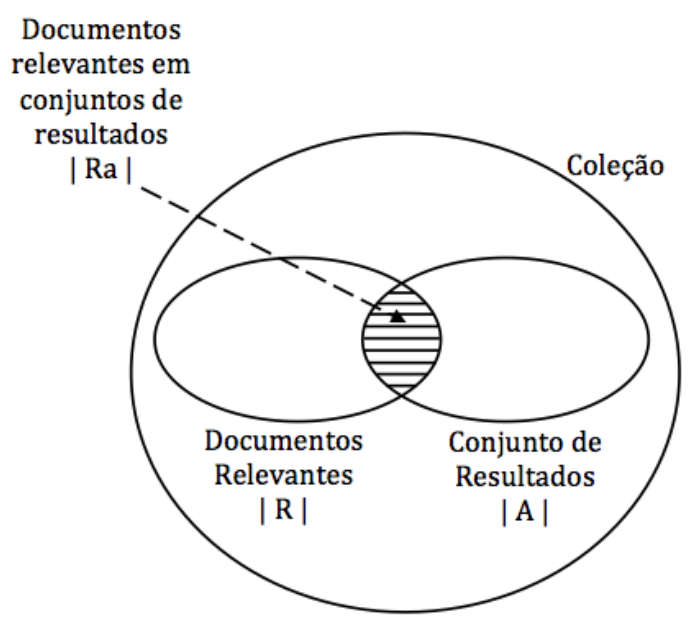

Figura 2.14: Documentos relevantes do conjunto de resultados.

Existem duas medidas de avaliação que são bem utilizadas:

- Cobertura: Fração de documentos relevantes (o conjunto R), recuperada, como pode-se ob- 
servar na equação 2.7

$$
\text { Cobertura }=\frac{\text { Número de documentos relevantes recuperados }}{\text { Número total de documentos relevantes na coleção }}=\frac{|R a|}{|R|}
$$

- Precisão: Fração dos documentos recuperados (o conjunto A), que são relevantes, como podese observar na equação 2.8

$$
\text { Precisão }=\frac{\text { Número de documentos relevantes recuperados }}{\text { Número total de documentos recuperados }}=\frac{|R a|}{|A|}
$$

As métricas de precisão e cobertura presumem que a relevância de um documento é avaliada independentemente de qualquer outro documento na mesma coleção. A medida-F assume valores entre 0 e 1 . Atribui-se valor 0 quando documentos não relevantes tem sido recuperados. E valor 1 quando todos os documentos classificados são relevantes. Além disso, ele assume um valor alto somente quando a precisão e cobertura são altas. Uma avaliação de recuperação de informação balanceada foi introduzida como uma forma de intermediar dois componentes, a medida-F.

$$
\begin{aligned}
F_{\beta} & =\frac{\left(1+\beta^{2}\right) \times P \times R}{\left(\beta^{2} \times P\right)+R} \\
& =\frac{2 P R}{P+R} \quad \text { Se } \beta=1
\end{aligned}
$$

O valor amplamente utilizado para $\beta$ é 1, a fim de dar igual peso para precisão e cobertura; a medida-F , é a média harmônica de precisão e cobertura [8].

\subsection{Considerações finais}

Nesse capítulo foram apresentados os principais conceitos utilizados para a construção da ontologia no domínio da arquitetura. Também se apresentaram as definições necessárias para o desenvolvimento de um sistema de informação para a recuperação de imagens arquitetônicas.

A construção da ontologia e o desenvolvimento do sistema de informação serão explicados no capítulo seguinte. 


\section{Capítulo 3}

\section{Recuperação de imagens baseada em ontologias para sis- temas colaborativos}

Os sistemas com ambientes colaborativos têm crescido em popularidade na web. Nestes sistemas, os usuários têm a possibilidade de compartilhar conteúdo e colaborarem descrevendo o conteúdo através de tags ou texto. No Arquigrafia, o conteúdo são imagens, descritas através de campos como autor, título, data e tags livres.

Esta etiquetação ou termos inseridos podem ser descritos de maneira não clara pelo usuário, originando um sistema que possui conteúdo não controlado dificultando a recuperação da informação.

As técnicas tradicionais para recuperação de informação como busca booleana ou palavra-chave continuam sendo utilizadas neste tipo de sistemas de ambientes colaborativos, porém como nestas técnicas o usuário é livre para utilizar a linguagem natural na consulta, nem sempre a informação recuperada é relevante para o usuário. Este é o caso do Arquigrafia, que utiliza a busca por palavras-chave.

Neste trabalho optamos por explorar uma abordagem com a finalidade de melhorar a recuperação de imagens, utilizando uma ontologia de domínio de arquitetura que foi construída para associar as tags ou palavras-chaves com conceitos pertencentes à área de arquitetura, com a finalidade de evitar a ambiguidade dos termos inseridos pelos usuários. Esta ontologia também foi utilizada para adicionar termos similares ou relacionados à consulta inicial e criar uma nova consulta estendida, que será usada na recuperação de informação.

\subsection{Trabalhos relacionados}

Na literatura encontramos alguns trabalhos que também utilizaram a abordagem de ontologias e modelos de recuperação da informação para problemas similares.

- Priyansh Arora [3], propõe um método para recuperar vídeos relevantes usando anotações semânticas. Para esse objetivo são criados documentos RDF com anotações detalhadas por cada vídeo. Todos esses documentos são criados manualmente e armazenados na ferramenta Twinkle, para realizar consultas na linguagem SPARQL e assim obter resultados relevantes. Neste trabalho foi concluído que as notações semânticas dos vídeos mapeados em documentos 
RDF melhoram a precisão da busca.

- Chauhan et al. [9], propõem um modelo conceitual para recuperação de informação semântica baseada em ontologia. Os autores apresentam o esqueleto de um sistema baseado em ontologias, que analisa a consulta inserida pelo usuário para extrair conceitos significativos que pertencem a uma ontologia, para finalmente expandir a consulta.

A ontologia utilizada é para o domínio do esporte. A etapa da consulta expandida é realizada em duas fases: a primeira é a expansão dos sinônimos dos termos da consulta e a segunda é usando a similaridade semântica dos termos da consulta. Todos estes termos são incluídos na consulta. Em seguida é realizada uma classificação de todos os termos para saber quais deles são classes ou instâncias. Após este procedimento é construída uma consulta em SPARQL apropriada, utilizando a base de conhecimento.

Finalmente, os documentos recuperados são devolvidos em ordem de relevância. Nos experimentos do trabalho de Chauhan et al. [9], são comparadas as consultas com e sem expansão. Em todos os experimentos, a precisão e cobertura melhoram consideravelmente.

- Mata et al. [34], apresentam a recuperação de imagens baseada na informação textual que está relacionada com a imagem. Para expandir as consultas, os autores utilizaram a ontologia de domínio médico $\mathrm{MeSH}^{1}$. Nos experimentos utilizaram as coleções de documentos como ImageCLEF $2009^{2}$ e $2010^{3}$. Os resultados dos experimentos mostraram que nem todas as estratégias de expansão são capazes de melhorar a eficácia do resultado.

- Os autores Fernández et al. [18], também aplicam a recuperação de informação baseada em ontologias. Neste trabalho as consultas são expressas em termos da linguagem de consultas para ontologias SPARQL, e utilizam recursos externos como uma ontologia e uma base de conhecimento obtida de vários repositórios heterogêneos; o processo de indexação é baseado em anotações semânticas, associações entre entidades semânticas da ontologia e os documentos existentes.

No processo de recuperação é utilizado o modelo espaço vetorial para calcular o valor de similaridade semântico entre a consulta e os documentos indexados relacionados. Para lidar com o problema de base de conhecimento incompleto que origina resultados ruins quando são executadas consultas em SPARQL, é proposta uma combinação da medida de similaridade semântica com a medida de similaridade de palavras chave, a qual ajuda a manter bons resultados em cenários similares.

- O autor Fabiano Duarte [5] propõe um modelo de recuperação e busca de informação interativa, na qual é esperado que o usuário realize buscas sequenciais no sistema, com o intuito

\footnotetext{
${ }^{1}$ MeSH:http://www.ncbi.nlm.nih.gov/mesh

${ }^{2}$ ImageCLEF 2009:http://www.imageclef .org/2009

${ }^{3}$ ImageCLEF 2010:http://www. imageclef .org/2010
} 
de utilizar os resultados visualizados, para ajudar ao usuário a melhorar sua próxima consulta.

Neste trabalho foi construída una ontologia, que utilizou como fonte de dados 622 citações de artigos que contém conceitos como publicação, autor, instituição, revista e palavras chaves. Usando esta ontologia foi construído um índice invertido semântico, que além de conter as informações requeridas pelo índice invertido clássico, contém a descrição do conceito a que ele está vinculado.

- O trabalho de Paz Trillo [46] apresenta o desenvolvimento de um sistema de coleção de vídeos de entrevistas (OnAIR), no qual o usuário pode realizar consultas. Este sistema utiliza uma ontologia de domínio da arte contemporânea a qual serve para expandir as consultas com termos relacionados aos originais. Neste trabalho as consultas são expandidas para permitir a recuperação de vídeos utilizando sinônimos e relações semânticas presentes na ontologia.

Dos trabalhos relacionados podemos ver que as anotações semânticas e ontologias, quando aplicados na recuperação de informação, são úteis para melhorar os resultados das buscas. Dos trabalhos [3], [5] e [18] destaca-se a importância de ter anotações semânticas nos documentos, com o objetivo de enriquecer os documentos com informações adicionais e úteis, e assim criar um índice invertido semântico.

Do trabalho [9] destaca-se a utilidade de expandir a consulta usando a informação semântica da ontologia, pois novos termos que tem relação semântica são adicionados na consulta, melhorando consideravelmente a precisão e cobertura. Deste trabalho vimos a importância de classificar os termos entre classes e instâncias para realizar um tratamento específico para os dois tipos. Do trabalho [46], reutilizamos a implementação das técnicas de recuperação de informação para busca de vídeos digitais, que foi expandida para o domínio de arquitetura, incluindo regras específicas para controlar a expansão da consulta e um novo tratamento na construção da similaridade entre termos.

\subsection{Visão geral da abordagem proposta}

A metodologia proposta é estruturada em quatro fases.

A primeira fase consiste na construção da ontologia do domínio de arquitetura OntoArq com instâncias extraídas do sistema Arquigrafia.

A segunda fase consiste na indexação e pré-processamento, na qual utilizamos os dados da coleção de imagens extraídas do sistema Arquigrafia e a técnica do stemming para ser aplicada a cada termo da coleção. Também nesta fase é necessário calcular os pesos dos termos, e relacionar cada termo com um ou mais documentos no índice invertido.

A terceira fase, consiste no processamento e cálculo da similaridade entre os termos da ontologia e os termos do índice invertido, que será utilizado pela quarta fase.

A quarta fase, consiste na expansão da consulta e recuperação de imagens, na qual a consulta inicial é analisada para adicionar termos relacionados a ela e que são obtidos da ontologia dando como 
resultado uma consulta estendida, que será utilizada para recuperar as imagens procuradas. As fases desta abordagem podem ser observadas na figura 3.1 .

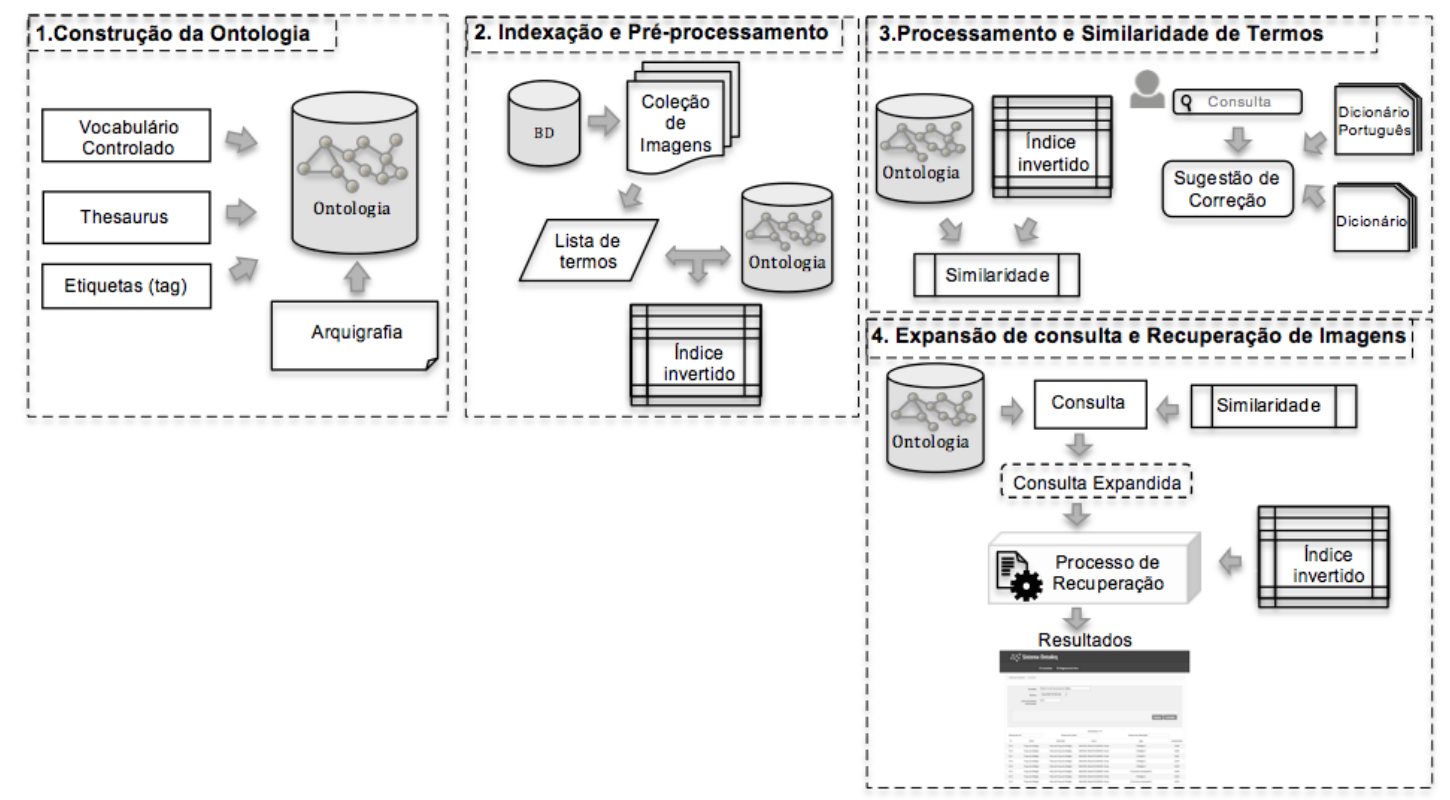

Figura 3.1: As quatro fases que são parte de nossa abordagem.

\subsection{Fase da construção da ontologia}

As ontologias descrevem os conceitos, as propriedades e relações existentes de uma forma estruturada e compreensiva com a finalidade de descrever o conhecimento de um determinado domínio.

Para esta primeira fase do presente trabalho foi necessária a construção de uma ontologia no domínio da área de arquitetura, e para que a modelagem de nossa ontologia seja adequada de tal maneira que possa ser reutilizada ou estendida, foi preciso utilizar uma metodologia.

Na literatura atual não existe uma única metodologia para a construção de uma ontologia. Pelo contrário, existe uma série de metodologias, métodos e linguagens que são utilizados dependendo da complexidade do domínio de aplicação da ontologia.

Para este trabalho nós optamos por utilizar a abordagem sistêmica proposta por Falbo, Menezes e Rocha [14], que reúne as principais características e processos das metodologias de Uschold e King [47] e de Gruninger e Fox [20].

A seguir temos os passos da metodologia, conforme visto na seção 2.5, aplicada a construção da nossa ontologia.

\subsubsection{Propósito e especificação de requisitos}

O principal propósito foi a modelagem dos principais conceitos do domínio da área de arquitetura para ser utilizado na web, permitindo que a ontologia construída possa ser usada por um sistema de recuperação de informação de imagens arquitetônicas. Portanto, a ontologia construída deve ser capaz de fornecer respostas a uma série de questões de competência dadas pelos especialistas da 
área da arquitetura. Estes especialistas são alunos de graduação e um professor doutor da área de arquitetura, os quais pertencem ao equipe do projeto Arquigrafia.

O fato de ter estas questões permitiu definir o escopo da ontologia, delimitando os conceitos relevantes para a construção dela. Essa delimitação foi dada devido à ontologia ser orientada para o domínio da área de arquitetura e estar mais voltada a um sistema de compartilhamento de imagens arquitetônicas.

Foi útil também para a construção da ontologia identificar os potenciais usuários, ou seja, identificar quem utilizará a ontologia; consideramos que parte da ontologia poderá ser reutilizada por outros usuários interessados no domínio de arquitetura, os quais poderão estendê-la. Entretanto, para o nosso caso, o usuário potencial é o sistema de compartilhamento de imagens arquitetônicas Arquigrafia, o qual utilizará a ontologia para refinar e/ou melhorar as consultas dadas pelos usuários. Em outras palavras, as consultas podem ser expandidas com um ou mais termos pertencentes à ontologia e relacionados à consulta, permitindo obter melhores resultados.

As seguintes questões de competência foram formuladas por arquitetos, potenciais usuários.

- Onde se localizam construções de taipa remanescentes em São Paulo?

- Quem é o autor do projeto da Praça do Relógio?

- Quais eram os principais arquitetos em atividade em São Paulo entre as décadas de 30 e 60 ?

- Quais eram os principais arquitetos em atividade no Rio de Janeiro entre as décadas de 30 e $60 ?$

- Quem projetou a Rodoviária de Cuiabá?

- Qual a data da obra do Conjunto Habitacional do Prefeito Mendes de Moraes?

- Quais são os principais edifícios residenciais no interior do Rio de Janeiro?

- Existem edifícios em vidro construídos no Brasil?

- Quais os edifícios projetados por Macedo Silvio Soares em São Paulo?

- Existem edifícios projetados por Plinio Croce no interior do estado de São Paulo ?

- Quem projetou a Biblioteca Brasiliana?

- Quais edifícios foram projetados por Gian Carlo Gasperini no Brasil?

- Onde encontro casas de madeira no Pará?

- Quais são os exemplares de arquiteturas do primeiro século (séc. XVI) do Brasil que ainda existem e podem ser visitados?

- As palafitas típicas da habitação ribeirinha no Norte do Brasil, podem ser vistas em que lugares da Amazônia? 


\subsubsection{Captura da ontologia}

Na captura foi considerado o escopo estabelecido no passo anterior para a definição dos conceitos, das propriedades e das relações relevantes para a ontologia. Estes conceitos foram obtidos a partir da análise de termos categorizados do Tesauro Experimental da Arquitetura [12], do vocabulário controlado da área da arquitetura do SIBi/USP [1] e dos dados relevantes extraídos do banco de dados do sistema Arquigrafia, tais como tags relacionadas às imagens, o título, a descrição, os autores das construções e sua localização.

Neste passo utilizou-se um dicionário de termos arquitetônicos [11] e o Tesauro Experimental de Arquitetura para evitar ambiguidades e inconsistências na criação de conceitos da ontologia. Os conceitos criados foram utilizados para formar a hierarquia de classes. Uma vez criada a taxonomia de classes também são criadas as propriedades, os relacionamentos entre as classes, e por último são criadas as instâncias. Assim, todos esses elementos deram como resultado o modelo da ontologia. Para detalhar o procedimento da construção da ontologia vamos dividi-lo em etapas.

a) Na primeira etapa foi criada a hierarquia de classes. Esta hierarquia contém conceitos relevantes que foram obtidos pela análise dos termos existentes no Tesauro Experimental, no vocabulário controlado da área de arquitetura e dos dados principais do banco de dados do Arquigrafia, as quais são as fontes que permitiram a construção da hierarquia. Nas figuras $3.3,3.5,3.7$ e 3.10 exibe-se a taxonomia de classes construída, divida em partes para um melhor entendimento. Na figura 3.11 está a hierarquia de classes completa.

Como primeira parte da hierarquia de classes considerou-se as tags do Arquigrafia que apresentam palavras genéricas, como por exemplo telhado, sacada, chaminé, etc, que precisavam ter uma representação, ou seja, uma classe associada. Para isso utilizou-se parte do Tesauro Experimental da Arquitetura relacionado a estas tags, exibido na Figura 3.2 e pela análise dos termos do tesauro criou-se as classes necessárias para associá-las as tags existentes, dando como resultado uma parte da hierarquia de classes, a qual é exibida na Figura 3.3.

Por exemplo: podemos observar na figura 3.2 que telhado está relacionado à categoria "Estrutura: cobertura" , assim esta categoria é considerada na ontologia como a classe "Cobertura" exibido na figura 3.3, o mesmo acontece com a maioria das tags.

Como segunda parte da hierarquia de classes considerou-se outras tags como concreto, concreto aparente, areia, argila, tijolo, etc. Após a observação do Tesauro Experimental da Arquitetura, determinou-se que elas estão relacionadas aos materiais de construção. Portanto, criou-se a hierarquia de classes para material de construção. Este tratamento de dados é aplicado para todas as tags do sistema do Arquigrafia.

Por exemplo, pode-se observar na figura 3.4 que existe o termo "concreto armado" e que está relacionado ao termo "Concreto", assim por esta categoria é criada uma classe "Concreto", e os termos "concreto armado", "concreto celular" entre outros são considerados como in- 


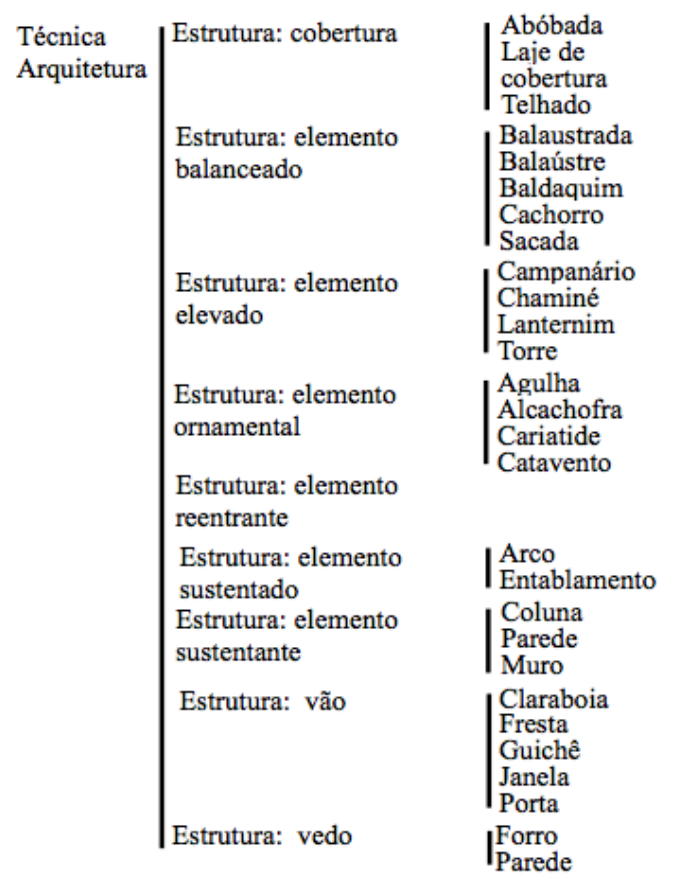

Figura 3.2: Primeira parte da categorização de termos do Tesauro Experimental da arquitetura.

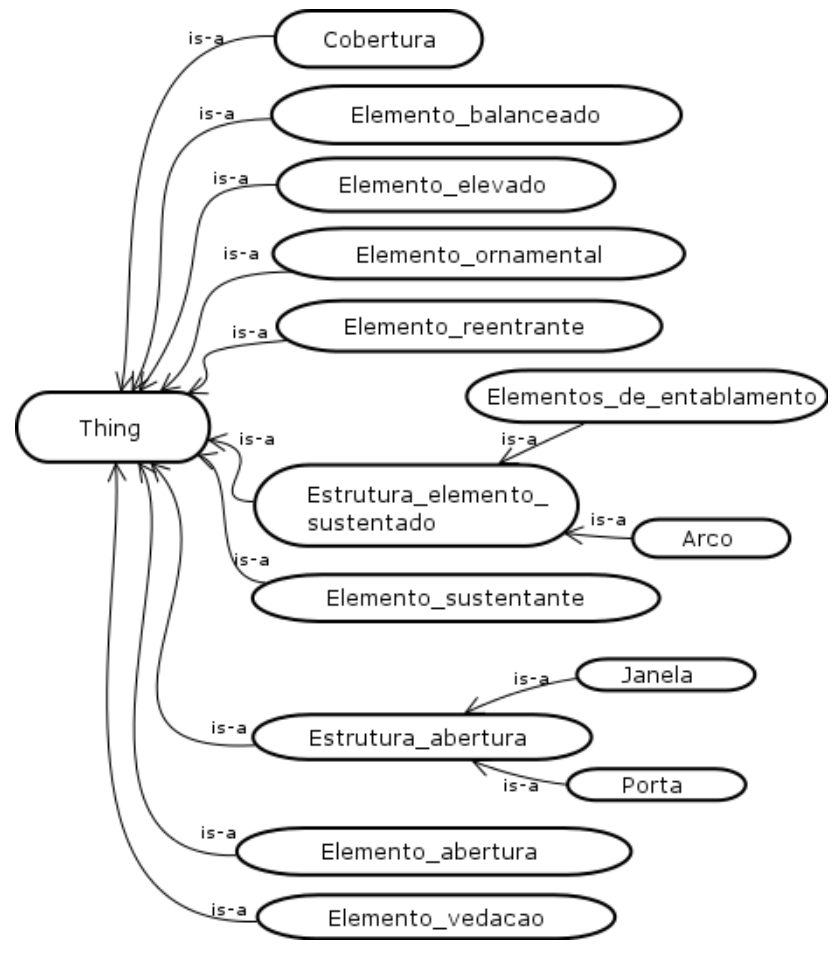

Figura 3.3: Primeira parte da hierarquia de classes da ontologia.

divíduos na ontologia. Na figura 3.5, mostra-se a classe material_contrucao e suas subclasses diretas. 


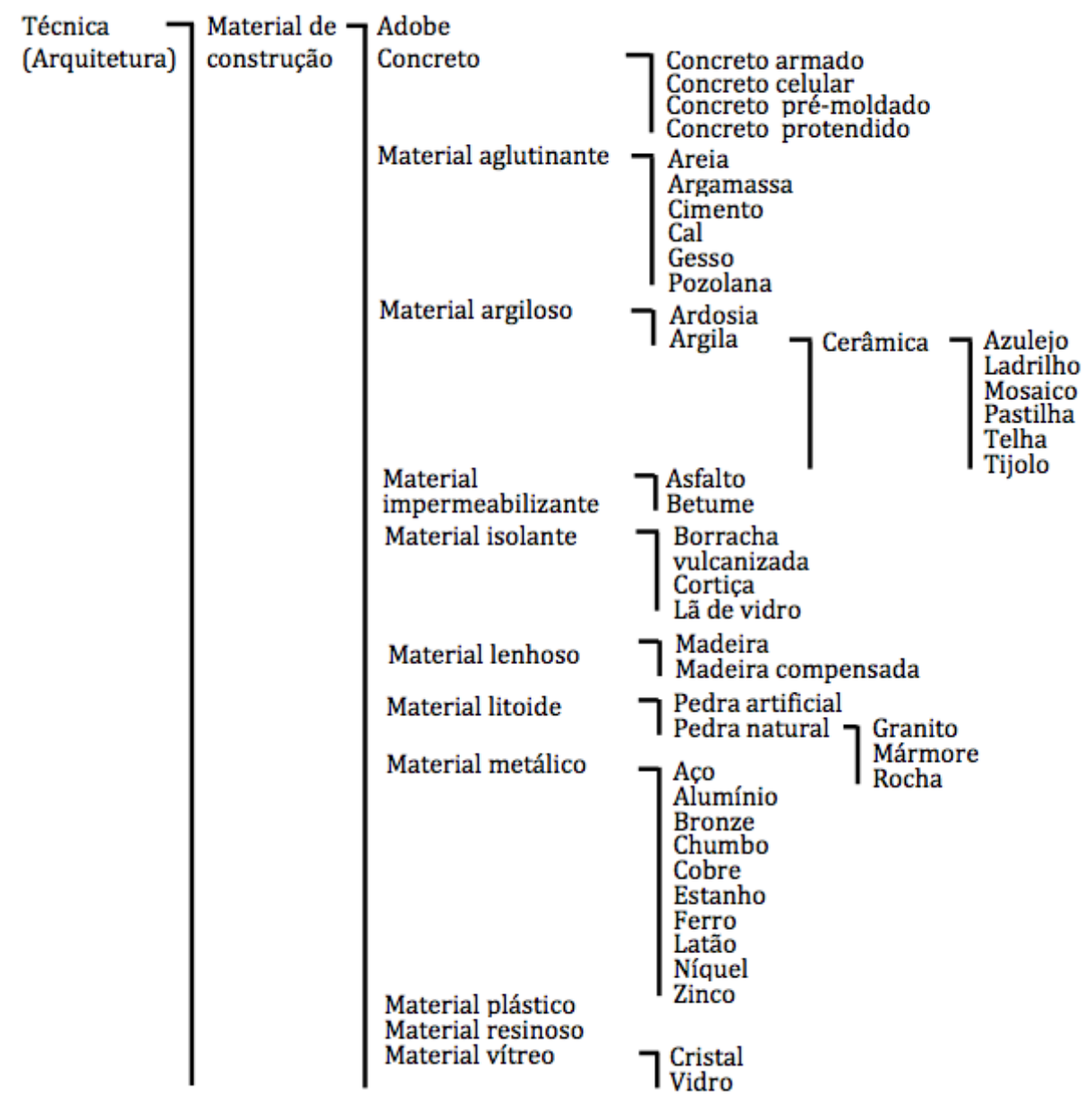

Figura 3.4: Segunda parte analisada do Tesauro Experimental da arquitetura.

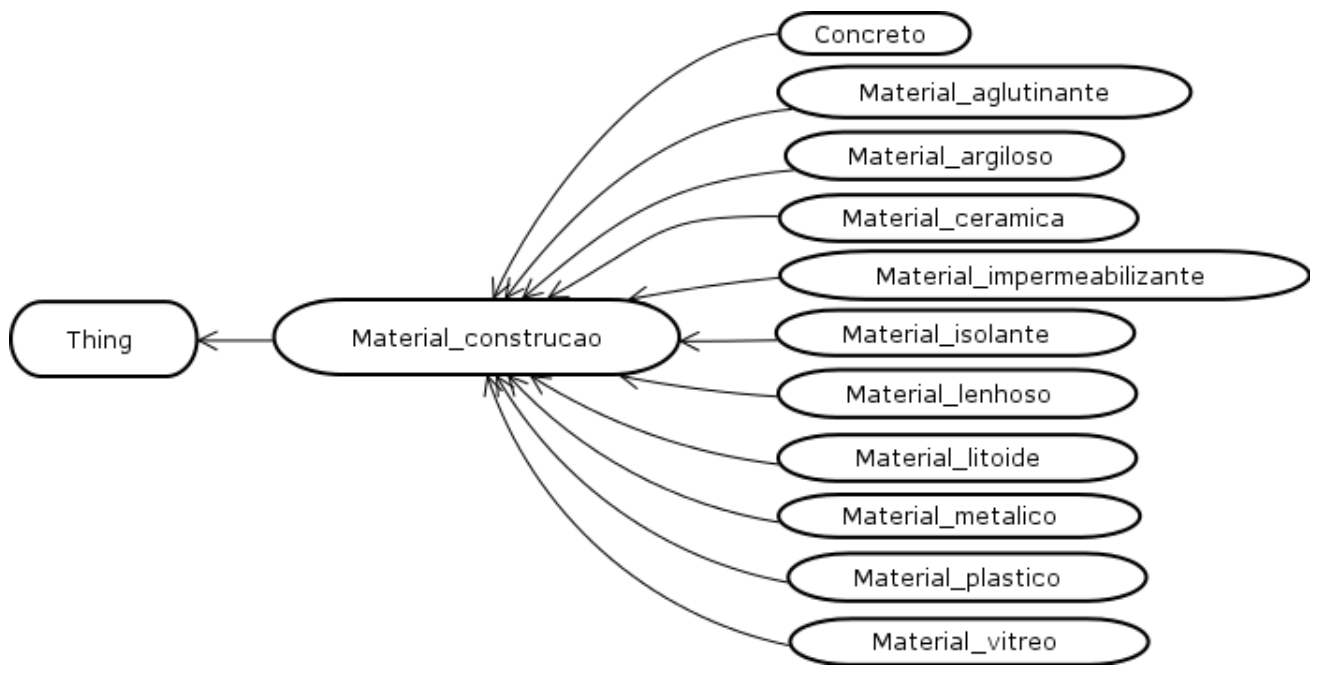

Figura 3.5: Segunda parte da hierarquia de classes na ontologia. 
Como terceira parte da hierarquia de classes considerou-se as referencias às construções existentes no Arquigrafia. Após a observação e análise desses dados, determinou-se que existem diferentes tipos de construções como hospitais, escolas, etc. Assim, para construir a hierarquia de classes de construções utilizou-se o vocabulário controlado da USP para a área de arquitetura.

No vocabulário controlado da USP existe uma categorização para edifícios, exibida na Figura 3.6. Esta categorização foi utilizada para construir a hierarquia de classes para construções observada na Figura 3.7.

Por exemplo, no vocabulário controlado pode-se observar o termo composto "Edifícios para comunicações" que esta relacionado ao termo "Edifícios", esses termos e sua relação foram criados na hierarquia de classes. Dessa forma, edifícios foi criado como a classe "Construcao_arquitetonica" e "Edificio_comunicacao" é adicionado como subclasse de "Construcao_arquitetonica".

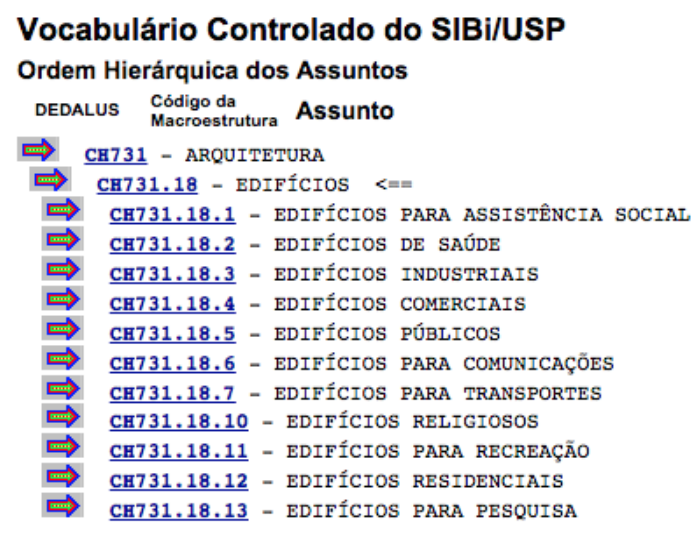

Figura 3.6: Terceira parte para a categorização de termos no Vocabulário controlado da USP.

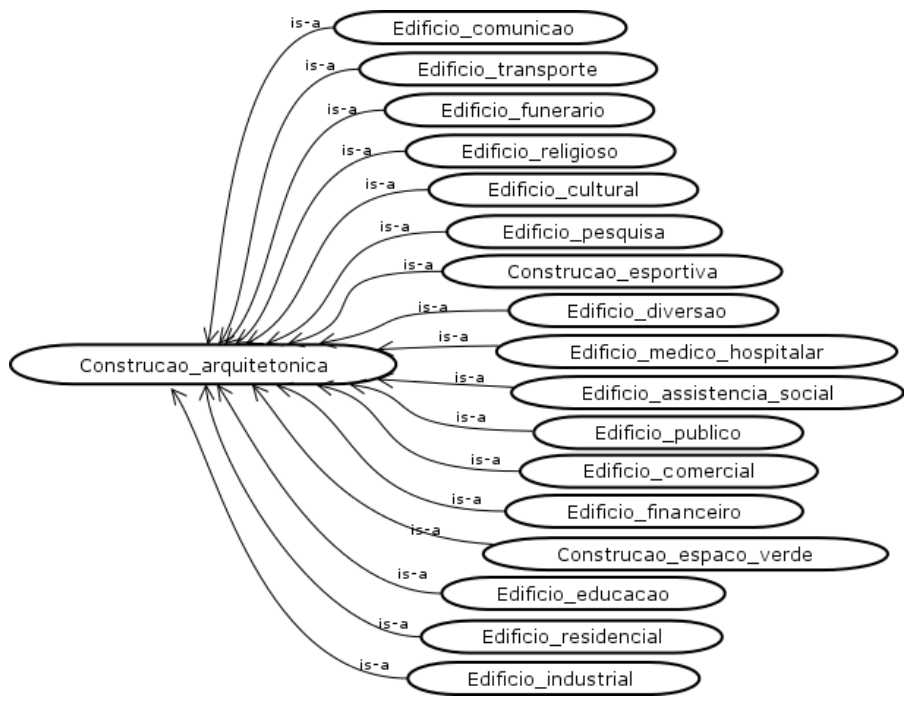

Figura 3.7: Hierarquia de classes para Construcao_arquitetonica com suas subclasses diretas. 
As subclasses até o nível 2 de profundidade da classe Construcao_arquitetonica são exibidas nas figuras 3.8 e 3.9 .

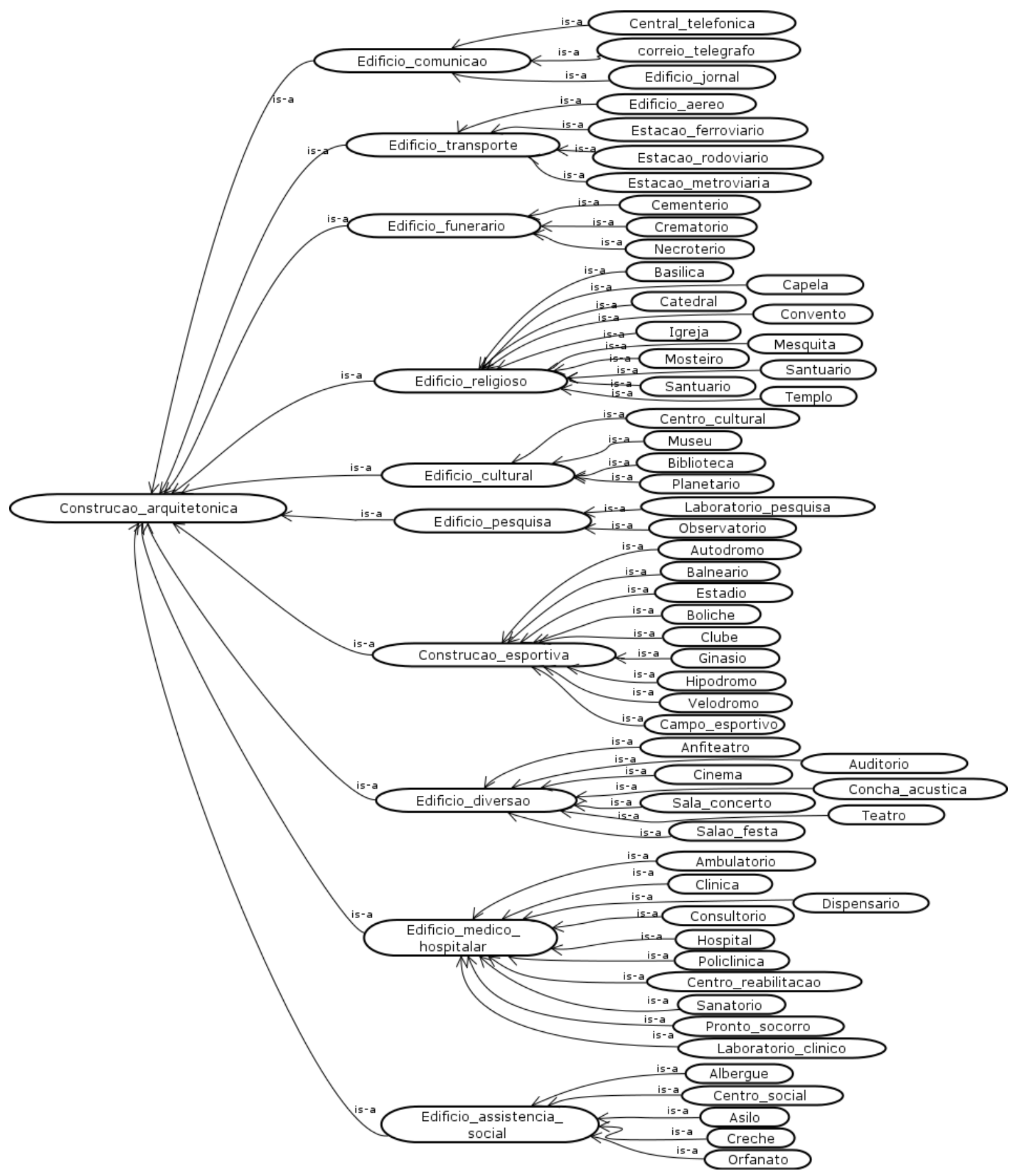

Figura 3.8: Hierarquia para a classe "Construcao_arquitetonica". 


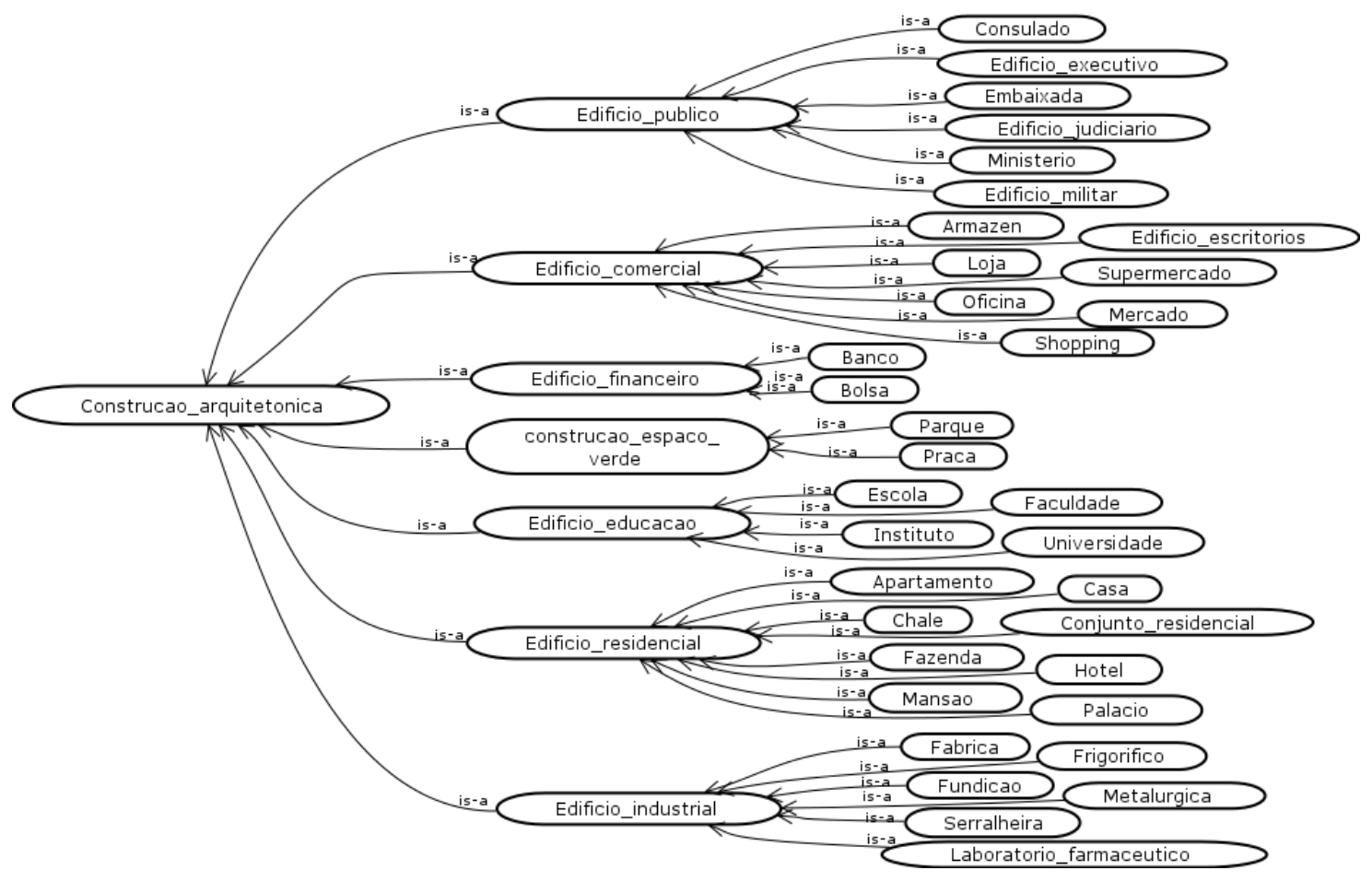

Figura 3.9: Continuação da hierarquia para a classe "Construcao_arquitetonica".

Esta hierarquia pode ser representada na sintaxe OWL. A seguir mostra-se um exemplo da hierarquia da classe "Construcao_arquitetonica" com suas subclasses "Edificio_cultural" e "Biblioteca" nessa linguagem.

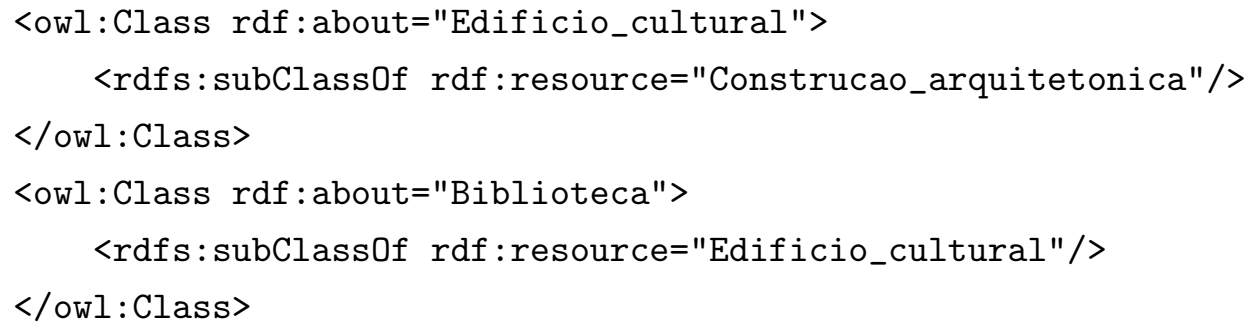

A partir da análise da informação relevante do sistema Arquigrafia foram criadas outras classes para serem adicionadas à taxonomia de classes exibida na figura 3.10.

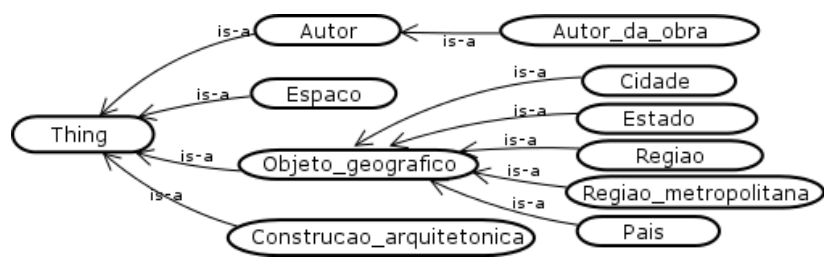

Figura 3.10: Parte da hierarquia de classes obtida da análise dos dados do sistema Arquigrafia. 
Finalmente temos na figura 3.11 toda a hierarquia de classes pertencentes à ontologia do domínio de arquitetura.

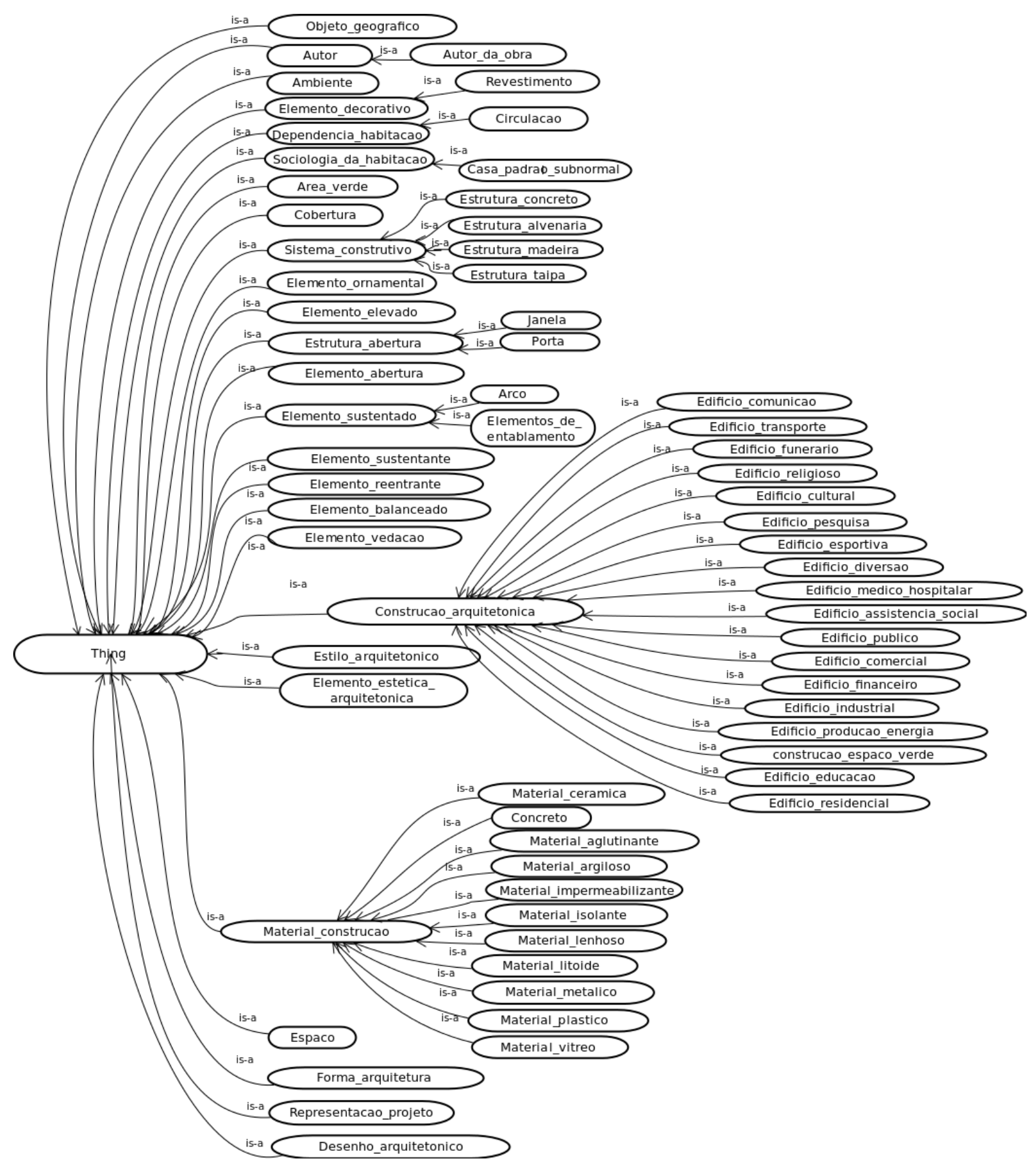

Figura 3.11: Hierarquia de classes da ontologia. 
b) Na segunda etapa foi realizada a população da ontologia através da criação de indivíduos ou instâncias extraídas do sistema Arquigrafia. Para isso, foi necessário analisar e identificar a dependência de cada dado, tais como título, descrição e tag com as classes ou subclasses da ontologia. Uma vez determinadas as instâncias, elas foram registradas de maneira manual no Protegé.

Uma instância ou indivíduo pode ser declarada na sintaxe OWL, por exemplo o dado "Vilanova_Artigas", a qual tornou-se uma instância da classe "Autor_da_obra".

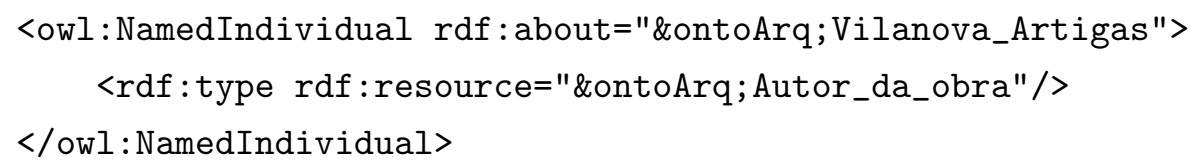

Algumas tags relacionadas às imagens do sistema Arquigrafia foram identificadas como instâncias para a classe "Material_construcao", por exemplo:

$\begin{array}{lll}\text { - Madeira } & \text { - Gesso } & \text { - Cerâmica } \\ \text { - Pedra } & \text { - Ferro } & \\ \text { - Vidro } & \text { - Cimento }\end{array}$

E os títulos das imagens foram detectados como instâncias das subclasses da classe "Construcao_arquitetonica", por exemplo os títulos das imagens Museu Judaico, Museu Paulista, Museu Theo Brandão obtidas do banco de dados do sistema Arquigrafia, foram determinados como instâncias da classe "Museu".

c) Na terceira etapa foram definidas as propriedades e as relações das classes existentes para a OntoArq. Existem dois tipos de propriedade: propriedade de objeto e a propriedade de tipo de dados. O primeiro tipo relaciona instâncias de duas classes o segundo relaciona uma instância de uma classe e um literal RDF ou tipos simples definidos de acordo com os tipos de dados de esquema XML como xsd:string, xsd:integer, xsd:dateTime, etc.

As propriedades foram obtidas a partir da análise dos dados existentes como títulos, descrições e tags das imagens do sistema Arquigrafia e como consequência dessa análise temos as seguintes propriedades de objeto para a ontologia:

- tem_ambiente

- tem_area_verde

- eh_autor

- tem_autor_da_obra

- eh_capital_do

- contem
- contido_em

- eh_material

- situado_em

- utiliza

- tem_espaco

- tem_estilo
- localizado_em

- tem_membro

- parte_de

- tem_regiao_metropolitana_capital

- sustentado_por 
Também temos as seguintes propriedades de tipo de dados existentes na ontologia.

- tem_data_da_obra

Estas propriedades foram usadas para construir as relações entre instâncias de classes da ontologia, utilizando o domínio e a imagem de uma propriedade. O domínio e a imagem podem ser vistos como um grafo, onde o domínio é o sujeito (origem), a imagem é o objeto (destino) e a propriedade é o predicado.

Na sequência exibiremos imagens das principais propriedades utilizadas para relacionar as instâncias das classes, com a finalidade de facilitar o entendimento da ontologia.

A propriedade "tem_ambiente" contribui para formar as relações entre as instâncias da classe "Construcao_arquitetonica" e as instâncias da classe "Ambiente", sendo a primeira classe o domínio e a segunda a imagem da relação. Desse modo, uma construção arquitetônica, tem vários ambientes ou nenhum, como por exemplo, quarto, sala, etc.

Já a propriedade inversa de "tem_ambiente", a propriedade "eh_ambiente", embora ela contribua para formar as relações entre as mesmas instâncias mencionadas, diferentemente da anterior, nesta relação a classe "Ambiente" é o domínio e a classe "Construcao_arquitetonica" é a imagem. Dessa forma, os indivíduos "sala", "quarto", etc., pertencentes à classe "Ambiente", também estão relacionados a um ou vários indivíduos da classe "Construcao_arquitetonica" (como observado na Figura 3.12).

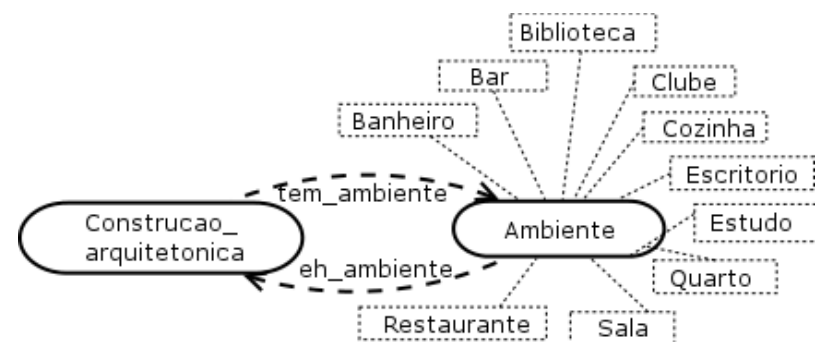

Figura 3.12: Relação existente entre as classes "Construcao_arquitetonica" e "Ambiente" .

A propriedade "sustentado_por" contribui para formar as relações entra as instâncias da classe "Construcao_arquitetonica" e "Elemento_sustentante". Dessa maneira, uma instância da classe "Construcao_arquitetonica" é relacionada a nenhuma ou várias instâncias da classe "Elemento_sustentante", como por exemplo, parede, coluna, etc. E a propriedade inversa de "sustentado_por", a propriedade "sustenta", tem como domínio a classe "Elemento_sustentante" e como a imagem a classe "Construcao_arquitetonica". Dessa forma, um elemento sustentante é relacionado a uma ou várias construções arquitetônicas. Estas propriedades podem ser observadas na Figura 3.13. 


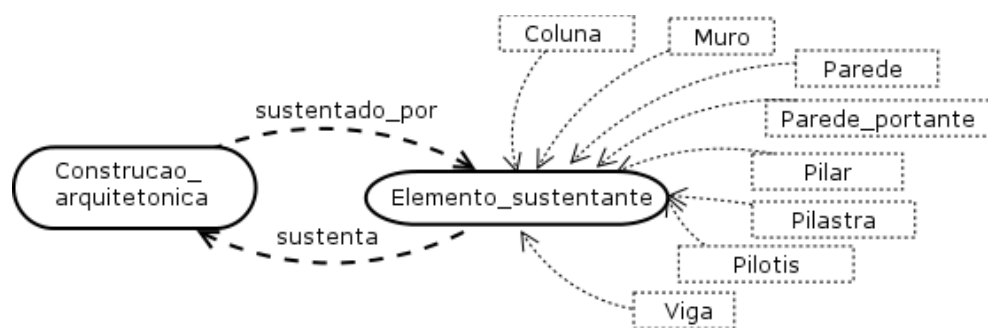

Figura 3.13: Relação existente entre as classes "Construcao_arquitetonica" e "Elemento_sustentante".

A propriedade "feito_de" relaciona as instâncias da classe "Construcao_arquitetonica" com a instância da classe "Material_construcao", sendo a primeira o domínio e a segunda a imagem da relação. Desse modo, uma construção arquitetônica é "feito_de" de um ou vários materiais de construção.

Já a propriedade inversa de "feito_de", a propriedade "eh_material", tem como domínio a classe "Material_construcao" e como imagem a classe "Construcao_arquitetonica". Dessa forma, uma instância da classe "Material_contrucao" é material de uma ou várias construções arquitetônicas (ver Figura 3.14).

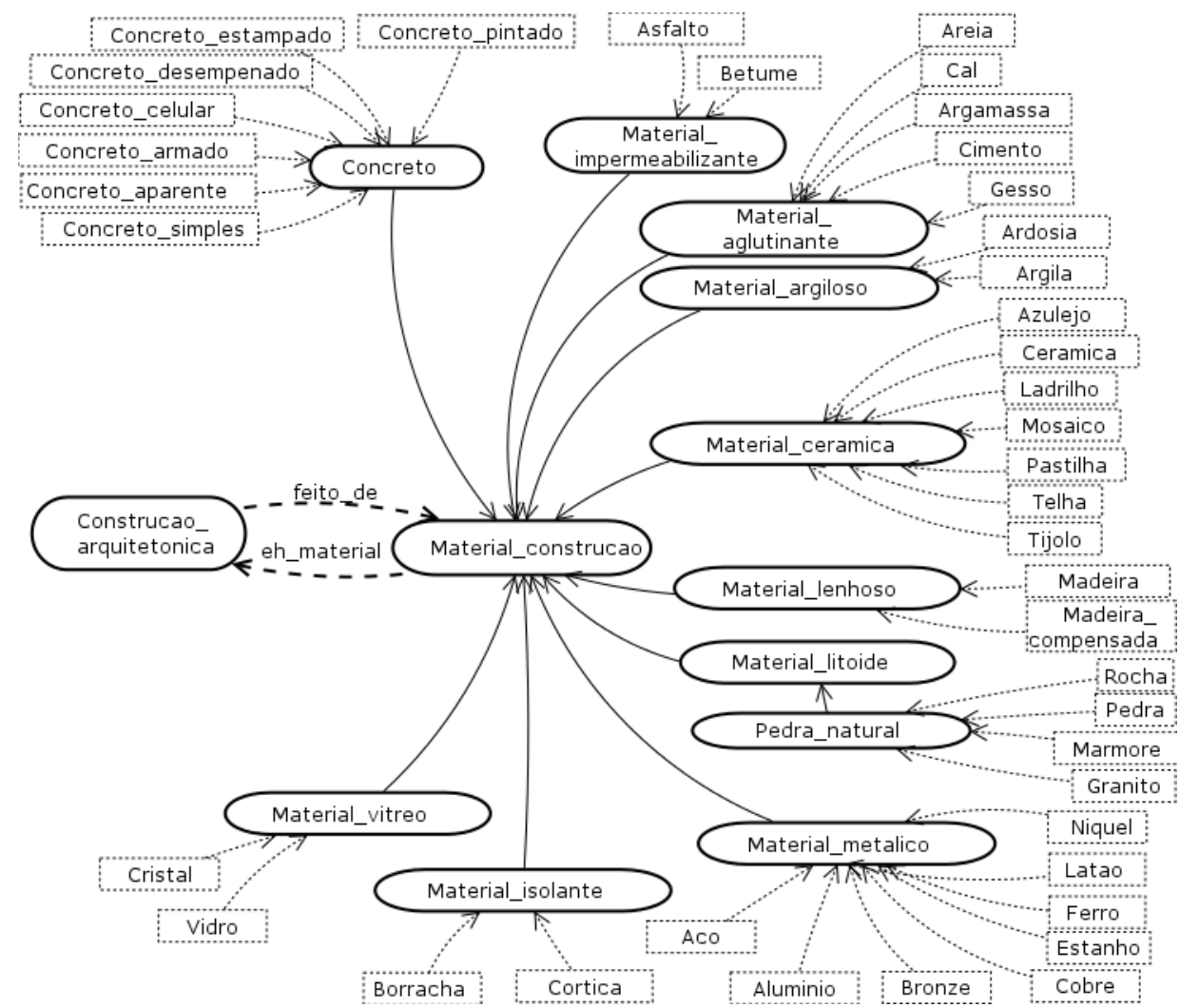

Figura 3.14: Relação existente entre as classes "Construcao_arquitetonica" e "Material_construcao".

A propriedade "tem_autor_da_obra" contribui para formar as relações entre as instâncias da classe "Construcao_arquitetonica" e as instâncias da classe "Autor_da_obra", sendo a 
primeira o domínio e a segunda a imagem da relação. Dessa maneira, uma construção arquitetônica é relacionada a um ou vários autores ou arquitetos.

Já a propriedade inversa de "tem_autor_da_obra", a propriedade "eh_autor_obra", o domínio é a classe "Autor_da_obra" e a imagem é a classe "Construcao_arquitetonica". Dessa forma, um autor ou arquiteto é relacionado a uma ou várias construções arquitetônicas.

Quanto à propriedade "tem_espaco", esta apresenta como domínio a classe "Construcao_arquitetonica" e como imagem a classe "Espaco". Ela contribui para formar as relações entre as instâncias de ambas as classes. Desse modo, uma única construção arquitetônica é apresentada como um tipo de espaço, seja público ou privado.

Já a propriedade inversa de "tem_espaco", a propriedade "eh_espaco_de" contribui para formar as relações entre as classes "Espaco" (domínio) e a classe "Construcao_arquitetonica" (imagem). Dessa maneira, um espaço público ou privado é apresentado como tipo de espaço de uma ou várias construções arquitetônicas.

Por último, a propriedade "situado_em" contribui para formar as relações entre as instâncias da classe "Construcao_arquitetonica" e as instâncias da classe "Objeto_geografico". Ela tem como domínio a classe "Construcao_arquitetonica" e como imagem a classe "Objeto_geografico". Esta propriedade tem por função especificar o lugar geográfico onde se situa uma dada construção arquitetônica. Já a propriedade inversa de "situado_em", a propriedade "posicao_geografica_de" determina a relação entre a instância da classe "Objeto_geografico" (domínio) e a instância da classe "Construcao_arquitetonica" (imagem). Por meio dela é possível especificar as várias construções arquitetônicas que se situam numa posição geográfica, cidade ou Estado (ver Figura 3.15).

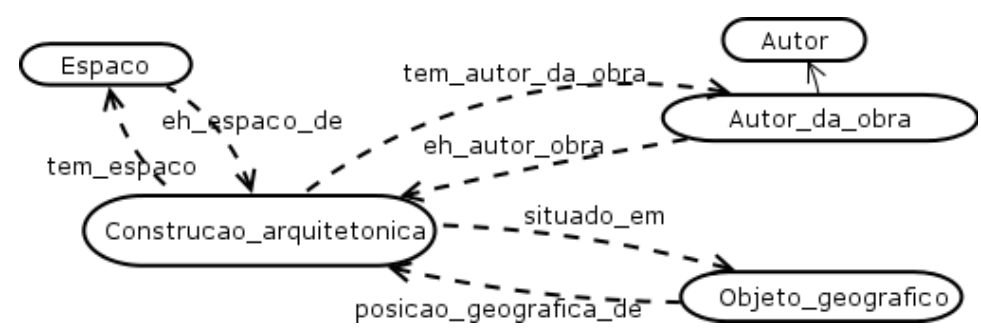

Figura 3.15: Propriedades existentes que relacionam as classes "Construcao_arquitetonica", "autor_da_obra", "objeto_geografico" e "espaço".

Quando é definida uma propriedade, existem muitas maneiras de restringir uma relação através da especificação do domínio e a imagem. No seguinte código em sintaxe OWL2 pode-se observar a restrição: do domínio da propriedade situado_em para a classe Construcao_arquitetonica e sua imagem para a classe Objeto_geografico. Este trecho de código também indica que a propriedade posicao_geografica_de é inversa de situado_em. 


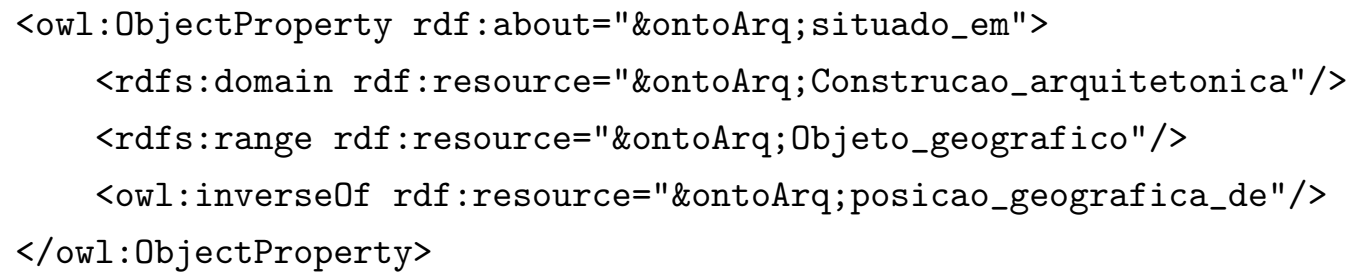

E o código em OWL2 para relacionar a propriedade de objeto feito_de com a instância de Igreja_nossa_senhora_da_consolacao da classe Igreja com a instância Vidro da classe Material_construcao é:

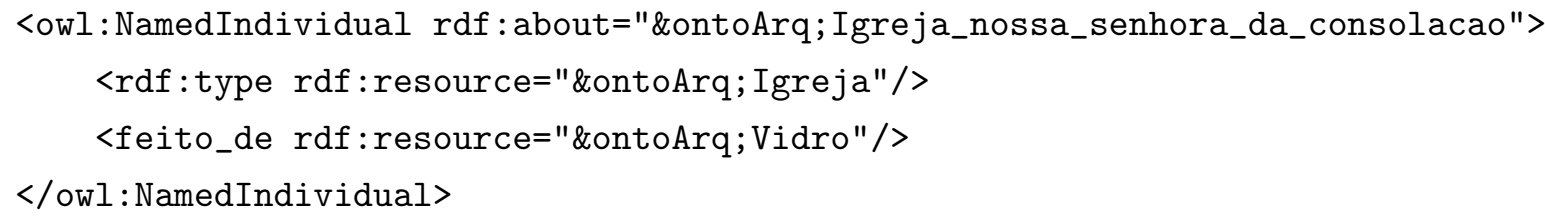

Outro exemplo de código em OWL2 para relacionar a propriedade de tipo de dado tem_data_da_obra com a instância Museu_de_Arte_Moderna da classe Museu com o literal $1954 \wedge \wedge$ dateTime é:

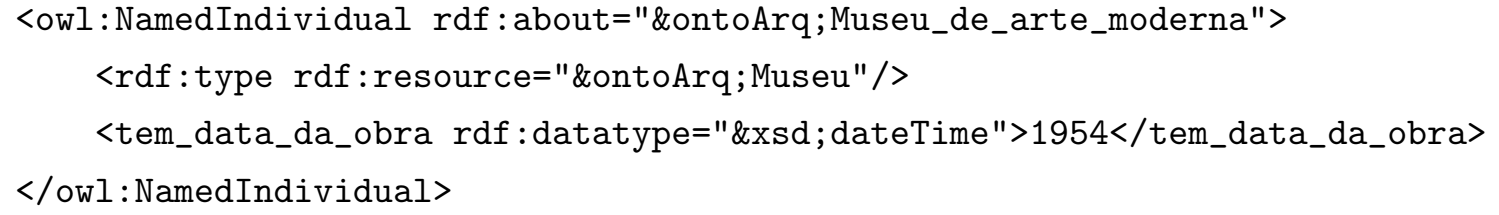

\subsubsection{Formalização da ontologia}

Neste passo a formalização da ontologia ajuda a evitar as incertezas e ambiguidades da linguagem natural existentes na fonte de dados, neste caso, o banco de dados do sistema Arquigrafia. A formalização permitiu adicionar conhecimento à ontologia através da adição de classes equivalentes ou sinônimos, propriedades equivalentes e detecção de classes disjuntas, assim como a criação de relações e instâncias.

O editor de ontologias Protégé, foi utilizado para a formalização da ontologia em OWL2 através da criação dos conceitos, das classes, das propriedades e das relações. 


\begin{tabular}{|c|c|}
\hline Autor & $\equiv \exists$ eh_autor.Construcao_arquitetonica \\
\hline Autor_da_obra & $\equiv \exists$ eh_autor_obra.Construcao_arquitetonica \\
\hline Material_construcao & $\equiv \exists$ eh_material.Construcao_arquitetonica \\
\hline Objeto_geografico & $\equiv \exists$ eh_ubicacao.Construcao_arquitetonica \\
\hline Sistema_construtivo & $\equiv \exists$ eh_material.Construcao_arquitetonica \\
\hline Cobertura & $\equiv \exists$ contido_em.Construcao_arquitetonica \\
\hline Dependencia_habitacao & $\equiv \exists$ parte_de.Construcao_arquitetonica \\
\hline Elemento_abertura & $\equiv \exists$ contido_em.Construcao_arquitetonica \\
\hline Elemento_balanceado & $\equiv \exists$ contido_em.Construcao_arquitetonica \\
\hline Elemento_decorativo & $\equiv \exists$ contido_em.Construcao_arquitetonica \\
\hline Elemento_elevado & $\equiv \exists$ contido_em.Construcao_arquitetonica \\
\hline Elemento_ornamental & $\equiv \exists$ contido_em.Construcao_arquitetonica \\
\hline Elemento_reentrante & $\equiv \exists$ contido_em.Construcao_arquitetonica \\
\hline Elemento_sustentante & $\equiv \exists$ sustenta.Construcao_arquitetonica \\
\hline Elemento_vedacao & $\equiv \exists$ contido_em.Construcao_arquitetonica \\
\hline Espaco & $\equiv \exists$ espaco_de.Construcao_arquitetonica \\
\hline Estilo_arquitetonico & $\equiv \exists$ estilo_de.Construcao_arquitetonica \\
\hline Estrutura_abertura & $\equiv \exists$ contido_em.Construcao_arquitetonica \\
\hline Estrutura_elemento_sustentado & $\equiv \exists$ contido_em.Construcao_arquitetonica \\
\hline Ambiente & $\equiv \exists$ eh_ambiente.Construcao_arquitetonica \\
\hline Area_verde & $\equiv \exists$ eh_area_verde.Construcao_arquitetonica \\
\hline
\end{tabular}

Classes equivalentes:

$$
\begin{array}{ll}
\text { Espaco_interior } & \equiv \text { Ambiente } \\
\text { Objeto_geografico } & \equiv \text { Localidade } \\
\text { Autor_da_obra } & \equiv \text { Arquiteto } \\
\text { Construcao_arquitetonica } & \equiv \text { Construcao } \\
\text { Elemento_decorativo } & \equiv \text { Recurso_decorativo }
\end{array}
$$

Classes Disjuntas:

$\begin{array}{lc}\text { Elemento_abertura } \sqcap \text { Elemento_reentrante } & \sqsubseteq \perp \\ \text { Elemento_balanceado } \sqcap \text { Elemento_decorativo } & \sqsubseteq \perp \\ \text { Elemento_decorativo } \sqcap \text { Elemento_balanceado } & \sqsubseteq \perp \\ \text { Elemento_elevado } \sqcap \text { Elemento_ornamental } & \sqsubseteq \perp \\ \text { Elemento_reentrante } \sqcap \text { Elemento_abertura } & \sqsubseteq \perp \\ \text { Elemento_ornamental } \sqcap \text { Cobertura } & \sqsubseteq \perp \\ \text { Cobertura } \sqcap \text { Elemento_elevado } & \sqsubseteq \perp \\ \text { Elemento_sustentante } \sqcap \text { Dependencia_habitacao } & \sqsubseteq \perp \\ \text { Dependencia_habitacao } \sqcap \text { Estrutura_elemento_sustentado } & \sqsubseteq \perp\end{array}$

Propriedades equivalentes:

$$
\text { eh_autor_obra } \equiv \text { projeta }
$$


A seguir, temos algumas figuras que mostram as classes, as propriedades e as relações criadas com o uso da ferramenta Protégé para construir a ontologia:

- A figura 3.16 mostra as classes criadas para a OntoArq da arquitetura no Protégé.

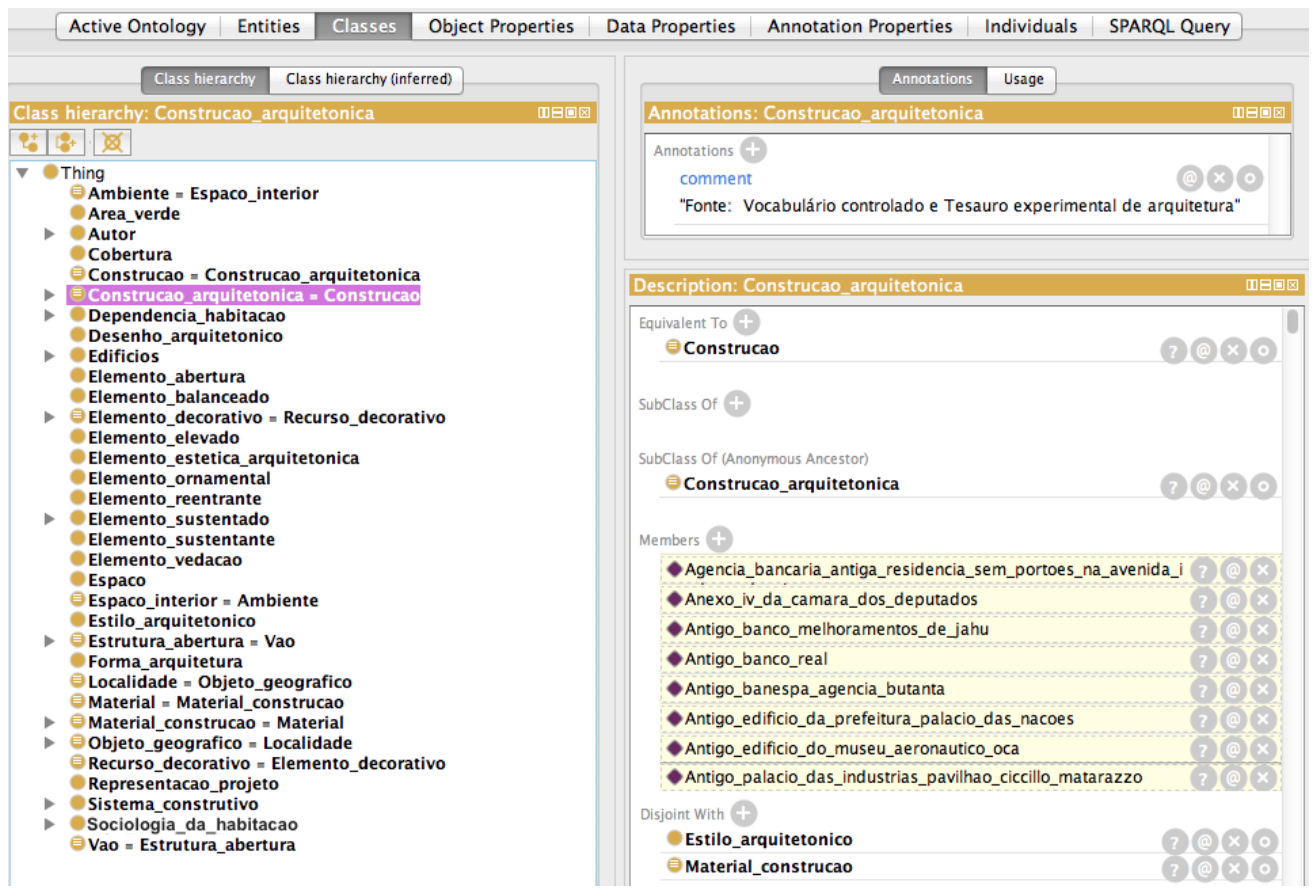

Figura 3.16: Classes criadas na ontologia pelo Protégé.

- A figura 3.17 exibe os indivíduos ou instâncias criadas para a classe "Museu" da ontologia no Protégé.

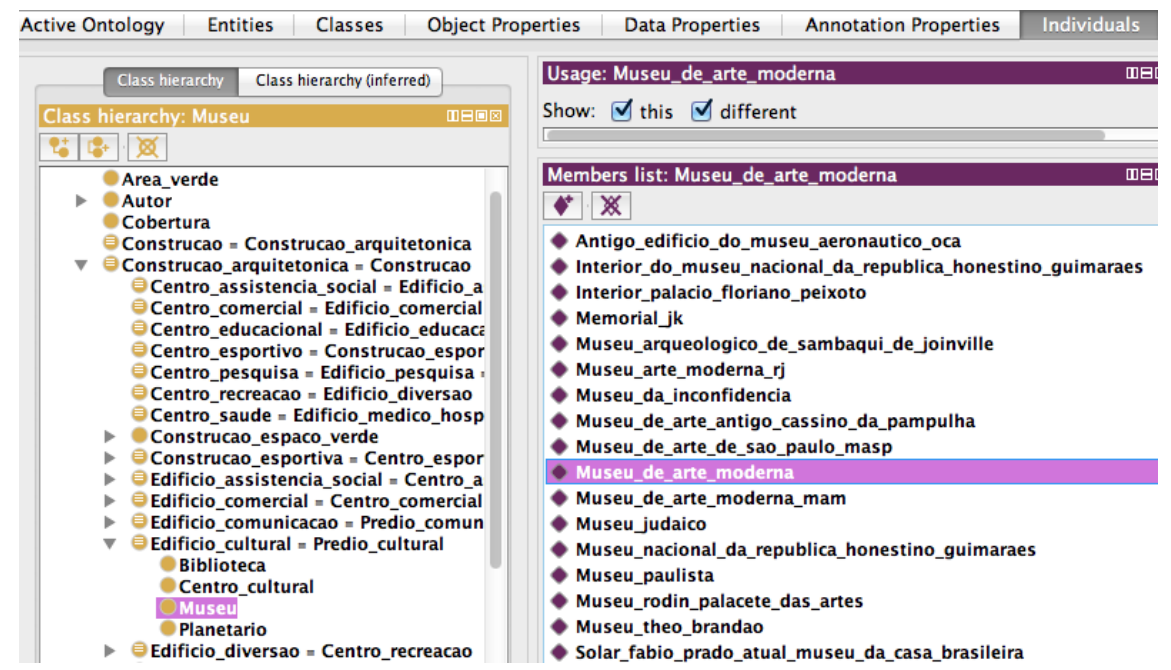

Figura 3.17: Lista dos indivíduos criados para a classe "Museu". 
- A figura 3.18 exibe as propriedades criadas para a ontologia no Protégé

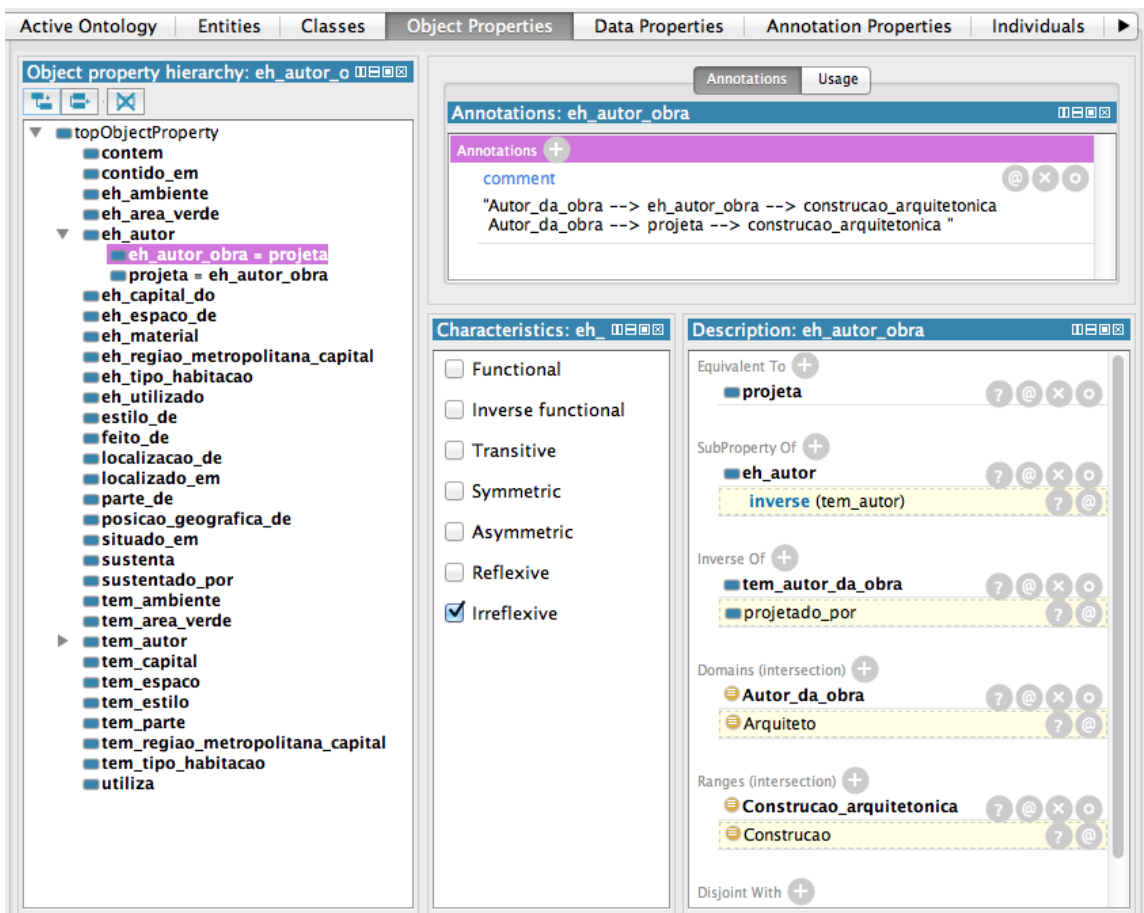

Figura 3.18: Lista de propriedades de objeto criadas para a ontologia no Protégé.

- A figura 3.19 exibe a propriedade de tipo de dado criado na ontologia pelo uso do Protégé.

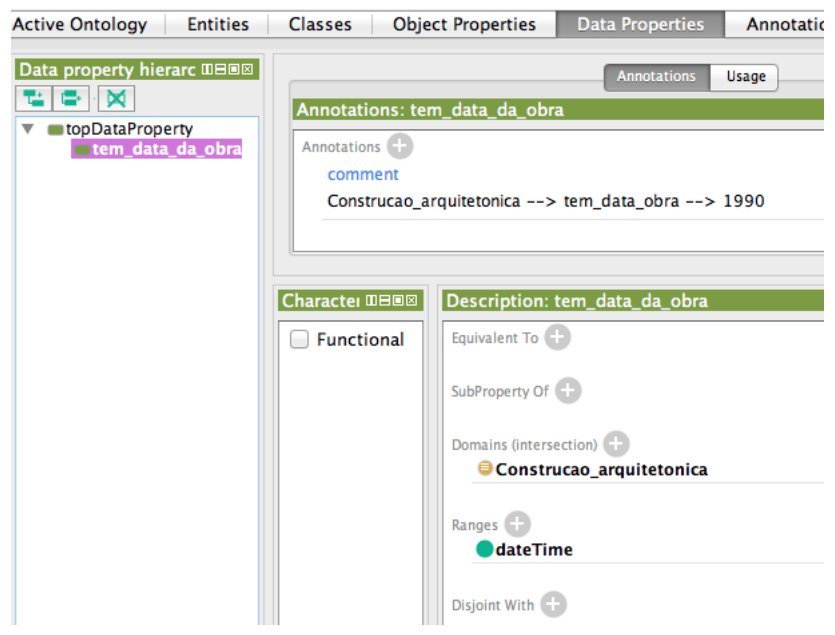

Figura 3.19: Propriedades de tipo de dado criada para a ontologia no Protégé.

- Na figura 3.20 exibe-se a relação existente entre a instância "Museu_de_arte_moderna" da classe "Museu" e da instância "Reidy_Affonso_Eduardo" da classe "Autor_da_obra" utilizando a propriedade "tem_autor_da_obra". 


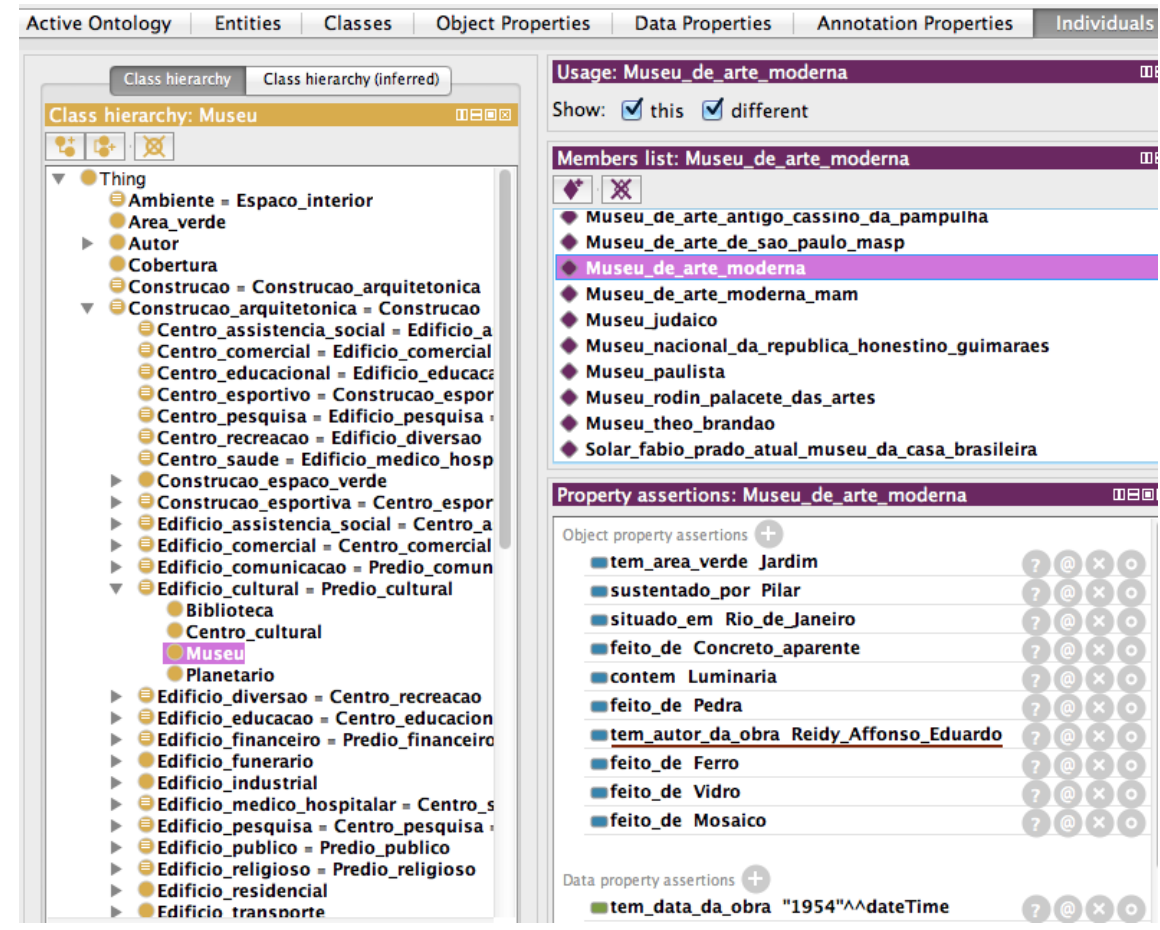

Figura 3.20: Propriedade "tem_autor_da_obra" para relacionar a instância "Museu_de_arte_moderna" e a instância "Reidy_Affonso_Eduardo" no Protégé.

\subsubsection{Integração com ontologias existentes}

$\mathrm{Na}$ literatura foram encontrados dois trabalhos de ontologias para o domínio de arquitetura.

O primeiro trabalho, de Yong Liu, et al. [29], utilizou uma ontologia para analisar os estilos de diferentes arquiteturas, suas primitivas geométricas (triângulos, pontos, linhas, etc.) e seus componentes arquitetônicos, tais como janela, porta, telhado, etc. Esta abordagem está orientada a gerar automaticamente o semi-estilo ou semi-estrutura de uma arquitetura, pelo uso das primitivas mencionadas, para serem convertidas em componentes semânticos os quais são parte de uma construção arquitetônica. Não nos foi possível acessar a essa ontologia para observarmos com maior detalhamento a hierarquia e relações criadas nessa ontologia.

Já o segundo trabalho, realizado por Hois, Bhatt e Kutz [25], possui uma ontologia modularizada em camadas: camada quantitativa, camada qualitativa e camada conceitual. A primeira camada quantitativa trabalha com dados métricos como altura, largura e posição. A segunda camada qualitativa lida com as relações entre os elementos de construção, por exemplo, a relação entre um sensor e uma parede, ou entre um sensor e uma porta. E a terceira camada conceitual está mais relacionada aos planos de construção. Esta camada apresenta uma classe denominada "BuildingType", a qual possui várias subclasses que também estão presentes nos termos categorizados do vocabulário controlado da USP. Na figura seguinte podemos ver essa similaridade entre classe "BuildingType" e a classe "Edifícios".

Embora existam termos similares nas hierarquias das classes mencionadas, para esta dis- 


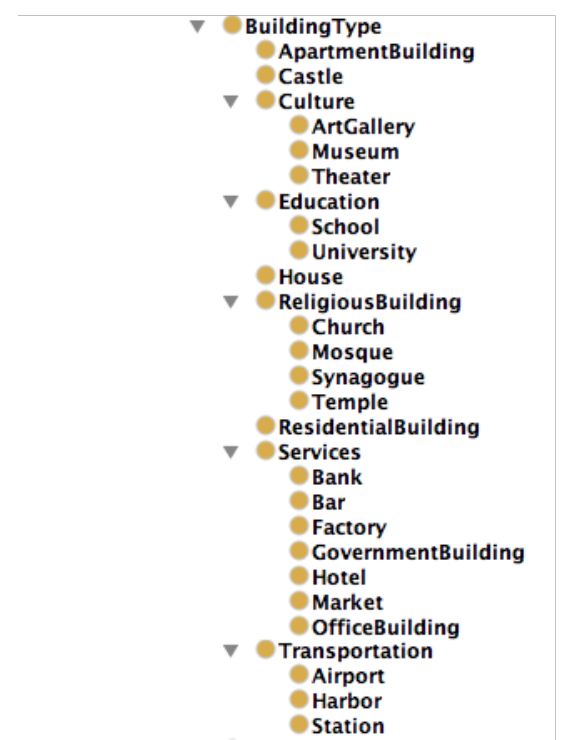

(a) Hierarquia da classe "BuildingType"

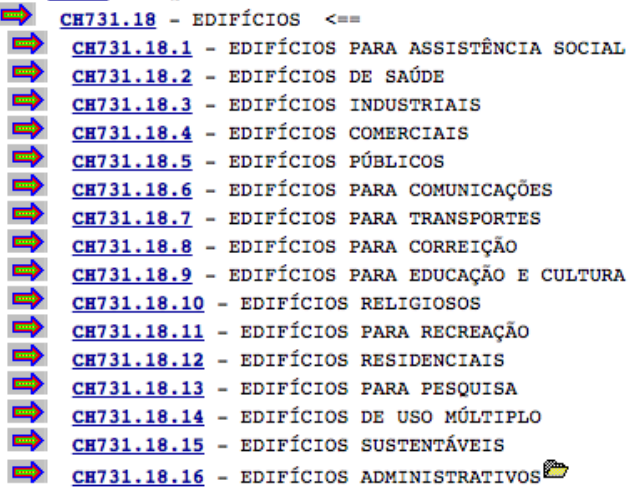

(b) Hierarquia da classe "Edificios"

sertação, optamos por utilizar os termos do vocabulário controlado, que já existem em nossa fonte de dados, e que serão importantes nas próximas fases da nossa abordagem.

\subsubsection{Avaliação}

Para validar a ontologia construída, primeiramente, foi necessário inferir as informações da ontologia a partir dos axiomas criados e após isso, desenvolver consultas na linguagem SPARQL ${ }^{4}$.

A inferência foi realizada pelo uso de um raciocinador, HermiT ou FaCT++ acoplados à ferramenta Protégé, a qual permitiu corrigir erros de inconsistência ou ambiguidade nas instâncias criadas para as classes da ontologia.

As consultas criadas na linguagem SPARQL conseguem responder as questões de competência dadas pelos especialistas na etapa de propósito e especificação de requisitos. Por exemplo, a questão "Onde encontro casas de madeira no Pará?" foi interpretada como o local onde se situa a "construção" do tipo "casa", feita de "madeira", material utilizado em sua construção. Com esta interpretação foi desenvolvida a seguinte consulta em SPARQL exibido no seguinte código.

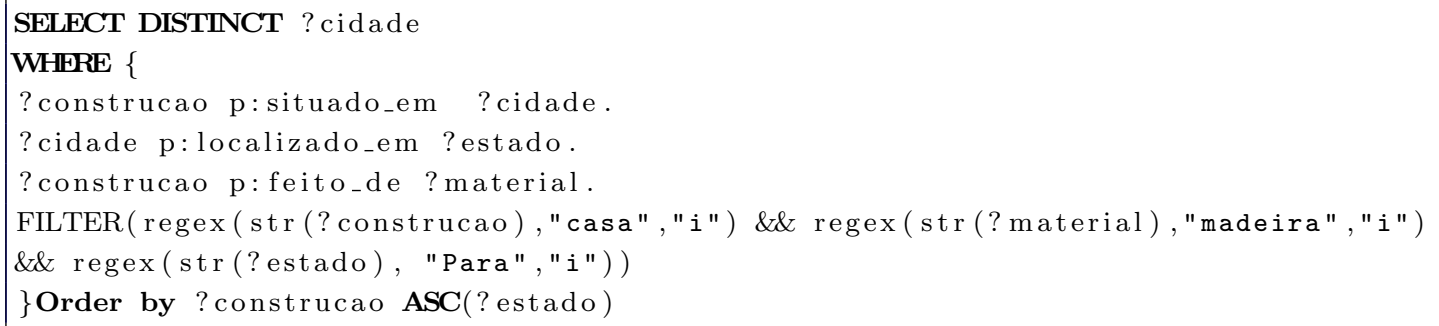

${ }^{4}$ SPARQL: http://sparql.org/ 
O resultado desta consulta é mostrado na figura 3.21 .

\section{cidade}

Belem

Figura 3.21: Exemplo de uma consulta "Onde encontro casas de madeira no Pará" realizada em SPARQL.

Na ontologia existem várias instâncias para os diferentes tipos de materiais de construção e as casas. Além disso, existe uma relação entre instâncias da classe "Casa" com instâncias da classe "Material_contrucao" e, diante disso, pode-se conhecer as casas que utilizaram a madeira como material de construção e onde estas casas estão localizadas. Por consequência, na ontologia todas as casas de madeira estão situadas na cidade de Belém do estado do Pará.

$\mathrm{Na}$ seguinte seção de documentação serão mostradas as demais consultas realizadas na linguagem SPARQL.

\subsubsection{Documentação}

Esta etapa consiste na análise das fontes de dados para identificação do propósito e do escopo, como descrito em etapas anteriores, e do público alvo, da formalização, da avaliação da ontologia e da reutilização da ontologia.

Como as fontes de dados estavam relacionadas à área de arquitetura, utilizamos um dicionário de termos arquitetônicos [11]. Suas definições contribuíram para a compreensão das fontes de dados e, por conseguinte, a criação dos conceitos da ontologia.

O público alvo da ontologia é o usuário interessado em informações sobre construções arquitetônicas. Além disso, para que os usuários possam se beneficiar ainda mais do uso da ontologia, é possível reutilizá-la posteriormente acrescentando novos conceitos ou classes.

Para compreender as classes criadas na ontologia, elaboramos um dicionário específico contendo as descrições das classes mais importantes. Este dicionário é descrito no apêndice A.

Na figura 3.22, podemos observar como a classe principal "Construcao_arquitetonica" se relaciona às demais instâncias de classes de OntoArq pelo emprego de certas propriedades.

Como as questões de competência descritas pelos especialistas estão em linguagem "natural", foi necessário primeiro analisar e interpretar manualmente cada questão, para só então transformálas em consultas na linguagem SPARQL. A tradução automática das questões de competência em consultas SPARQL foge do escopo do trabalho. A seguir, mostraremos a interpretação e a tradução das questões de competência na linguagem SPARQL. 


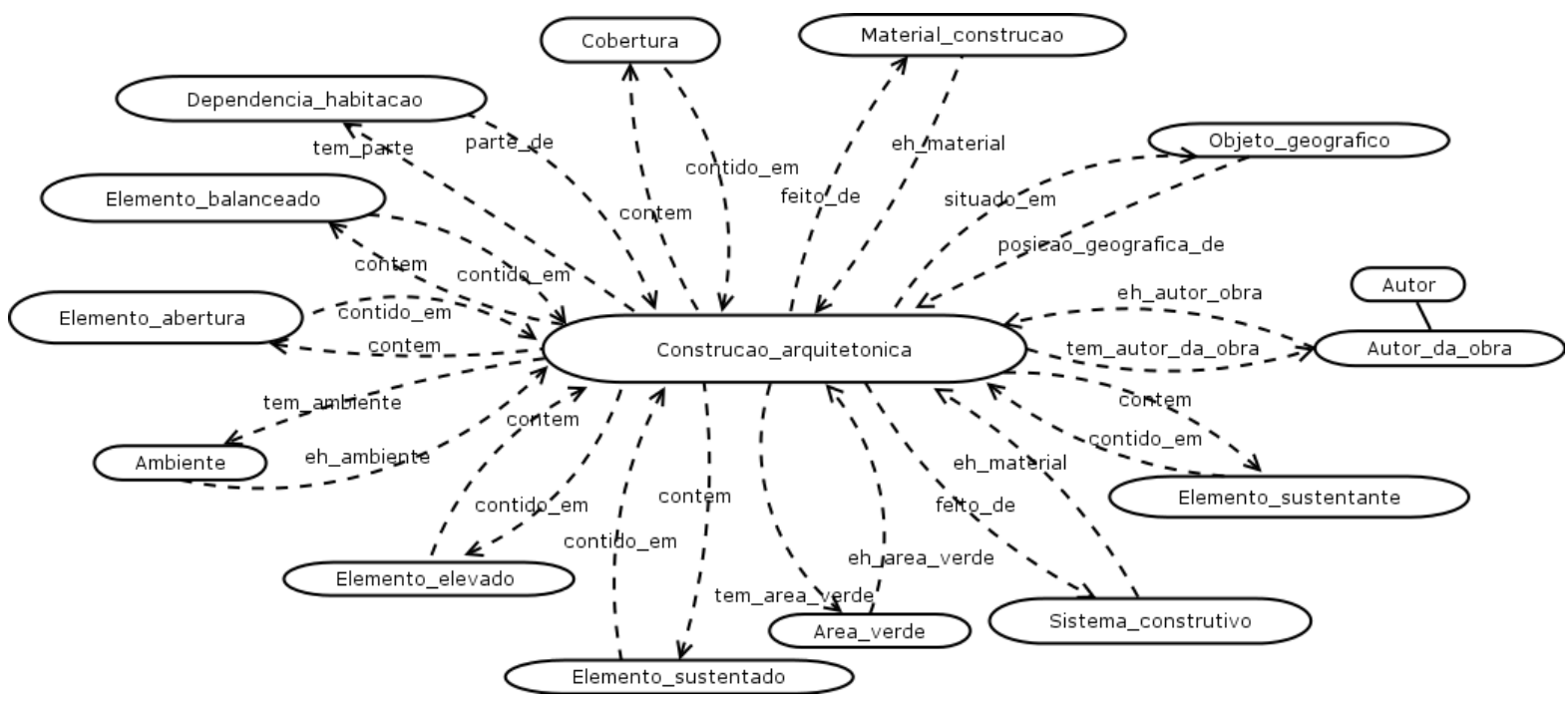

Figura 3.22: Relações principais na ontologia utilizada para o sistema Arquigrafia.

A seguir, mostraremos as questões de competência com sua interpretação, e com sua consulta já traduzida na linguagem SPARQL.

1 Onde se localizam as construções de taipa remanescentes em São Paulo?

Entende-se que "construções de taipa" são edifícios que foram construídos utilizando o material "taipa" e que estão localizados no estado de "São Paulo". Na ontologia existem instâncias para a classe "construcao" relacionadas a uma instância de classe "material_de_construcao" que está localizado em um "estado" específico.

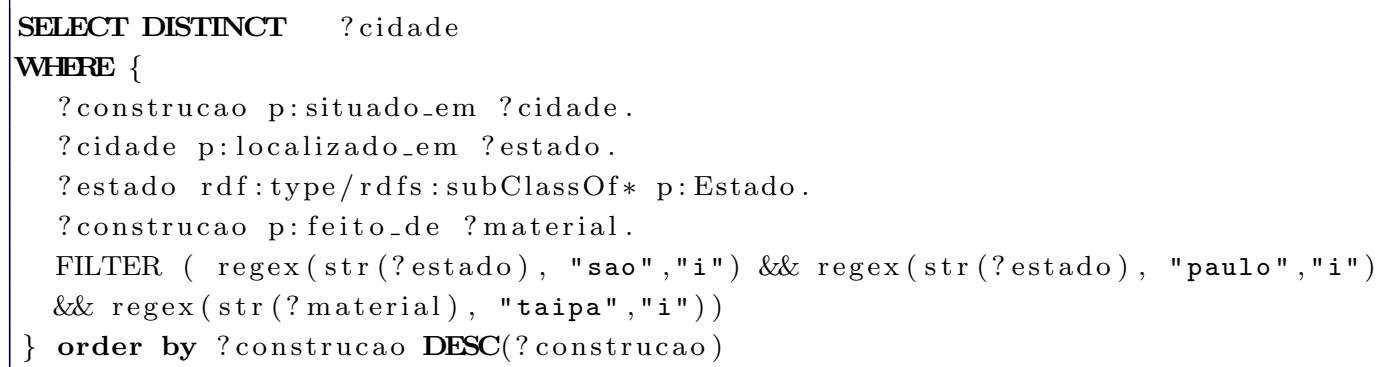

O resultado da consulta é exibido na figura 3.23 .

$$
\begin{aligned}
& \text { cidade } \\
& \text { Sao_paulo }
\end{aligned}
$$

Figura 3.23: Resultado da questão "Onde se localizam as construções de taipa remanescentes em São Paulo?". 


\section{Quem é o autor do projeto da Praça do Relógio?.}

Entende-se, "autor de projeto", como o autor da obra da Praça do relógio.

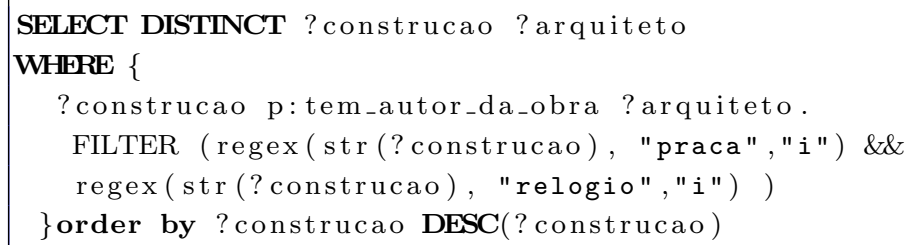

O resultado da consulta exibe dois autores da obra "Praça do relógio", que é exibido na figura 3.24 .

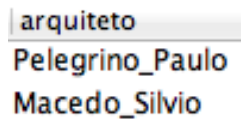

Figura 3.24: Resultado da questão "Quem é o autor do projeto da Praça do Relógio?".

3 Quais eram os principais arquitetos em atividade em São Paulo entre as décadas de 30 e 60?

Entende-se, "arquitetos em atividade" como os autores das obras ou construções do Estado de São Paulo, nas décadas de 30 e 60. O intervalo dessas décadas corresponde a valores maiores ou iguais a 1930 e menores que 1970.

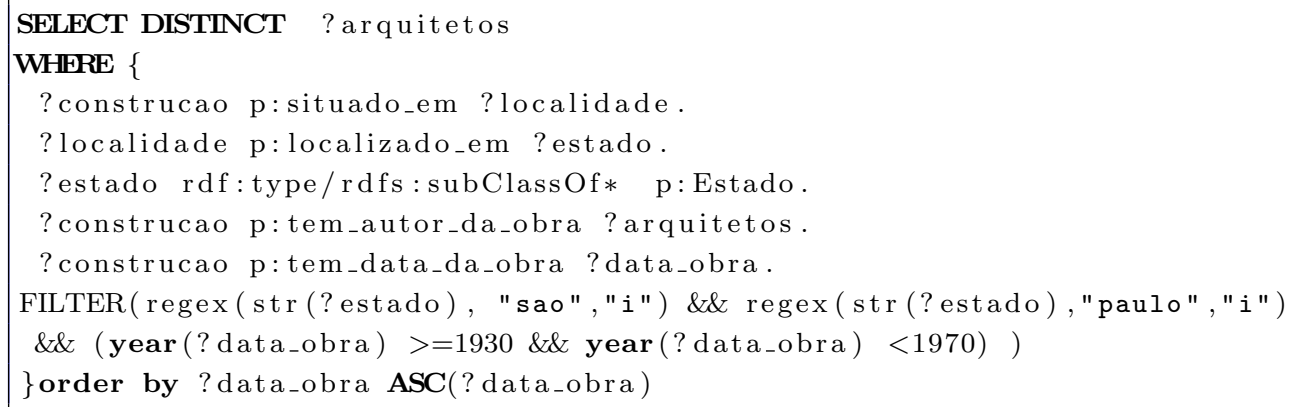

O resultado da consulta mostra uma lista de arquitetos que projetaram construções entre as décadas mencionadas, como é exibido na figura 3.25. 


\begin{tabular}{l}
\hline arquitetos \\
\hline Adolf_Franz_Heep \\
Artigas_Joao_Batista_Vilanova \\
Gasperini_Gian_Carlo \\
Gian_Carlo_Gasperini \\
Guedes_Sobrinho_Joaquim_Manoel \\
Heep_Adolf_Franz \\
Jacques_Pilon \\
Levi_Rino \\
Osvaldo_Arthur_Bratke \\
Pilon_Jacques_Emile_Paul
\end{tabular}

Figura 3.25: Resultado da questão "Quais eram os principais arquitetos em atividade em São Paulo entre as décadas de 30 e 60 ?".

4 Quais eram os principais arquitetos em atividade no Rio de Janeiro entre as décadas de 30 e 60 ?

Para esta questão a interpretação e tradução na linguagem SPARQL é semelhante à anterior, porém o nome do estado é Rio de Janeiro.

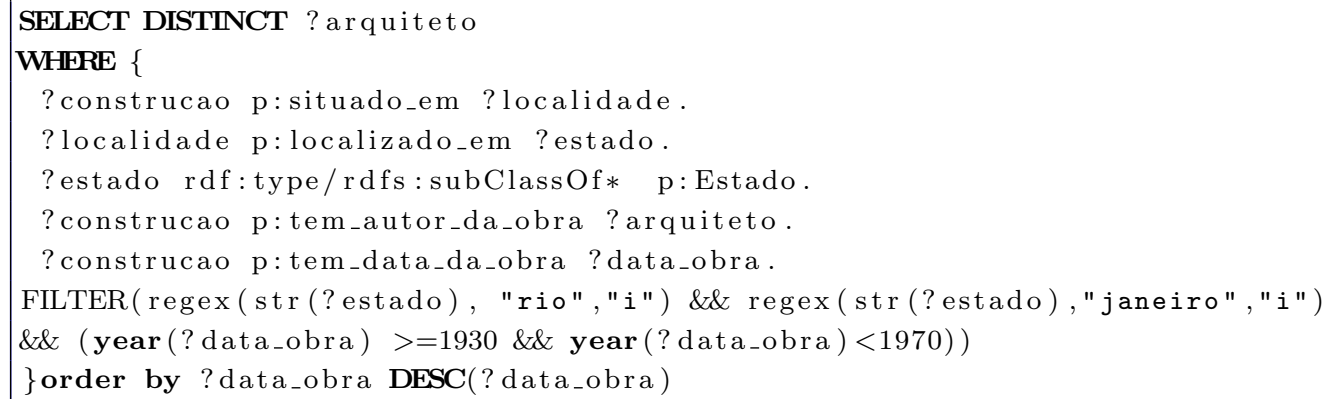

O resultado da consulta é exibido na figura 3.26 .

\begin{tabular}{l}
\hline arquiteto \\
\hline Costa_Lucio_Marcal_Ferreira_Ribeiro_De_Lima_e \\
Reidy_Affonso_Eduardo \\
Niemeyer_Oscar_Ribeiro_De_Almeida_De \\
Bastos_Pedro_Paulo_Bernardes \\
Carneiro_Antonio_Dias \\
Valdetaro_Oscar \\
Azevedo_Orlando \\
Ramos_Waldir
\end{tabular}

Figura 3.26: Resultado da questão "Quais eram os principais arquitetos em atividade no Rio de Janeiro entre as décadas de 30 e 60 ?". 


\section{Quem projetou a Rodoviária de Cuiabá?}

$\mathrm{Na}$ ontologia, entende-se "autores de obra" como as pessoas que "projetaram" ou são "autores da obra" de uma construção. Neste caso, a "rodoviária de Cuiabá" representa a construção em questão.

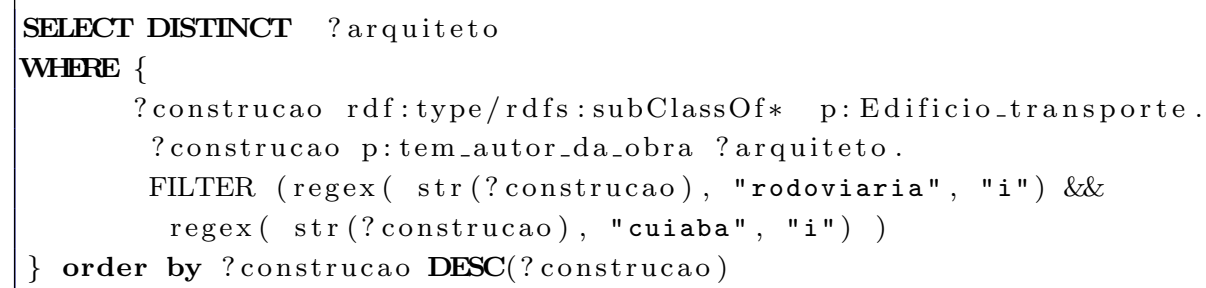

Esta consulta não encontrou resultados, pois o sistema Arquigrafia não tinha esses dados.

6 Qual a data da obra do Conjunto Habitacional Prefeito Mendes de Moraes?. Entende-se "data da obra" como data de construção do "Conjunto Habitacional" com o nome "Prefeito Mendes de Moraes".

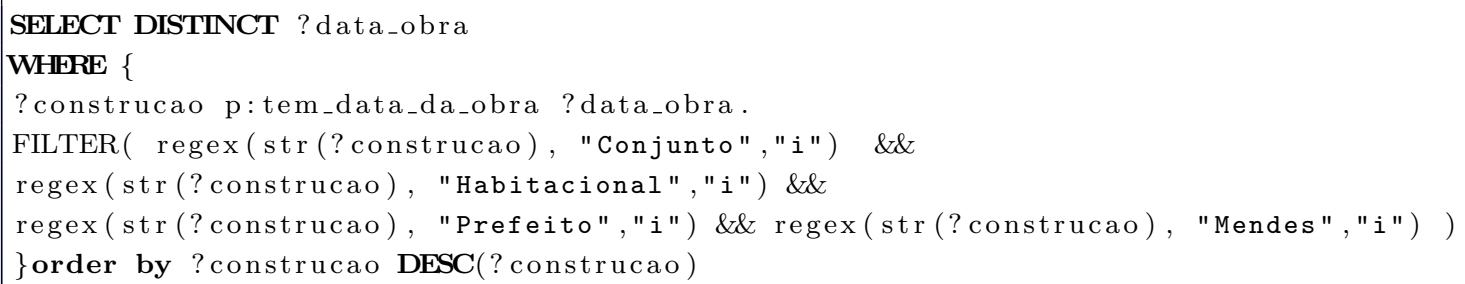

Pode-se observar dois resultados para a edificação "Conjunto Habitacional Prefeito Mendes de Moraes". Isto ocorre porque a data da obra desta construção foi desenvolvida entre os anos de 1946 e 1952, como pode ser observado na figura 3.27 .

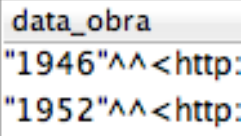

Figura 3.27: Resultado da questão "Qual a data da obra do Conjunto Habitacional Prefeito Mendes de Moraes?".

7 Quais são os principais edifícios residenciais no interior do Rio de Janeiro?.

Entende-se por "edifícios residenciais" construções como "casa, apartamento, fazenda, hotel, conjunto residencial". A frase "interior do Rio de Janeiro" refere-se informalmente à região que abrange todos os municípios do Rio de Janeiro, exceto a Região Metropolitana do mesmo. Vale mencionar que nem todos os municípios pertencem a uma determinada região metropolitana. Na ontologia atual temos as edificações residenciais com suas respectivas localidades. 


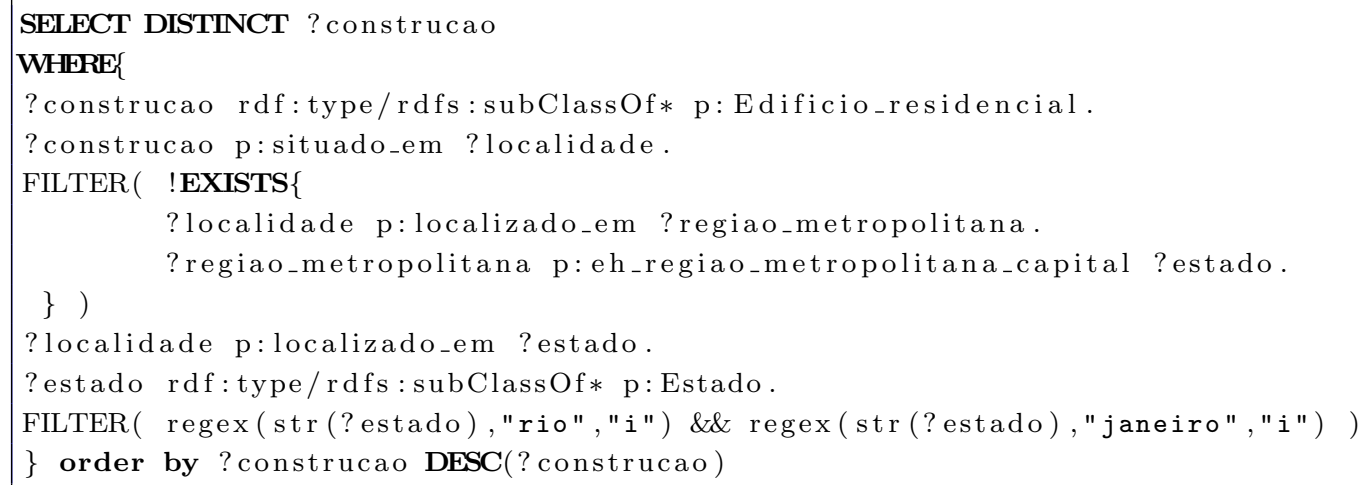

O resultado da consulta é exibido na figura 3.28, a qual mostra três edificações residenciais, que não pertencem a uma região metropolitana específica mas sim ao estado do Rio de Janeiro.

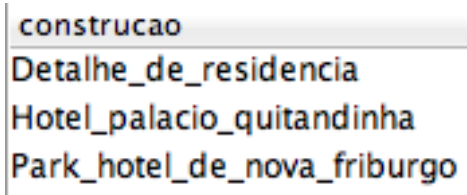

Figura 3.28: Resultado da questão "Quais são os principais edifícios residenciais no interior do Rio de Janeiro?".

\section{Existem edifícios em vidro construídos no Brasil?.}

Entende-se como "edifício em vidro" aqueles edifícios ou construções que utilizaram como material de construção o "vidro" e estas construções estão localizados no país, "Brasil".

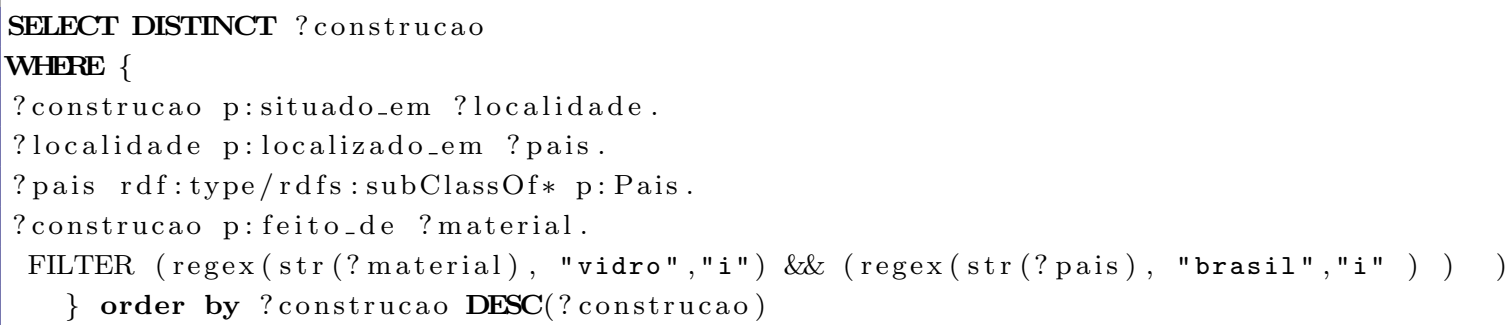

O resultado da consulta é exibido na figura 3.29, a qual mostra uma lista de construções arquitetônicas como casas, escolas, hospitais, etc., os quais utilizaram o material vidro para sua construção. 


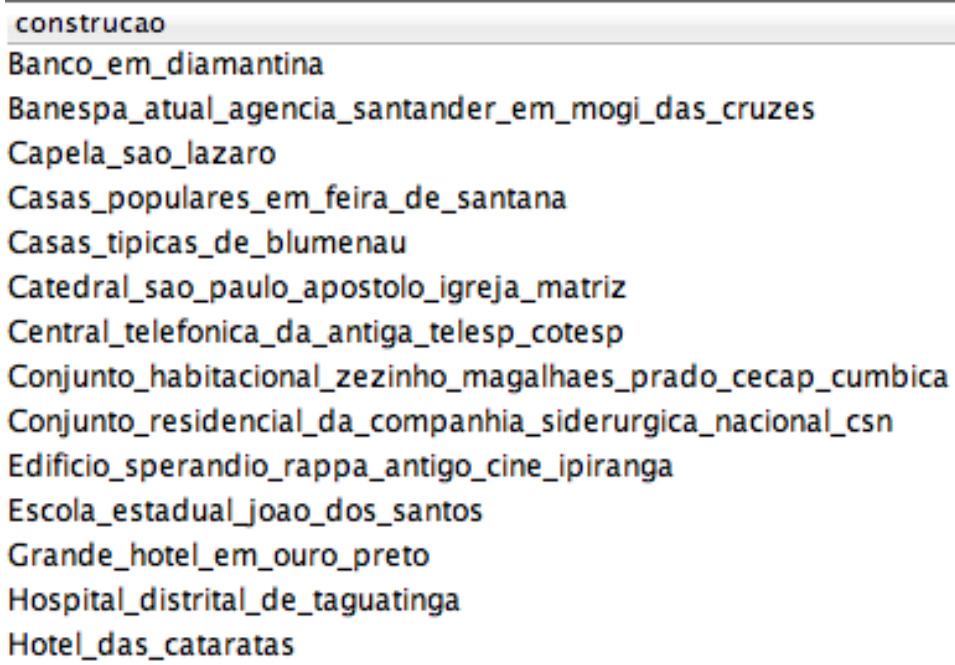

Figura 3.29: Resultado para a questão "Existem edifícios em vidro construídos no Brasil?".

9 Quais são os edifícios projetados por Macedo Silvio Soares em São Paulo?.

Entende-se "edifício projetado" como edifícios construídos pelo arquiteto ou autor da obra "Macedo Silvio Soares" na localidade do estado de "São Paulo".

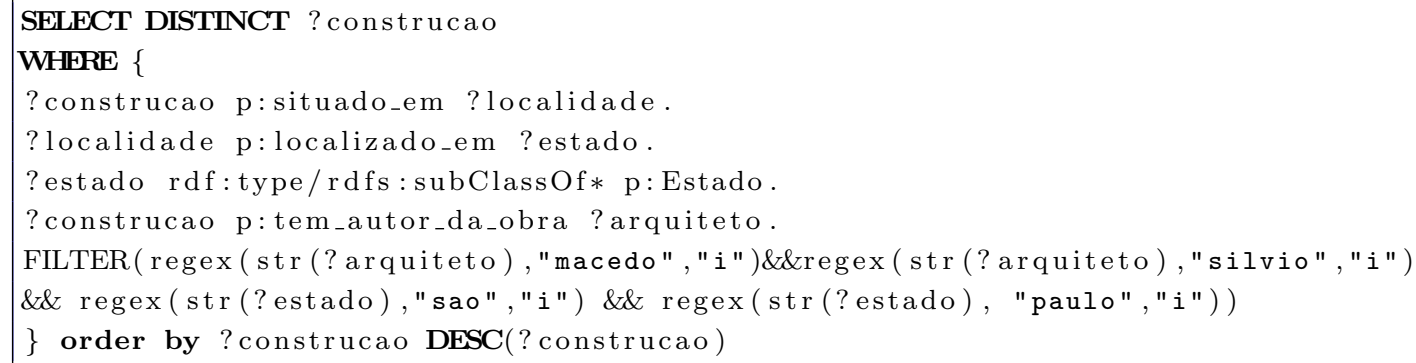

O resultado da consulta é exibido na figura 3.30, a qual mostra a construção projetada por Macedo Silvo Soares no estado de São Paulo.

construcao

Praca_do_relogio

Figura 3.30: Resultado da questão "Quais são os edifícios projetados por Macedo Silvio Soares em São Paulo?". 
10 Existem edifícios projetados por Plinio Croce no interior do estado de São Paulo? Entende-se "edifício projetado" como uma construção que tem como "autor da obra" ou "arquiteto", "Plinio Croce". O "interior do estado de São Paulo" é considerado como todos os municípios que não pertencem à região metropolitana capital do estado de "São Paulo".

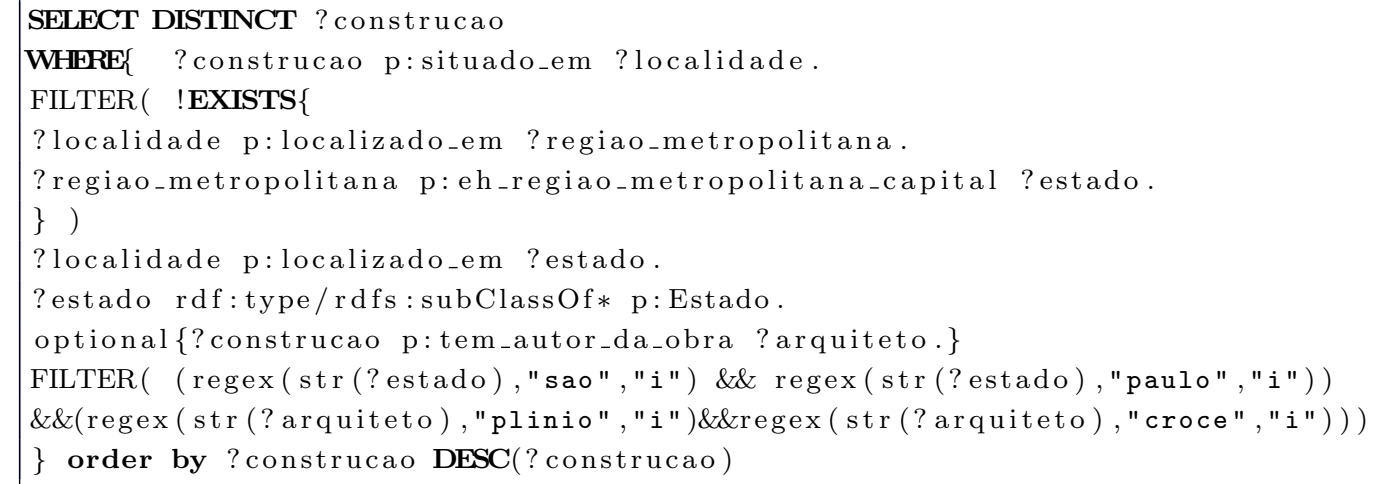

Esta consulta não possui resultado, pois na ontologia, as construções projetadas por Plinio Croce pertencem à capital São Paulo.

\section{Quem projetou a biblioteca Brasiliana? .}

Entende-se como "Quem" o autor da obra ou arquiteto de uma construção nomeada como "biblioteca Brasiliana".

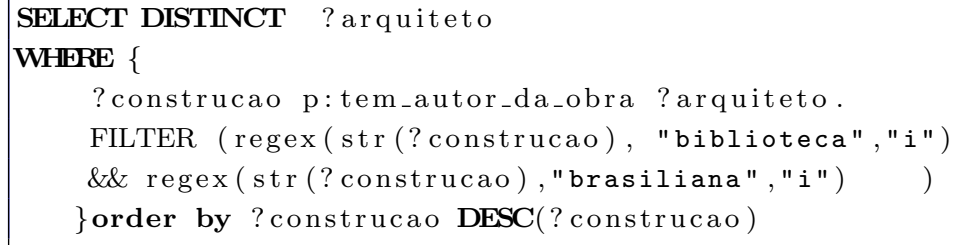

O resultado é exibido na figura figura 3.31, a qual mostra os arquitetos que projetaram a biblioteca Brasiliana.

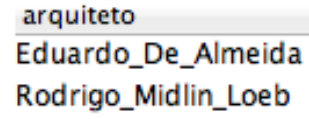

Figura 3.31: Resultado da questão "Quem projetou a Biblioteca Brasiliana?". 


\section{Quais edificios foram projetados por Gian Carlo Gasperini no Brasil?.}

Entende-se "edifícios projetados" como construções nas quais o autor da obra refere-se a "Gian Carlo Gasperini", localizadas no país "Brasil".

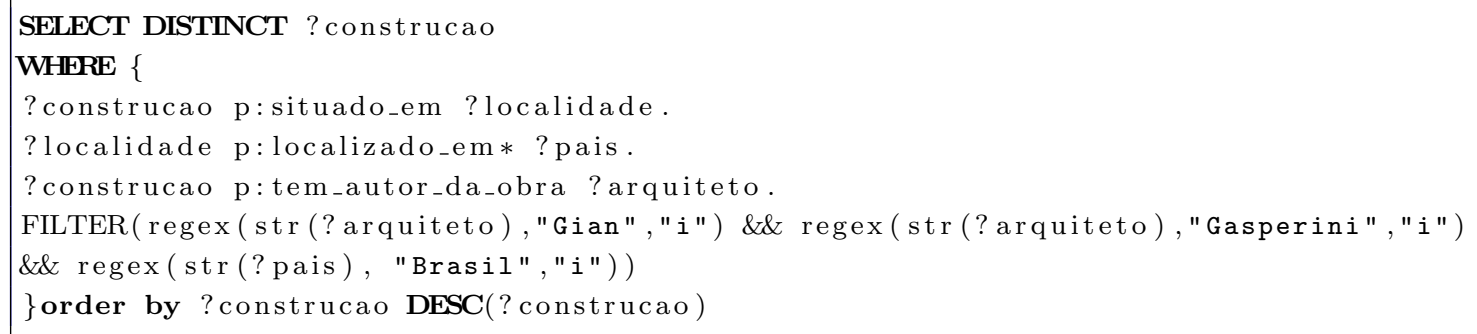

O resultado da consulta é exibido na figura 3.32, a qual mostra uma lista de construções que foram projetadas por Gian Carlo Gasperini no Brasil.

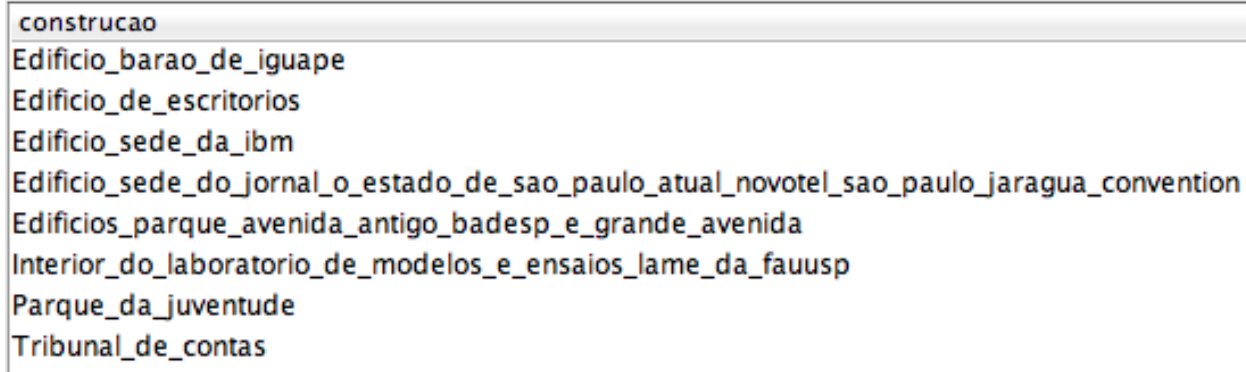

Figura 3.32: Resultado da questão "Quais edifícios foram projetados por Gian Carlo Gasperini no Brasil?".

13 Quais são os exemplares de arquiteturas do primeiro século (séc.XVI) do Brasil que ainda existem e podem ser visitados?.

$\mathrm{Na}$ ontologia foram incluídas elaborado informações de edifícios, localidades, materiais e datas das construções, contudo não estão presentes informações relacionadas à história do Brasil. A colonização do Brasil é um exemplo. No entanto, a ontologia poderá responder quais são os "exemplares de edificações arquitetônicas" que foram construídos num século específico, como por exemplo o século XVI.

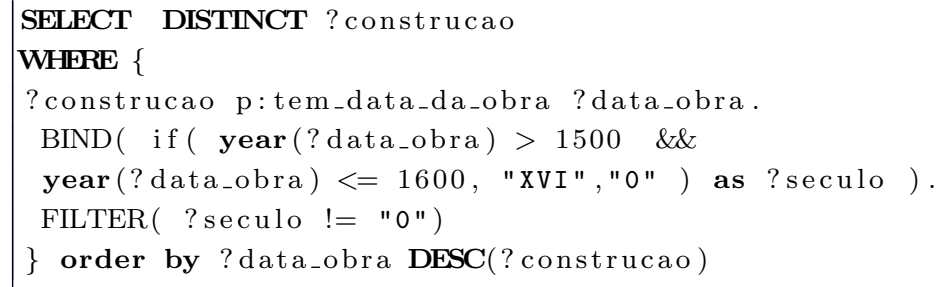

O resultado da consulta é exibido na figura 3.33, a qual mostra as construções que foram desenvolvidas no século XVI. 
Figura 3.33: Resultado da questão "Quais são os exemplares de arquiteturas do primeiro século (séc. XVI) do Brasil que ainda existem e podem ser visitados?".

14 As palafitas típicas da habitação ribeirinha no Norte do Brasil, podem ser vistas em que lugares da Amazônia?.

Entende-se "palafita típica" como um tipo de habitação social de uma construção localizada na região norte. "Lugares da Amazônia" refere-se a todos os estados da região norte do Brasil. Atualmente em nossa ontologia existe uma relação entre uma construção arquitetônica, seu tipo de habitação social, e sua localização. Para esta questão de competência, a edificação é uma habitação ribeirinha que tem um tipo de habitação social como "palafita", e que está localizada na região do norte do Brasil.

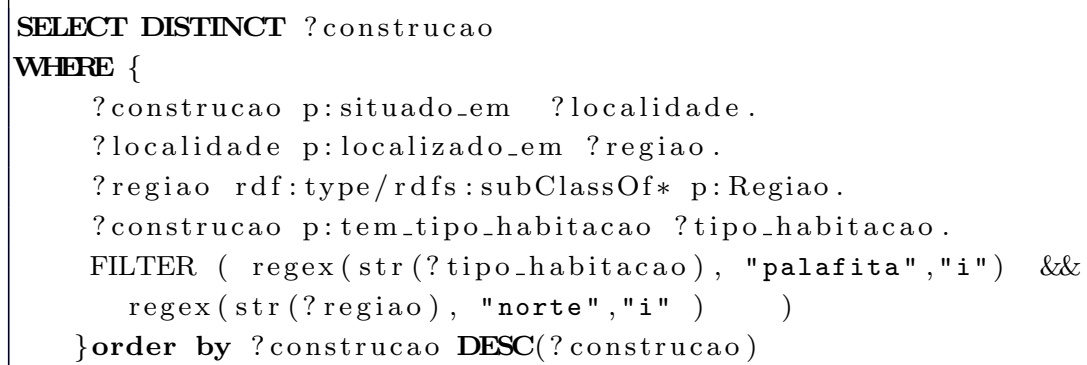

O resultado da consulta é exibido na figura 3.34 .

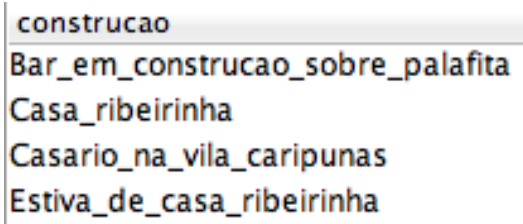

Figura 3.34: Resultado da questão "As palafitas típicas da habitação ribeirinha no Norte do Brasil, podem ser vistas em que lugares da Amazônia?".

As fases seguintes contribuirão para o desenvolvimento do sistema de recuperação de imagens arquitetônicas.

\subsection{Fase de Indexação e Pré-processamento}

Nesta fase é construído o índice invertido, o qual utiliza uma lista de termos com os dados da coleção de documentos extraídos do Arquigrafia e a informação da ontologia. A seguir, explica-se o processo de construção de cada uma destas estruturas. 


\subsubsection{Indexação e pré-processamento}

A geração da estrutura para a indexação de documentos foi baseada no trabalho de Paz Trillo [46], com alterações no tratamento dos termos pertencentes a cada documento da coleção. Esse tratamento foi a inferência dos termos utilizando a ontologia construída no domínio de arquitetura.

Segundo Baeza Yates [4] o índice invertido melhora o desempenho do motor de busca, sendo assim para a indexação de documentos é necessário a criação de um índice invertido.

Para o processo de indexação foram utilizadas como fonte de dados a coleção de documentos e a ontologia desenvolvida na fase anterior, com o intuito de extrair os termos e indexá-los aos documentos relacionados.

- A coleção de documentos foi obtida do banco de dados do Arquigrafia. Nesta coleção cada documento contém dados relevantes relacionados a uma imagem arquitetônica, tais como o título da construção, a descrição, o autor, a cidade, o estado e as tags, onde cada dado possui um ou mais termos ou palavras. "Biblioteca Brasiliana", título dado a uma imagem da construção arquitetônica, é um exemplo.

- O uso da ontologia nesta fase tem por objetivo enriquecer a indexação, visto que ela em sua modelagem possui uma hierarquia de classes, instâncias e seus equivalentes ou sinônimos que serão utilizados neste processo de indexação.

- A técnica de stemming é utilizada, pois permite que as raízes morfológicas de cada termo do token sejam armazenadas no indice invertido, proporcionando assim, que termos com diferentes terminações (como construções ou construção) sejam armazenados na forma da sua raiz.

Para mapear os conceitos existentes na ontologia, seja de uma de suas classes ou instâncias, são considerados, para cada documento da coleção, primeiramente, os três termos próximos, em seguida, os dois termos próximos e, finalmente, um único. Desse modo, pela determinação dos termos mapeados, estabelecemos um token.

Eles podem conter termos compostos, como o que ocorre, por exemplo, em nomes de autores e de construções arquitetônicas. Quanto aos termos não encontrados na ontologia, esses também são utilizados para estabelecer tokens, mas eles contém apenas um único termo.

Os tokens encontrados na ontologia podem ser de diferentes tipos, conforme a origem dos dados; isto é, se o token estiver relacionado a autor, então o token será "token_autor"; se estiver relacionado a localização geográfica, será "token_lugar"; se estiver relacionado a construção, seja pelo campo título, descrição ou tags, então o token será "token_da_ontologia".

Para a extensão desses tipos de tokens pode-se utilizar a hierarquia de classes ou as relações semânticas. Utilizamos a hierarquia de classes para os tipos "token_da_ontologia". Dessa forma, se 
o token é uma classe, procuramos o seu ancestral (superclasse) e as classes equivalentes. Caso ele seja uma instância, então obtemos a classe à qual pertence.

Também, para o tipo "token_da_ontologia", se o campo de origem é uma tag, e ela existir na ontologia, então procuramos se ela possui alguma propriedade relacionada ao título. Caso exista alguma propriedade, então essa tag é expandida. Desta forma, se a tag é uma instância, procuramos a classe a qual ela pertence e adicionamos essa classe ao índice invertido.

Por exemplo, se temos o título "Parque Dom Pedro II" e a tag "público"; pela ontologia observamos a relação: Parque_dom_Pedro_II $\rightarrow$ "tem_espaco" $\rightarrow$ Publico, onde "tem_espaco" é uma propriedade. Portanto, procuramos a classe a qual o termo "público" pertence, que é a classe "Espaco", que será adicionada ao índice invertido.

As classes expandidas serão criadas no índice invertido como tokens, os quais serão relacionados ao documento lido. Por exemplo, se no documento com "Id 1025" lemos o token "Igreja de São Pedro", pela ontologia identificamos que ele é uma instância. Assim, procura-se a classe a qual pertence, isto é, "Igreja", este novo termo será adicionado ao índice invertido e relacionado ao mesmo documento.

Para os tokens de tipo "token_autor", geramos diferentes formas de nome de autor a serem adicionadas ao índice invertido e ligadas ao documento lido. Por exemplo, se o nome fosse "Bratke Oswaldo Arthur", a outra forma do nome seria "Arthur Bratke", o qual seria adicionado ao índice invertido.

Para os tokens de tipo "token_lugar", utilizamos a relação semântica; isto é, a propriedade transitiva "localizado_em". Assim, se o token é uma cidade, ao utilizarmos a propriedade "localizado_em", poderemos obter o Estado e o país aos quais essa cidade pertence. Dessa maneira, o Estado e país encontrados serão os novos tokens adicionados no índice invertido para o documento que está sendo processado.

Para todos os tokens criados, com exceção dos tokens de tipo "token_lugar" e "token_autor" serão removidos as palavras de parada. Logo, a cada token será aplicado o stemming, permitindo assim obter as raízes morfológicas de cada termo do token.

Por último, no índice invertido são armazenados os tokens, com seu número de ocorrências no documento a qual pertence. Também, são guardados o número de documentos na qual o token aparece e a frequência total do token na coleção de documentos.

A seguir, temos o Algoritmo 1 Criacao_Indice_Expandido baseado no trabalho [46], para a geração do índice invertido. 


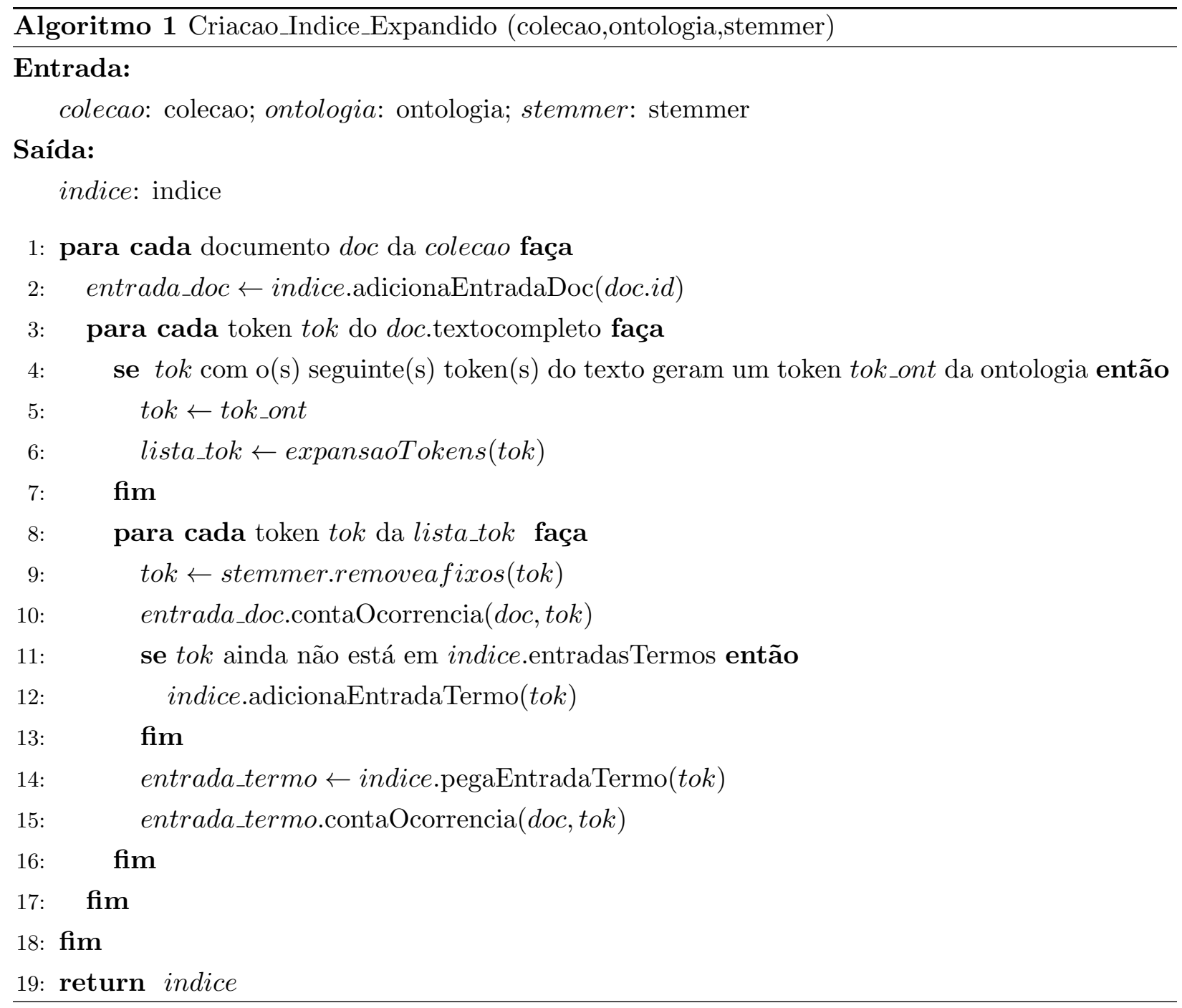

\subsection{Fase de processamento e similaridade de termos}

Neste passo, construímos uma estrutura de similaridade de termos que correspondem à ontologia e ao índice invertido.

No Algoritmo 2 EstruturaSimilaridadeTermos é apresentado o fluxo de atividades realizado para construir a estrutura de similaridade.

Primeiro, comparamos cada token da ontologia com o token do índice invertido para calcular o valor de similaridade entre eles, o qual depende da hierarquia existente na ontologia.

Sendo $t_{1}$ o token da ontologia e $t_{2}$ o token do índice invertido, o primeiro podendo ser representado por uma instância $i_{1}$ ou uma classe $c_{1}$ e o segundo, se ele existir na ontologia, podendo ser representado por uma instância $i_{2}$ ou classe $c_{2}$.

- Se $t_{1}$ e $t_{2}$ são iguais, o valor de similaridade é 1.0 .

- Se $t_{2}$ não existe na ontologia, o valor de similaridade é 0.0 . 
- Se $c_{1}$ e $c_{2}$ são disjuntos na ontologia, o valor de similaridade é 0.0 .

- Se $c_{1}$ e $c_{2}$ são equivalentes na ontologia, o valor de similaridade é 1.0.

- Se $i_{1}$ e $i_{2}$, são similares na ontologia, o valor de similaridade é 1.0.

Se nenhum dos casos acima se aplica, então usamos a equação 3.1 para calcular o valor de similaridade entre $t_{1}$ e $t_{2}$ acima mencionadas. Mas antes é necessário identificar se os tokens são instâncias ou classes. Se algum dos tokens for uma instância, então é necessário encontrar a classe, a qual ela pertence. Assim, se temos $i_{1}$ encontraremos a classe $C_{a}$, a qual pertence. Do mesmo modo, para $i_{2}$ encontraremos a classe $C_{b}$, a qual ela pertence.

E se os tokens fossem as classes $c_{1}$ e $c_{2}$ seriam representadas como $C_{a}$ e $C_{b}$ respectivamente.

$$
\operatorname{sim}\left(t_{1}, t_{2}\right)=\beta \times \frac{2 \times \log P\left(C_{\text {sup }}\right)}{\log P\left(C_{a}\right)+\log P\left(C_{b}\right)}+(1-\beta) \times \frac{\operatorname{prop}\left(C_{a}, C_{b}\right)+\operatorname{prop}\left(C_{b}, C_{a}\right)}{\operatorname{prop}\left(C_{a}\right)+\operatorname{prop}\left(C_{b}\right)}
$$

O primeiro fator é baseado na hierarquia da ontologia, onde $C_{\text {sup }}$ é a classe superior ou classe pai e $P\left(C_{\text {sup }}\right)$ é a probabilidade de ocorrência. Do mesma maneira, $P\left(C_{a}\right)$ é a probabilidade de frequência de $C_{a}$ e $P\left(C_{b}\right)$ é a probabilidade de frequência de $C_{b}$ [28].

O segundo fator calcula o relacionamento dos termos $C_{a}$ e $C_{b}$ utilizando a contagem de suas propriedades,prop $\left(C_{a}, C_{b}\right)$ representa a quantidade de propriedades que tem $C_{a}$ como domínio e $C_{b}$ como imagem, de modo inverso acontece com $\operatorname{prop}\left(C_{b}, C_{a}\right)$, logo $\operatorname{prop}\left(C_{a}\right)$ e $\operatorname{prop}\left(C_{b}\right)$ armazenam a quantidade de propriedades dos termos $C_{a}$ e $C_{b}$, respectivamente [46].

No segundo passo, a similaridade calculada é armazenada em uma estrutura do tipo chave-valor, na qual a chave é composta por dois termos. O primeiro termo pertence à ontologia. O segundo

termo pertence ao índice invertido. O valor é a similaridade entre eles. É importante destacar que pelo fato de ser um processo muito pesado e demorado, a atualização da estrutura de similaridade acontece em intervalo de tempo e o agendamento é configurável. Assim, este valor pode ser utilizado pelas fases seguintes obtendo simplesmente o valor de similaridade entre dois termos, melhorando o tempo de resposta das consultas.

Nesta fase é processada a consulta e são identificados os tokens, os quais são inicializados com um peso inicial igual a 1.0. Também é realizada uma análise da consulta para detectar possíveis erros ortográficos e devolver sugestões para cada palavra. Para isso foi criado um dicionário técnico da ontologia composto por classes e instâncias com termos técnicos da área de arquitetura.

\subsection{Expansão de consulta e recuperação de imagens}

\subsubsection{Expansão de consulta}

A ambiguidade da linguagem "natural", manifesta-se pela presença de termos que não correspondem à informação precisa de um conceito [6]. Portanto, empregou-se o processo de expansão 


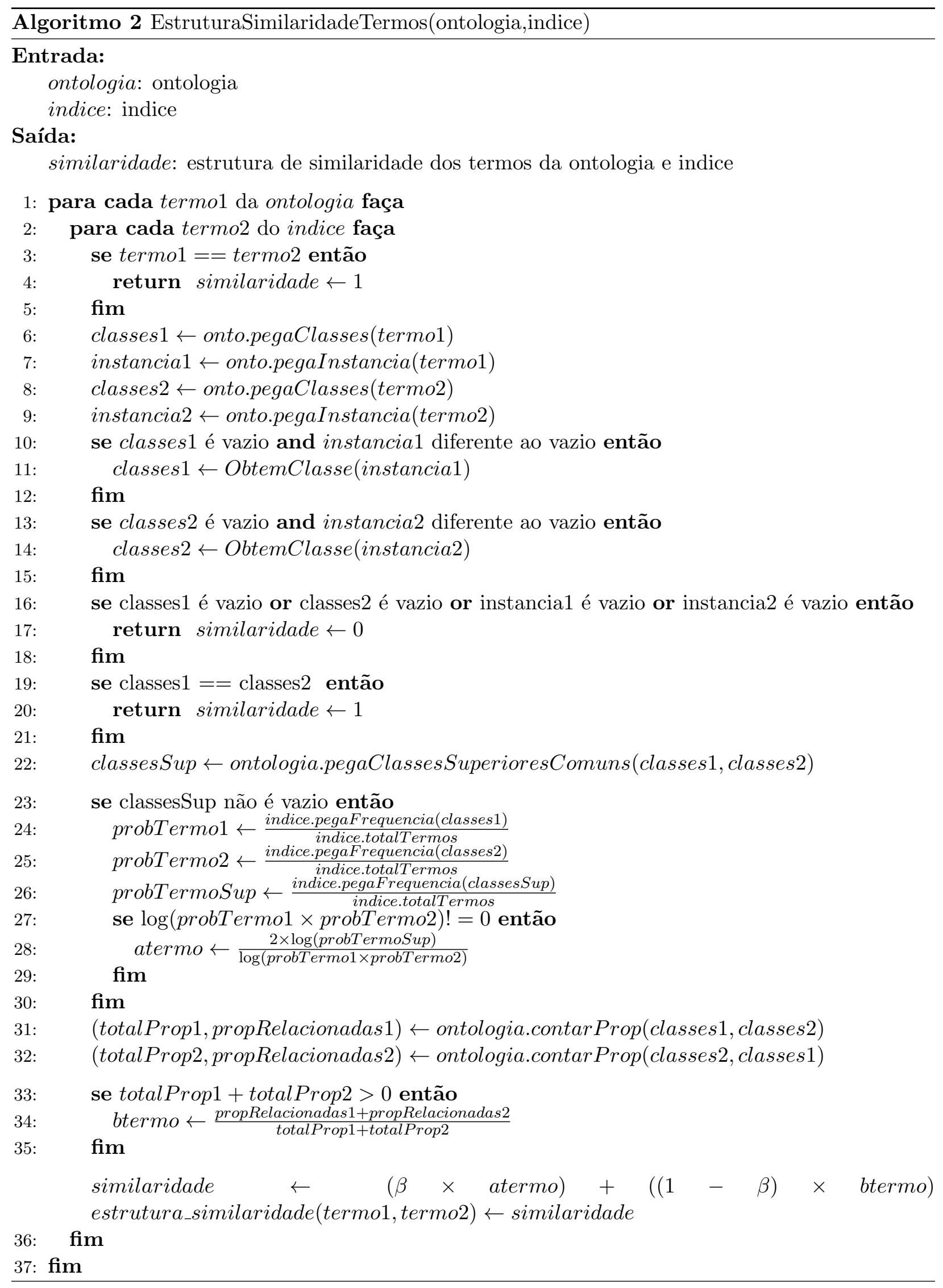


da consulta. Esse processo consiste na adição de novos termos que, por sua vez, se relacionam aos termos iniciais da consulta.

Primeiramente, ignoram-se as "palavras de parada" da consulta, de modo que cada um dos termos da consulta passe a denominar um token específico. Em seguida, para identificarmos o tipo específico de cada token, utilizamos a ontologia. Por fim, para a expansão da consulta, utilizamos a hierarquia da ontologia e suas relações semânticas.

Para o processo de adição de novos termos é necessário antes identificar os tipos de tokens da consulta. Estes podem ser:

- Classe-raiz: classe sem ancestrais (superclasses) mas com subclasses.

- Classe-intermediária: classe com ancestrais (superclasses) e subclasses.

- Classe-folha: classe com ancestrais (superclasses) mas sem subclasses.

- Instância: corresponde ao indivíduo de certa classe da ontologia.

Para o processo de distinção dos tokens torna possível adicionar os novos termos extraídos da ontologia e da estrutura de similaridade de termos. Os novos termos obtidos da ontologia dependerão, assim, do tipo de token da consulta. Desse modo, teremos:

- Se na consulta encontrarmos o token do tipo "instância" e, igualmente, o termo que faz referência a um "autor", então empregaremos a relação "tem_autor_da_obra" da ontologia para recuperar os autores relacionados ao token "instância".

Exemplo: para a consulta Quem é o autor da biblioteca brasiliana?, através da ontologia identificamos a instância "biblioteca_brasiliana" e o termo "autor". Por essa razão, utilizamos a propriedade "tem_autor_da_obra" para relacioná-la à instância "biblioteca_brasiliana". Dessa forma, obtemos como resultado os autores da obra "biblioteca Brasiliana".

- Se na consulta encontrarmos o token do tipo "instância" e este pertencer à classe "Autor_da_obra", então utilizaremos a relação semântica "eh_autor", recuperando todas as construções relacionadas ao token do tipo "instancia". Com esse resultado, calculamos o subconjunto das construções considerando apenas os tokens que possuem relação com a consulta.

Exemplo: para a consulta, Quais são os edifícios projetados por Macedo Silvio Soares em São Paulo?, por meio da ontologia identificamos que "Macedo Silvio Soares" é uma instância da classe "Autor_da_obra", e, igualmente, que o termo "edifícios" é uma classe da ontologia. Desse modo, utilizamos a propriedade "eh_autor" para relacionar a instância "Macedo Silvio Soares" às construções ou edifícios projetados por ele.

- Se na consulta encontrarmos o token do tipo "instância" e este pertencer à classe "Material_construcao", então utilizaremos a relação semântica "eh_material" para buscar as construções relacionadas ao material requisitado. Com esse resultado, calculamos o subconjunto das construções considerando apenas os tokens que possuem relação com a consulta. 
Exemplo: para a consulta Casas de madeira, através da ontologia identificamos que "Casa" é uma classe, e "madeira" é uma instância da classe "Material_construcao". Desse modo, utilizamos a propriedade "eh_material" para relacionar a instância "madeira" com o tipo de construção "casa".

- Se a consulta não possuir tokens do tipo "instância" relacionados às classes "Autor_da_obra" ou "Material_contrucao", executa-se a expansão através da hierarquia da ontologia.

- Se o token for do tipo "classe-raiz" ou "Classe-intermediária", expandimos suas subclasses. Se a consulta não apresentar nenhuma instância mas, ao invés disso, encontrarmos o token do tipo "Classe-folha", expandimos as instâncias desse token. Exemplo: para a consulta Construções Esportivas, através da ontologia verificamos que "Construcoes_esportivas" é uma classe. Por conseguinte, expandimos suas subclasses "campo_esportivo", "estadio", "clube", etc.

Nesta etapa para cada token da consulta será associado um peso que é obtido pela contagem de aparições na consulta. Para cada token será atribuído um peso inicial 1.0. Porém, se o token pertence à hierarquia da classe "Construcao_arquitetonica" será associado um peso ponderado menor do que 1.0.

Além disso, na consulta são adicionados termos similares por cada token, os quais têm relação com a consulta e são recuperados da estrutura de similaridade.

Para encontrar a similaridade de cada termo $t$ do índice invertido com cada termo da consulta $q$, utilizamos a equação 3.2 :

$$
\operatorname{sim}(t, q)=\sum_{t_{i} \in q} w_{i, q} \times \operatorname{sim}\left(t, t_{i}\right)
$$

onde $w_{i, q}$ é o peso do termo $t_{i}$ da consulta $q$ e a $\operatorname{sim}\left(t, t_{i}\right)$ é a similaridade entre o termos $t$ do índice invertido com os termos $t_{i}$ da consulta.

Se $\operatorname{sim}(t, q)$ é diferente de 0.0 , então pode-se escolher o termo $t$ do índice invertido a ser adicionado à consulta e verificamos se $w_{e x}(t, q)$ (valor da similaridade acumulado e normalizado ) é maior do que 0.03. A equação 3.3 obtém o valor de $w_{e x}(t, q)$ :

$$
w_{e x}(t, q)=\frac{\operatorname{sim}(t, q)}{\sum_{t_{i} \in q} w_{i, q}}
$$

Se o termo $t$ pertence à consulta, então o peso $t$ será incrementado com o valor de $w_{e x}(t, q)$, caso contrário se $t$ não existe na consulta será adicionado e o peso de $t$ será igual ao valor de $w_{e x}(t, q)$.

Nesta fase também foram desenvolvidas várias técnicas para controlar a expansão de termos. As técnicas são Expandida, Expandida-ponderada, Não-expandida e Expandida-ponderada-kw.

As técnicas Expandida e Expandida-ponderada, utilizam a hierarquia e a relação semântica da ontologia para adicionar novos termos na consulta. A técnica Não-expandida, não utiliza a ontologia. Por último, a técnica Expandida-ponderada-kw é uma combinação entre a técnica Expandidaponderada e a $N \tilde{a} o$ expandida. Todas estas técnicas foram aplicadas nos experimentos de consultas 
e são mostradas no capítulo 4 .

\subsubsection{Recuperação de imagens}

Para a recuperação utilizou-se os documentos das imagens e as consultas dos usuários. Cada documento de imagem é representado em um vetor espacial que irá conter os pesos de todos os termos pertencentes ao documento. Tem-se também outro vetor espacial que contém os pesos dos termos da consulta.

Estes vetores pertencem à teoria do modelo de espaço vetorial descrito na seção 2.9.3.2, que utiliza o peso dos termos para calcular a similaridade existente entre o documento de imagem e a consulta.

Calculamos o grau de similaridade do documento $d_{j}$ e a consulta $q$ como a correlação entre os vetores $\vec{d}_{j}$ (vetor de documento) e $\vec{q}$ (vetor da consulta).

$$
\operatorname{sim}\left(d_{j}, q\right)=\cos \left(d_{j}, q\right)=\frac{\vec{d}_{j} \bullet \vec{q}}{\left|\overrightarrow{d_{j}}\right| \times|\vec{q}|}=\frac{\sum_{i=1}^{t} w_{i, j} \times w_{i, q}}{\sqrt{\sum_{i=1}^{t} w_{i, j}^{2}} \times \sqrt{\sum_{i=1}^{t} w_{i, q}^{2}}}
$$

A similaridade $\operatorname{sim}\left(d_{j}, q\right)$ pode ter valores entre 0 e 1 desde que $w_{i, j} \geq 0$ e $w_{i, q} \geq 0$. Enquanto que o $w_{i, j}$ é o peso do termo $i$ no documento $j$ e $w_{i, q}$ é o peso do termo $i$ na consulta $q$. Para os resultados da similaridade foi estabelecido o limiar de 0.03 , para recuperar os documentos acima desse limiar.

Com estes cálculos obteremos uma lista de todas as imagens com as informações relevantes respectivas que tenham maior similaridade com a consulta expandida, com o fim de retornar as imagens mais relevantes para o usuário. O sistema implementado para a recuperação de informação pode ser observado no apêndice B.

\subsubsection{Considerações finais}

Nesse capítulo, foi apresentada a construção da ontologia para o domínio arquitetônico e de um sistema de recuperação de imagens arquitetônicas. Para o desenvolvimento da ontologia, utilizamos fontes que serviram como um catálogo de terminologia padronizada para área da arquitetura: vocabulário controlado da USP e o Tesauro Experimental da Arquitetura. A proposta desta abordagem é a utilização da ontologia para expandir a consulta feita pelo usuário.

Estas consultas podem ser em linguagem natural. Por outro lado, para a implementação do sistema de recuperação de imagens arquitetônicas foi necessário entender e aplicar os conceitos do modelo de espaço vetorial. Também foi necessário criar uma estrutura de similaridade, para ser utilizada na expansão de consultas feitas pelos usuários. A ontologia, em conjunto com o sistema de recuperação, permitiram que as consultas realizadas pelos usuários pudessem ser estendidas e portanto, que mais documentos relevantes pudessem ser recuperados. 


\section{Capítulo 4}

\section{Experimentos e Resultados}

Neste capítulo, apresentamos os documentos que foram utilizados e gerados em cada fase da abordagem proposta para a construção da ontologia OntoArq e o desenvolvimento de um sistema de recuperação de imagens. Os resultados das consultas realizadas no sistema de recuperação são apresentados nesta seção.

\subsection{Conjunto de dados}

Foram utilizados dois conjuntos de dados, um para a ontologia e outro para o sistema de recuperação.

\subsubsection{Conjunto de dados para a ontologia}

Três fontes de dados foram utilizadas para a construção da ontologia. A primeira fonte foi o tesauro experimental da área de arquitetura [16]; a segunda fonte foi o vocabulário controlado do $S I B i / U S P$ para a área de arquitetura; e a terceira e última fonte foi a informação principal do sistema Arquigrafia.

As duas primeiras fontes possuíam termos arquitetônicos que estavam organizados segundo suas relações semânticas. A terceira fonte, extraída do banco de dados Arquigrafia, estava composta por título, descrição, cidade, estado, autor e tags. E pela análise de seus dados, encontrou-se algumas características, tais como:

- Vários registros com o mesmo título, descrição, cidade, estado, autor, mas que se diferenciam em algumas tags;

- Não eram obrigatórios todos os atributos, por este motivo os campos descrição, cidade, estado e autor podiam estar vazios.

Na tabela 4.1 exibe-se um exemplo das características mencionadas acima na fonte de dados Arquigrafia: 


\begin{tabular}{|c|c|c|c|c|c|c|}
\hline Id & Titulo & Descrição & Cidade & Estado & Autor & Tags \\
\hline 2419 & Praça do Relógio & $\begin{array}{l}\text { Vista da Praça } \\
\text { do Relógio }\end{array}$ & São Paulo & $\mathrm{SP}$ & $\begin{array}{l}\text { MACEDO, Silvio; } \\
\text { PELEGRINO, } \\
\text { Paulo }\end{array}$ & 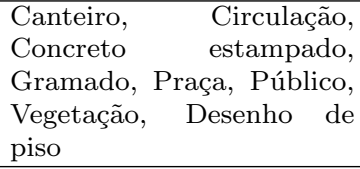 \\
\hline 2846 & Praça do Relógio & $\begin{array}{l}\text { Vista da Praça } \\
\text { do Relógio }\end{array}$ & São Paulo & $\mathrm{SP}$ & $\begin{array}{l}\text { MACEDO, Silvio; } \\
\text { PELEGRINO, } \\
\text { Paulo }\end{array}$ & $\begin{array}{l}\text { Canteiro, } \\
\text { Concreto } \\
\text { Gramado, } \\
\text { estampadaão, } \\
\text { Vegetaçãa, Forração }\end{array}$ \\
\hline 2417 & Praça do Relógio & $\begin{array}{l}\text { Vista da Praça } \\
\text { do Relógio }\end{array}$ & São Paulo & $\mathrm{SP}$ & $\begin{array}{l}\text { MACEDO, Silvio; } \\
\text { PELEGRINO, } \\
\text { Paulo }\end{array}$ & 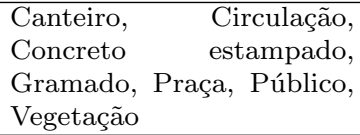 \\
\hline 2418 & Praça do Relógio & $\begin{array}{l}\text { Vista da Praça } \\
\text { do Relógio }\end{array}$ & São Paulo & $\mathrm{SP}$ & $\begin{array}{l}\text { MACEDO, Silvio; } \\
\text { PELEGRINO, } \\
\text { Paulo }\end{array}$ & $\begin{array}{l}\text { Canteiro, } \\
\text { Concreto } \\
\text { Gramado, } \\
\text { estampaçãa,o, } \\
\text { Vegetação, Público, }\end{array}$ \\
\hline 52 & $\begin{array}{l}\text { Igreja do Senhor do } \\
\text { Bonfim }\end{array}$ & & $\begin{array}{l}\text { Marechal } \\
\text { Deodoro }\end{array}$ & $\mathrm{AL}$ & & Frontão, Igreja, Voluta \\
\hline 53 & $\begin{array}{l}\text { Igreja do Senhor do } \\
\text { Bonfim }\end{array}$ & & $\begin{array}{l}\text { Marechal } \\
\text { Deodoro }\end{array}$ & $\mathrm{AL}$ & & $\begin{array}{l}\text { Frontão, Igreja, Voluta, } \\
\text { Escadaria }\end{array}$ \\
\hline 2179 & $\begin{array}{l}\text { Residência } \\
\text { Oswaldo Libe- } \\
\text { rato }\end{array}$ & $\begin{array}{l}\text { Fachada da } \\
\text { Residência } \\
\text { Oswaldo Libe- } \\
\text { rato }\end{array}$ & & & $\begin{array}{l}\text { MARTINHO, Ara- } \\
\text { ken }\end{array}$ & $\begin{array}{l}\text { Alvenaria, Calçada, Casa, } \\
\text { Coluna, Corrimão, Degrau, } \\
\text { Esquadro, Fachada, Ferro, } \\
\text { Garagem, Guarda corpo, } \\
\text { Guarda-corpo, Habitação, } \\
\text { Pano de vidro, Patamar, } \\
\text { Porta, Residência, Rua, } \\
\text { Varanda, Vidro }\end{array}$ \\
\hline 2236 & Museu Judaico & & São Paulo & SP & & $\begin{array}{l}\text { Dark, Dirty, Preto e } \\
\text { Branco, Sao Paulo }\end{array}$ \\
\hline 2336 & $\begin{array}{l}\text { Biblioteca Brasili- } \\
\text { ana Guita e José } \\
\text { Mindlin }\end{array}$ & & São Paulo & $\mathrm{SP}$ & $\begin{array}{l}\text { Eduardo de Al- } \\
\text { meida;Rodrigo } \\
\text { Mindlin Loeb }\end{array}$ & $\begin{array}{l}\text { Arquitetura Brasileira, Ar- } \\
\text { quitetura contemporânea, } \\
\text { Biblioteca, Concreto apa- } \\
\text { rente }\end{array}$ \\
\hline 3375 & $\begin{array}{l}\text { Residência } \quad \text { Lígia } \\
\text { Carneiro }\end{array}$ & $\begin{array}{lr}\text { Vista da } & \text { co- } \\
\text { bertura e da } \\
\text { claraboia da } \\
\text { Residência } \\
\text { Lígia Carneiro }\end{array}$ & & & $\begin{array}{l}\text { ROCHA, Paulo } \\
\text { Archias Mendes da }\end{array}$ & $\begin{array}{l}\text { Caixilho, Casa, Claraboia, } \\
\text { Cobertura, Concreto, } \\
\text { Concreto aparente, Cons- } \\
\text { trução, Estrutura, Ferro, } \\
\text { Habitação, Instalações, } \\
\text { Laje, Residência, Vidro, } \\
\text { Viga }\end{array}$ \\
\hline
\end{tabular}

Tabela 4.1: Alguns dados extraídos do Arquigrafia

Na tabela vemos itens diferentes, identificados pelos $I d s$, com a mesma descrição, às vezes com variações nas tags. No Arquigrafia temos, por exemplo, diversas fotos da "Praça do Relógio".

\subsubsection{Conjunto de dados para o sistema de recuperação}

No capitulo anterior pode-se observar a existência de 3 fases mais relacionadas ao sistema de recuperação de imagens. Cada fase é dependente da fase anterior, isso porque utilizam as estruturas criadas pelas outras fases. Por exemplo, na fase de indexação e pré-processamento, foram criadas a coleção de documentos e o índice invertido. Para a fase de processamento e similaridade de termos, foi criada a estrutura de similaridade. A fase de expansão de consulta e recuperação de imagens, que é a fase responsável pelo funcionamento do sistema de recuperação de imagens, empregou as estruturas criadas nas fases anteriores. 
As questões de competência fornecidas pelos especialistas da área de arquitetura do Arquigrafia foram utilizadas para validar nossa abordagem.

Essas questões de competência foram consideradas como consultas e foram executadas no sistema de recuperação implementado. Para cada consulta foi necessário determinar quais são os documentos relevantes, ou seja, documentos que estejam totalmente relacionadas à consulta. Para isso, foi necessário criar consultas Mysql ao banco de dados do sistema Arquigrafia para cada questão de competência. Estas consultas retornavam uma lista de documentos. E cada documento retornado era analisado para determinar se ele era relevante o não para a consulta. Este processo pode ser observado na figura 4.1.

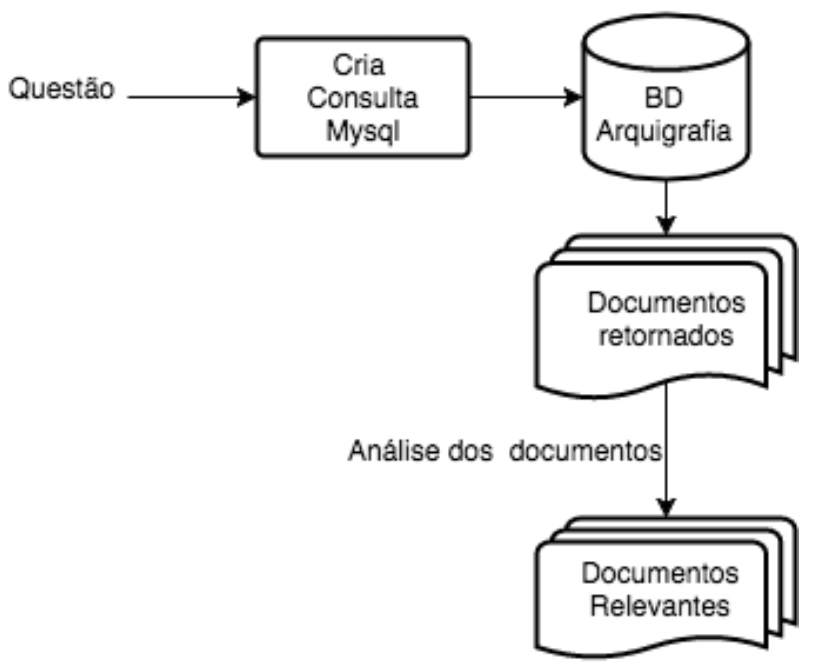

Figura 4.1: Passos para determinar os conjuntos de documentos relevantes para cada questão de competência.

Desta maneira, para cada questão de competência, obtemos um conjunto de documentos relevantes e pode-se calcular o seu número. Isto pode ser observado na tabela 4.2.

O número total de documentos relevantes de cada questão de competência será utilizado para obter os valores das medidas de avaliação tais como precisão, cobertura e medida-F.

\subsection{Avaliação de resultados e discussão}

Para os experimentos foram utilizadas consultas baseadas nas questões de competência descritas na seção 3.3.1 e consultas relacionadas ao Log de busca do Analytics. Ambas foram consideradas importantes para os experimentos e foram testadas no sistema de recuperação de informação desenvolvido neste trabalho, o qual opera em conjunto com a ontologia construída.

Para a avaliação dos resultados, desenvolveu-se cinco técnicas ou processos para a recuperação dos documentos relacionados às imagens. As técnicas "Expandida-ponderada", "Expandida", "Não Expandida", "Busca booleana" e "Expandida-ponderada-kw". As duas primeiras técnicas utilizam a ontologia e o modelo do espaço vetorial, descrito na seção 2.9.3.2. A técnica "Não Expandida" e "Busca booleana" não utilizam a ontologia, porém a técnica "Não Expandida" utiliza o modelo vetorial. Por último a técnica "Expandida-ponderada-kw" é a combinação de duas técnicas. Elas 


\begin{tabular}{|l|l|l|}
\hline $\begin{array}{l}\text { Consultas relacionadas às questões } \\
\text { de competência }\end{array}$ & $\begin{array}{l}\text { Conjunto de do- } \\
\text { cumentos relevan- } \\
\text { tes. Ids dos Docu- } \\
\text { mentos }\end{array}$ & $\begin{array}{l}\text { Número } \\
\text { total de } \\
\text { docu- } \\
\text { mentos } \\
\text { relevan- } \\
\text { tes }\end{array}$ \\
\hline $\begin{array}{l}\text { Quem é o autor do projeto da Praça do } \\
\text { Relógio? }\end{array}$ & $2416,2417, \ldots, 3543$ & 105 \\
\hline $\begin{array}{l}\text { Existem edifícios em vidro construídos } \\
\text { no Brasil? }\end{array}$ & $90,94, \ldots, 4509$ & 1332 \\
\hline $\begin{array}{l}\text { Onde se localizam construções de taipa } \\
\text { remanescentes em São Paulo? }\end{array}$ & $2961,2966, \ldots, 2974$ & 5 \\
\hline Quem projetou a Rodoviária de Jau? & $1089,1090, \ldots, 1324$ & 49 \\
\hline $\begin{array}{l}\text { Quais são os principais edifícios residen- } \\
\text { ciais no interior do Rio de Janeiro? }\end{array}$ & $723,829, \ldots, 4192$ & 85 \\
\hline $\begin{array}{l}\text { Quais os edifícios projetados por Macedo } \\
\text { Silvio Soares em São Paulo? }\end{array}$ & $2416,2417, \ldots, 3543$ & 105 \\
\hline $\begin{array}{l}\text { Existem edifícios projetados por Plínio } \\
\text { Croce no interior do estado de São } \\
\text { Paulo? }\end{array}$ & $1422,1423, \ldots, 3368$ & 24 \\
\hline Quem projetou a Biblioteca Brasiliana? & 2336,2337 & 2 \\
\hline $\begin{array}{l}\text { Quais edifícios foram projetados por } \\
\text { Gian Carlo Gasperini no Brasil? }\end{array}$ & $842,843, \ldots, 4494$ & 94 \\
\hline $\begin{array}{l}\text { Onde encontro casas de madeira no } \\
\text { Pará? }\end{array}$ & $894,895, \ldots, 3304$ & 36 \\
\hline $\begin{array}{l}\text { As palafitas típicas da habitação ribeiri- } \\
\text { nha no Norte do Brasil, podem ser vistas } \\
\text { em que lugares da Amazônia? }\end{array}$ & $894,895, \ldots, 919$ \\
\hline
\end{tabular}

Tabela 4.2: Número total de documentos relevantes para cada questão de competência.

são a técnica "Expandida-ponderada" e a "Não Expandida". A seguir, explicaremos cada técnica.

a) Expandida-ponderada: Consiste na adição de novos termos relacionados à consulta utilizando a ontologia. Contudo, os pesos dos termos expandidos serão ponderados se eles pertencerem à classe com maior nível de hierarquia. Tendo essa consulta sido expandida pela adição de termos de pesos alterados, aplicamos o cálculo de similaridade entre o vetor da consulta e o vetor de documento. Este processo faz parte do modelo do espaço vetorial.

b) Expandida: Consiste na adição de novos termos à consulta, utilizando a relação semântica obtida a partir da ontologia. Como resultado, temos a consulta expandida. Assim, criamos o vetor de consulta e calculamos a similaridade entre esse vetor e o vetor de documento para recuperar os documentos mais similares.

c) Não-expandida: Consiste no uso dos termos da consulta para recuperar os documentos que contêm esses mesmos termos, utilizando o índice invertido para depois calcular a similaridade 
entre o vetor de consulta e o vetor de documento. Este processo faz parte do modelo do espaço vetorial, no qual os documentos mais similares à consulta serão recuperados. Para esta técnica, não utilizamos a ontologia.

d) Busca-booleana: Seleciona todos os documentos que satisfazem os termos da consulta utilizando o operador "or". Este processo está descrito na seção 2.9.3.1.

e) Expandida-ponderada-kw: Consiste em calcular a combinação da pontuação de classificação por uma combinação linear das pontuações de entrada. Isto é, $\lambda \operatorname{sim}(d, q)+(1-\lambda) k \operatorname{sim}(d, q)$, onde sim é o calculo de similaridade utilizando a expansão de termos e ksim é cálculo de similaridade sem expansão de termos (técnica "Não-expandida"), e $\lambda \in[0,1]$. Este tipo de abordagem corresponde ao uso da estratégia CombSum que foi aplicada no trabalho de Fernández [18], a principal diferença é que para nosso trabalho utilizamos a técnica "Expandida-ponderada" para sim e $\lambda=0.7$.

Assim, ao aplicar qualquer dessas técnicas no sistema de recuperação de informação e consultar no motor busca cada questão de competência como uma consulta, o sistema retorna uma quantidade de documentos para cada uma das consultas. Estes documentos recuperados podem ser relevantes ou não para a consulta.

Para saber quais são relevantes para uma determinada consulta, é necessário comparar todos os documentos recuperados pelo sistema de recuperação com o conjunto de documentos relevantes obtidos na seção anterior 4.1.2. Desta maneira, podemos calcular qual é o numero de documentos relevantes recuperados para cada questão de competência. Após estes resultados, pode-se calcular as medidas de avaliação para precisão, cobertura e medida-F descritas na seção 2.10 .

Na Tabela 4.3, apresentamos o resultado das métricas de precisão, cobertura e medida-F, relativas à técnica "Expandida Ponderada", que usa a ontologia. Pelos experimentos, obteve-se melhores resultados empregando essa técnica na maior parte das consultas relacionadas às questões de competência. O limiar de mínima similaridade utilizado para esta técnica foi 0.07 .

O comportamento das métricas é influenciado pela variação do limiar, fazendo com que, enquanto a precisão aumente, a cobertura diminua, ou o contrário.

Ao realizar os experimentos para a técnica surgiram os seguintes casos:

- Para o primeiro caso, em que a precisão e cobertura são altas, a consulta "Quem é o autor do projeto da Praça do Relógio?", deveria ter retornado 105 documentos relevantes. Utilizando-se a técnica "Expandida-ponderada", pode-se observar que foram retornados 145 documentos, dos quais, 105 eram relevantes e 40 não. Em razão disso, a precisão foi de $72 \%$ e a cobertura de $100 \%$. Os 40 documentos continham termos que estavam relacionados a algum termo da consulta, seja "praça" ou "relógio". A cobertura tem alto valor, pois todos os documentos relevantes contêm o texto "praça do relógio", relacionado ao título da imagem. 


\begin{tabular}{|l|l|l|l|l|l|}
\hline $\begin{array}{l}\text { Consultas relacionadas às } \\
\text { questões de competência }\end{array}$ & Precisão & Cobertura & $\begin{array}{l}\text { Medida- } \\
\text { F }\end{array}$ & $\begin{array}{l}\text { Doc. } \\
\text { rele- } \\
\text { vantes } \\
\text { na } \\
\text { coleção }\end{array}$ & $\begin{array}{l}\text { Doc. } \\
\text { cuperados } \\
\text { por } \\
\text { sulta } \\
\text { con- }\end{array}$ \\
\hline $\begin{array}{l}\text { Quem é o autor do projeto da Praça } \\
\text { do Relógio? }\end{array}$ & 0.72 & 1.00 & 0.84 & 105 & 145 \\
\hline $\begin{array}{l}\text { Existem edifícios em vidro cons- } \\
\text { truídos no Brasil? }\end{array}$ & 0.88 & 0.02 & 0.03 & 1332 & 25 \\
\hline $\begin{array}{l}\text { Onde se localizam construções de } \\
\text { taipa remanescentes em São Paulo? }\end{array}$ & 0.16 & 1.00 & 0.28 & 5 & 31 \\
\hline Quem projetou a Rodoviária de Jau? & 0.69 & 1.00 & 0.82 & 49 & 71 \\
\hline $\begin{array}{l}\text { Quais são os principais edifícios resi- } \\
\text { denciais no interior do Rio de Janeiro? }\end{array}$ & 0.04 & 0.04 & 0.04 & 85 & 76 \\
\hline $\begin{array}{l}\text { Quais os edifícios projetados por Ma- } \\
\text { cedo Silvio Soares em São Paulo? }\end{array}$ & 0.88 & 0.98 & 0.93 & 105 & 117 \\
\hline $\begin{array}{l}\text { Existem edifícios projetados por } \\
\text { Plínio Croce no interior do estado de } \\
\text { São Paulo? }\end{array}$ & 1.00 & 1.00 & 1.00 & 24 & 24 \\
\hline $\begin{array}{l}\text { Quem projetou a Biblioteca Brasili- } \\
\text { ana? }\end{array}$ & 1.00 & 1.00 & 1.00 & 2 & 2 \\
\hline $\begin{array}{l}\text { Quais edifícios foram projetados por } \\
\text { Gian Carlo Gasperini no Brasil? }\end{array}$ & 0.80 & 0.04 & 0.08 & 94 & 5 \\
\hline $\begin{array}{l}\text { Onde encontro casas de madeira no } \\
\text { Pará? }\end{array}$ & 0.53 & 0.50 & 0.51 & 36 & 34 \\
\hline $\begin{array}{l}\text { As palafitas típicas da habitação ribei- } \\
\text { rinha no Norte do Brasil, podem ser } \\
\text { vistas em que lugares da Amazônia? }\end{array}$ & 0.77 & 1.00 & 0.87 & 24 & 31 \\
\hline
\end{tabular}

Tabela 4.3: Resultado das métricas de precisão, cobertura e medida-F, para a técnica "Expandida Ponderada".

- O segundo caso, em que a precisão possui um valor alto e a cobertura possui um valor baixo. Por exemplo, na consulta "Existem edifícios em vidro construídos no Brasil?", deveria ter retornado 1332 documentos relevantes. Contudo foram recuperados apenas 25 documentos para um limiar mínimo de similaridade de 0.07 .

Aplicando o cálculo da métrica de precisão, ou seja, o número de documentos relevantes recuperados sobre o número total de documentos recuperados, embora tenha-se obtido uma precisão de $88 \%$ a cobertura foi apenas de $0.2 \%$, pois 1310 documentos relevantes não foram recuperados.

Atribuímos este comportamento ao termo vidro, o qual se relaciona a "material de construção". Isto faz com que o termo vidro seja expandido por meio da relação semântica eh_material da ontologia, estendendo assim a consulta a vários termos também relacionados às construções deste material. 
Tal expansão gera o aumento do tamanho do vetor da consulta e, ao calcular-se a similaridade com cada vetor do documento, obtém-se valores baixos. Assim, observando os resultados desta consulta (que empregou a técnica "Expandida-ponderada") tem-se que para um valor mínimo de similaridade menor a 0.03 a cobertura começa a aumentar desde $6.3 \%$ e a precisão vai diminuindo lentamente.

\subsection{Comparação de resultados}

Esta seção apresenta a discussão dos resultados observados em 3 tipos de experimentos realizados com 20 consultas, sendo uma parte relacionada às questões de competência e as demais consultas extraídas do Log do Analytics do sistema Arquigrafia. A seguir, apresentamos os resultados da precisão e da cobertura para as diferentes técnicas mencionadas na seção anterior.

a) Em primeiro lugar, apresentamos os resultados das consultas que utilizaram a indexação e espaço vetorial com ou sem ontologias.

- Para a consulta "Quem é o autor do projeto da Praça do Relógio", a observação das Figuras 4.2 e 4.3 revela que os resultados obtidos para as técnicas "Expandida", "Expandida-ponderada" e "Expandida-ponderada-kw" alcançam uma cobertura de $100 \%$ e uma precisão com tendência ao aumento, podendo chegar a $98 \%$ conforme cresce o limiar.

Na Figura 4.2 por exemplo, observa-se que, embora o limiar de mínima similaridade seja alterado numa escala entre 0.01 e 0.15 , o valor da cobertura permanece constante em $100 \%$ e a precisão cresce conforme o valor do limiar é aumentado. Isto ocorre pois todos os documentos recuperados possuem algum termo relacionado à consulta. A maioria desses documentos possui o termo composto "praça do relógio", fazendo com que a cobertura e precisão começe a aumentar quando o limiar é maior que 0.07. 


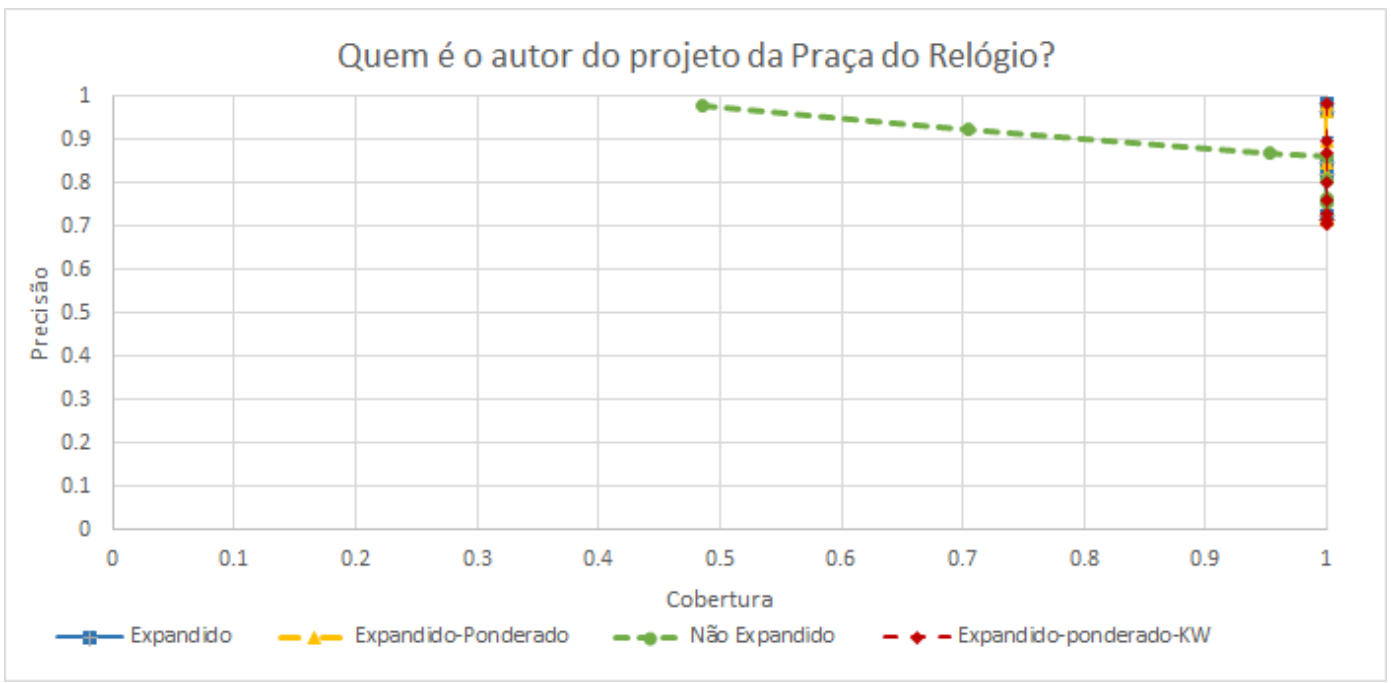

Figura 4.2: Precisão e cobertura para a consulta "Quem é o autor do projeto da Praça do Relógio?" .

\begin{tabular}{|l|l|l|l|l|l|l|l|l|}
\hline & \multicolumn{2}{|l|}{ Expandida } & \multicolumn{2}{l|}{$\begin{array}{l}\text { Expandida- } \\
\text { ponderada }\end{array}$} & \multicolumn{2}{l|}{$\begin{array}{l}\text { Expandida- } \\
\text { ponderada-kw }\end{array}$} & \multicolumn{2}{l|}{ Não expandida } \\
\hline Limiar & Precisão & Cobertura & Precisão & Cobertura & Precisão & Cobertura & Precisão & Cobertura \\
\hline 0.01 & 0.71 & 1.00 & 0.71 & 1.00 & 0.70 & 1.00 & 0.76 & 1.00 \\
\hline 0.03 & 0.71 & 1.00 & 0.71 & 1.00 & 0.70 & 1.00 & 0.76 & 1.00 \\
\hline 0.05 & 0.71 & 1.00 & 0.71 & 1.00 & 0.71 & 1.00 & 0.76 & 1.00 \\
\hline 0.07 & 0.72 & 1.00 & 0.72 & 1.00 & 0.73 & 1.00 & 0.77 & 1.00 \\
\hline 0.09 & 0.82 & 1.00 & 0.82 & 1.00 & 0.76 & 1.00 & 0.81 & 1.00 \\
\hline 0.10 & 0.85 & 1.00 & 0.85 & 1.00 & 0.80 & 1.00 & 0.86 & 1.00 \\
\hline 0.11 & 0.90 & 1.00 & 0.90 & 1.00 & 0.87 & 1.00 & 0.87 & 1.00 \\
\hline 0.13 & 0.96 & 1.00 & 0.96 & 1.00 & 0.90 & 1.00 & 0.93 & 0.70 \\
\hline 0.15 & 0.98 & 1.00 & 0.98 & 1.00 & 0.98 & 1.00 & 0.98 & 0.49 \\
\hline
\end{tabular}

Tabela 4.4: Resultados das métricas para Quem é o autor do projeto da Praça do Relógio?

Na Figura 4.3 observamos que a medida-F obtém o melhor ponto em aproximadamente 0.11 para o limiar de mínima similaridade. Esta imagem, quando comparada à Figura 4.2, contribui para a obtenção do valor do limiar que maximiza as métricas de precisão e cobertura. 


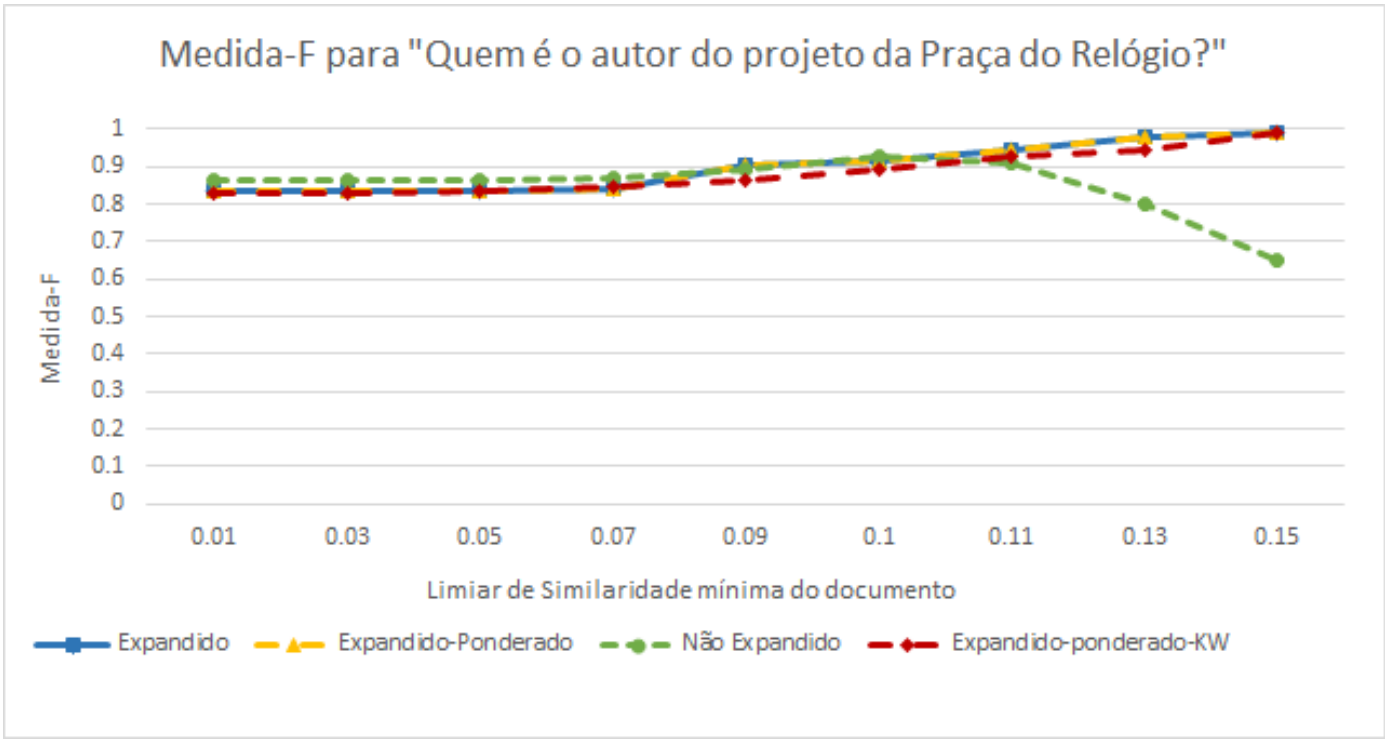

Figura 4.3: Medida-F para "Quem é o autor do projeto da Praça do Relógio?" .

- Para a consulta "Onde encontro casas de madeira no Pará?", conforme podemos observar nas Figuras 4.4 e 4.5, os resultados para as técnicas "Expandida-ponderada" e "Expandida" alcançam métricas de precisão, cobertura e medida-F maiores do que a técnica "Não-expandida".

Na Figura 4.4, observamos que a técnica "Expandida-ponderada" alcança uma precisão máxima de $53 \%$ e uma cobertura de $50 \%$ para um valor de 0.07 do limiar de mínima similaridade.

E a técnica "Expandida" alcança uma precisão máxima de $43 \%$ e uma cobertura de $50 \%$ para o mesmo valor do limiar. Atribuímos estes resultados ao termo "madeira" instância da classe material de construção e ao termo "Pará" instância da classe estado. Para o termo madeira são adicionadas as construções de casas que estão relacionados a esse material. E para o termo Pará são adicionadas as cidades que pertencem a este estado. Assim, com a consulta expandida consegue-se recuperar aproximadamente a metade dos documentos relevantes ao utilizar ambas técnicas.

A técnica "Expandida-ponderada-kw" alcança uma precisão máxima de $30 \%$ e uma cobertura de $58 \%$ para um valor de 0.05 do limiar. Atribuímos estes resultados aos baixos valores pertencentes à técnica "Não Expandida", a qual trabalha em conjunção com a técnica "Expandida-ponderada', embora esta última técnica tenha valores acima de $50 \%$, seus valores são diminuídos ao ser multiplicados por um coeficiente de 0.7 e somados aos valores da técnica "Não Expandida".

Quanto à técnica "Não expandida", obteve uma precisão máxima de 5\% e uma cobertura de $100 \%$ para um limiar de 0.01 . Isto ocorre pois esta técnica não tem expansão 
de termos. Portanto, os documentos recuperados possuem algum termo pertencente à consulta.

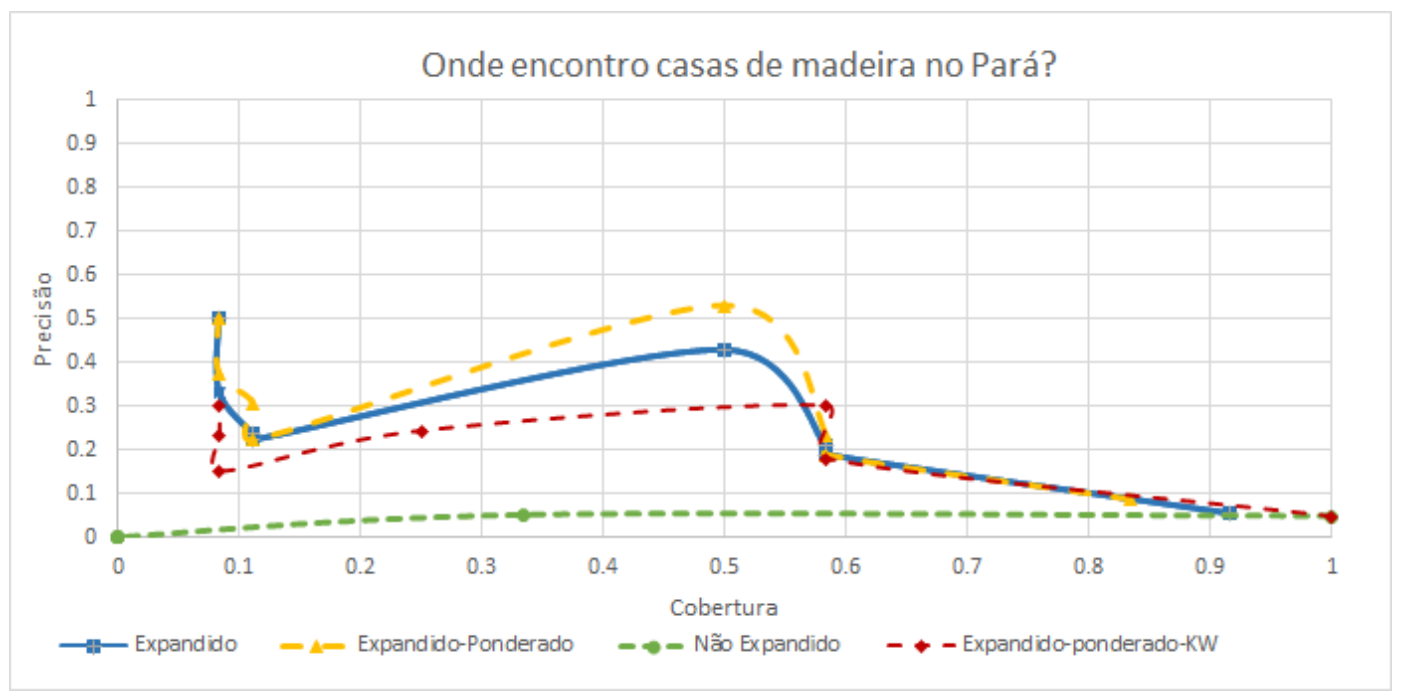

Figura 4.4: Precisão e cobertura para "Onde encontro casas de madeira no Pará?."

\begin{tabular}{|l|l|l|l|l|l|l|l|l|}
\hline & \multicolumn{2}{|l|}{ Expandida } & \multicolumn{2}{l|}{$\begin{array}{l}\text { Expandida- } \\
\text { ponderada }\end{array}$} & \multicolumn{2}{l|}{$\begin{array}{l}\text { Expandida- } \\
\text { ponderado-kw }\end{array}$} & \multicolumn{2}{l|}{ Não-expandida } \\
\hline Limiar & Precisão & Cobertura & Precisão & Cobertura & Precisão & Cobertura & Precisão & Cobertura \\
\hline 0.01 & 0.05 & 0.92 & 0.09 & 0.83 & 0.05 & 1.00 & 0.05 & 1.00 \\
\hline 0.03 & 0.19 & 0.58 & 0.19 & 0.58 & 0.18 & 0.58 & 0.05 & 0.33 \\
\hline 0.05 & 0.21 & 0.58 & 0.23 & 0.58 & 0.30 & 0.58 & 0.00 & 0.00 \\
\hline 0.07 & 0.43 & 0.50 & 0.53 & 0.50 & 0.24 & 0.25 & 0.00 & 0.00 \\
\hline 0.09 & 0.22 & 0.11 & 0.22 & 0.11 & 0.15 & 0.08 & 0.00 & 0.00 \\
\hline 0.10 & 0.24 & 0.11 & 0.31 & 0.11 & 0.23 & 0.08 & 0.00 & 0.00 \\
\hline 0.11 & 0.33 & 0.08 & 0.38 & 0.08 & 0.30 & 0.08 & 0.00 & 0.00 \\
\hline 0.13 & 0.50 & 0.08 & 0.50 & 0.08 & 0.00 & 0.00 & 0.00 & 0.00 \\
\hline 0.15 & 0.00 & 0.00 & 0.00 & 0.00 & 0.00 & 0.00 & 0.00 & 0.00 \\
\hline
\end{tabular}

Tabela 4.5: Resultados das métricas para Onde encontro casas de madeira no Pará?

Na Figura 4.5, observamos que a Medida-F obtém o melhor valor no ponto 0.07 para o limiar de mínima similaridade. Esta imagem complementa a Figura 4.4 para obtenção do valor do limiar que maximiza as métricas de precisão e cobertura. 


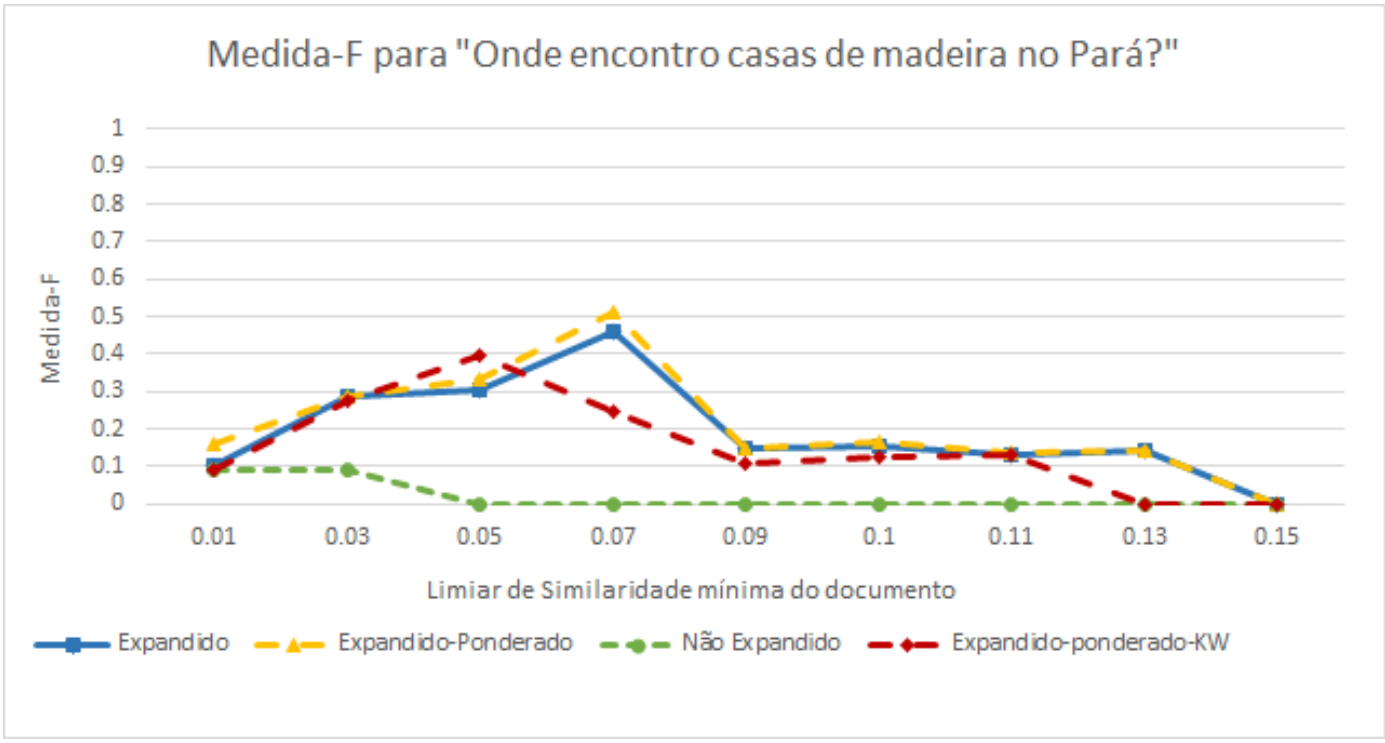

Figura 4.5: Medida-F para "Onde encontro casas de madeira no Pará.?"

b) Em segundo lugar, apresentamos a comparação dos resultados das consultas, com limiar mínimo de similaridade de 0.07, para as técnicas que trabalham com ou sem ontologia e utilizam o modelo de espaço vetorial. Também incluímos a técnica de busca booleana.

- A Figura 4.6 traz um resultado comparativo de todas as técnicas anteriormente mencionadas, para a consulta "Quem projetou a rodoviária de Jaú?". Observamos que a técnica "Expandida-ponderada-kw" apresenta um resultado levemente superior à técnica "Expandida-ponderada".

A técnica "Expandida-ponderada-kw" emprega a combinação de duas técnicas, Expandida-ponderada e Não expandida, as quais são multiplicadas por um fator de 0.7 e 0.3 respectivamente, após essa operação os resultados são somados. Por esse motivo,o valor de precisão foi de $72 \%$, o valor de cobertura foi de $100 \%$ e a medida-F foi de $83.7 \%$.

E para a técnica "Expandida-ponderada" que emprega a ontologia para expansão dos termos relacionados à consulta. Para esta técnica o valor de precisão foi de $69 \%$, o valor de cobertura foi de $100 \%$ e a medida-F foi de $81.6 \%$. Atribuímos estes resultados ao termo composto "rodoviária de Jaú", existente na ontologia como instância da classe "Estação rodoviária". Assim, ao usar a relação semântica "tem_autor" desta instância, adicionase os autores relacionados a "rodoviária de Jaú", dando também uma ponderação do peso ao termo "rodoviária". Após isso, recuperamos todos os documentos relacionados à consulta expandida.

E para a técnica "Não-expandida", se relaciona à indexação de termos, mas não utiliza a ontologia. Esta técnica alcança o valor de $56.3 \%$ para precisão, o valor de 
$100 \%$ para a cobertura e uma medida-F de $72.1 \%$. Isto ocorre pois todos os documentos recuperados possuem algum termo relacionado à consulta.

A técnica "Expandida" apresenta uma precisão de 43.3\%, uma cobertura de $100 \%$ e uma medida-F de $60.4 \%$. Embora esta técnica use a ontologia para adicionar novos termos relacionados a "rodoviária de Jaú", não foi suficiente para recuperar todos os documentos relevantes.

Observou-se também o resultado com a "Busca-booleana", a qual apresenta uma cobertura de $100 \%$ e uma precisão de $42.9 \%$ com uma medida-F de $60 \%$. Isto indica que, embora tenha sido possível recuperar todos os documentos relacionados aos termos da consulta com o uso do operador OR, nem todos os documentos recuperados eram relevantes.

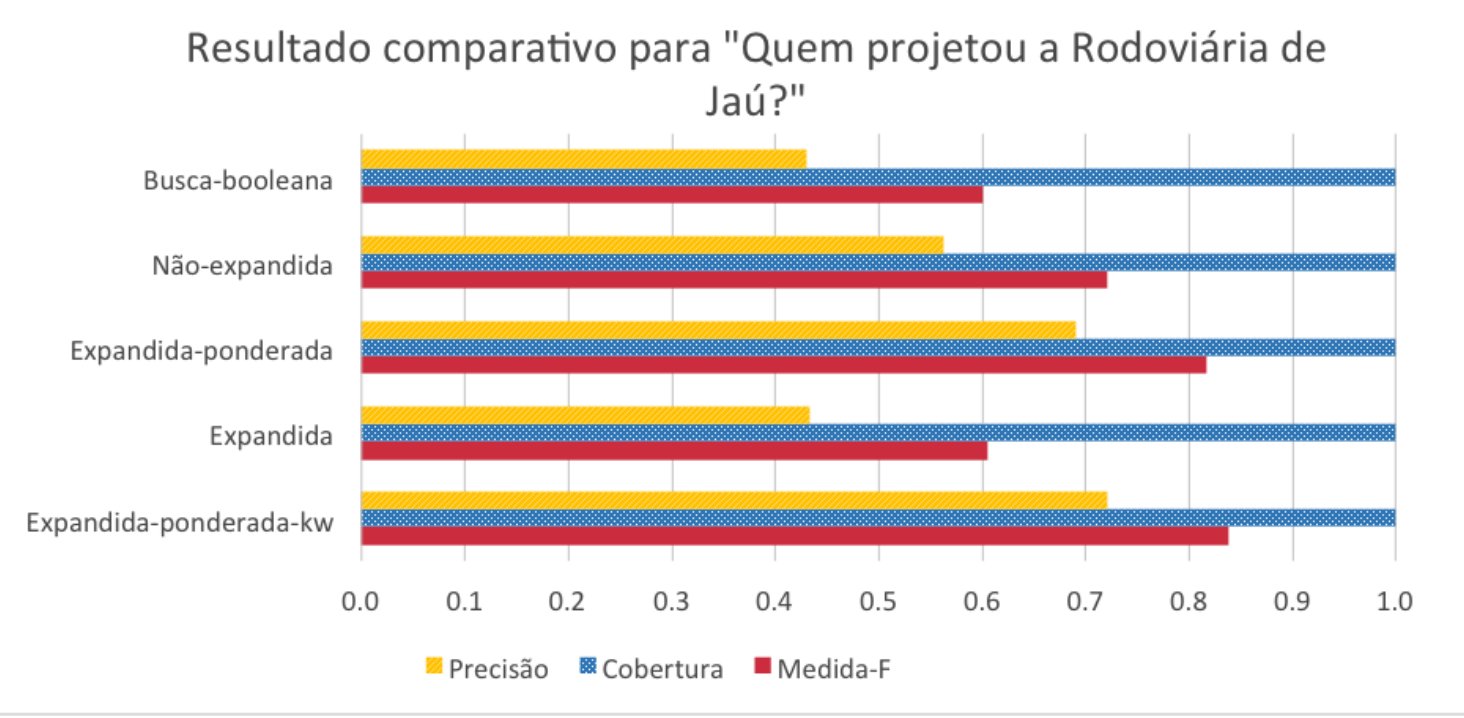

Figura 4.6: Resultado comparativo da consulta "Quem projetou a rodoviária de Jaú?" .

- A Figura 4.7 mostra um resultado comparativo de todas as técnicas utilizadas para a consulta "Onde encontro casas de madeira no Pará?". Ela revela que a técnica "Expandida-ponderada" alcança um resultado levemente superior ao da técnica "Expandida" e "Expandida-ponderada-kw".

Ressaltamos que as três técnicas usaram a ontologia para obtenção de melhores resultados, porém, a última técnica também usa a técnica "Não expandida", estas técnicas mencionadas foram superiores aos resultados da busca booleana.

A leve melhoria é devida, por um lado, à ocorrência do termo "madeira" na ontologia como instância da classe "material de construção" e, de outro, porque o termo "Pará" é reconhecido como token de lugar. Assim, ao consultar os termos relacionados a "Pará", a busca retorna as cidades que pertencem ao estado do Pará, tomadas como termos 
expandidos. Por consequência, ao recuperar os documentos desta consulta, também são recuperados os documentos que contêm os termos expandidos como, por exemplo, "Belém".

Contudo, quando não é empregada a expansão de termos, são recuperados apenas os documentos que contém os termos "casas", "madeira" ou "Pará". O que significa que muitos documentos relevantes não foram recuperados e outros não relevantes foram recuperados.

Observou-se também o resultado com a "Busca booleana", a qual apresenta um valor de $100 \%$ para a cobertura e um valor de $4.6 \%$ para precisão. Isto indica que, embora tenha sido possível recuperar todos os documentos relacionados aos termos da consulta com o operador OR, nem todos os documentos recuperados eram relevantes.

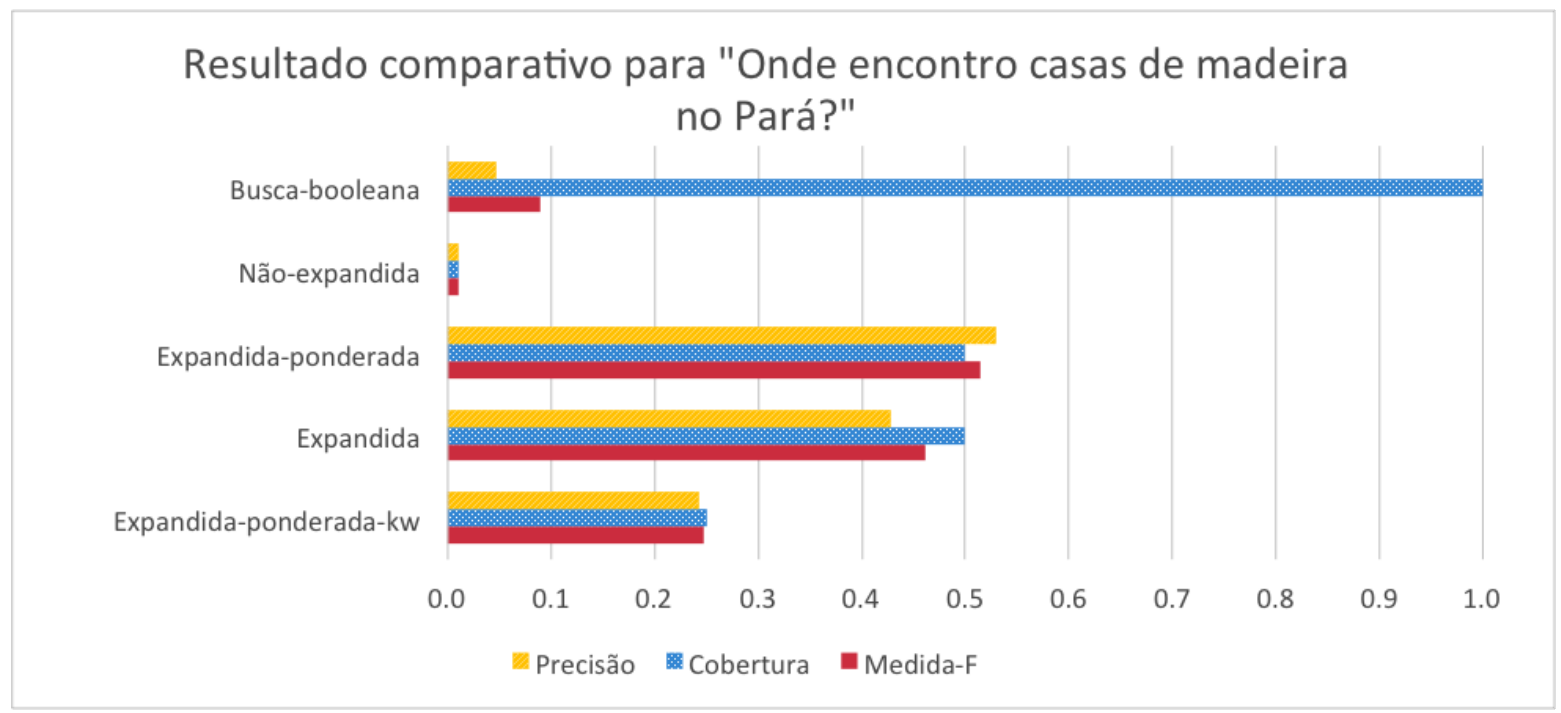

Figura 4.7: Resultado comparativo para "Onde encontro casas de madeira no Pará."

c) Em terceiro lugar, mostraremos a comparação dos resultados de algumas consultas extraídas do "Log do Analytics" do sistema Arquigrafia, que foram consideradas importantes para nossos experimentos.

Utilizamos o conjunto de consultas que possuíam termos implícitos, como por exemplo a consulta "Edifício de Educação", que possui informação implícita, como "escola", "faculdade", etc., os quais são tipos de "Edifícios de Educação".

Ao comparar as diferentes técnicas que utilizam ou não a ontologia, para o limiar mínimo de similaridade de 0.07 , pode-se observar que o uso da ontologia para este tipo de consulta melhora os resultados para a precisão e cobertura.

- Por exemplo a consulta "Edifícios de educação", a Figura 4.8 apresenta um resultado comparativo das técnicas utilizadas para a consulta Edifícios de educação, na qual a 
técnica "Expandida" teve um valor de $91.4 \%$ para a medida-F, que é levemente melhor que a técnica "Expandida-ponderada-kw", a qual tem uma medida-F de $75.6 \%$ e "Expandida-ponderada", que tem uma medida-F de $74.1 \%$.

As três técnicas utilizam a ontologia para melhorar seus resultados. Porém, a técnica "Expandida-ponderada-kw" também utiliza a técnica "Não expandida" (não usa a ontologia) multiplicado por 0.3 .

Para a primeira técnica obteve-se o valor $98.6 \%$ para a precisão e o valor de $85.2 \%$ para a cobertura. Para a segunda técnica, obteve-se o valor $67.5 \%$ para a precisão e o valor de $85.9 \%$ para a cobertura. Quanto à terceira técnica, obteve-se o valor $66.6 \%$ para a precisão e o valor de $83.3 \%$ para a cobertura.

Os resultados dessas três técnicas foram melhores que o resultado da técnica "não expandida" e da "busca booleana", o que se deve ao fato de elas não utilizarem a ontologia.

A melhoria dos resultados das técnicas que usam a ontologia para esta consulta, é devida à ocorrência dos termos "Edifício de educação", os quais existem na ontologia como classe, permitindo, assim, a adição de novos termos, utilizando a sua hierarquia. A classe "Edifício de educação" está composta pelas subclasses "universidades", "escolas", "institutos" e "faculdades".

Portanto, estes termos são adicionados à consulta para conseguir recuperar os documentos (das imagens) relacionados a eles. Contudo, quando não foi utilizada a expansão de termos, foram recuperados documentos que possuíam somente os termos "edifícios" ou "educação", como é o caso da "Busca booleana" e da técnica "Não-expandida". A busca booleana obteve o valor de $9.0 \%$ para a precisão e um valor de $35.0 \%$ para a cobertura. Isto ocorre pois ela usa o operador "or " que recupera todos os documentos relacionados a cada termo da consulta, e muitos deles não são relevantes para tal consulta.

A técnica "Não-expandida" teve o valor de $2.0 \%$ para precisão e o valor de $3.0 \%$ para a cobertura, pois ela só consegue recuperar os documentos que contêm os termos da consulta. 


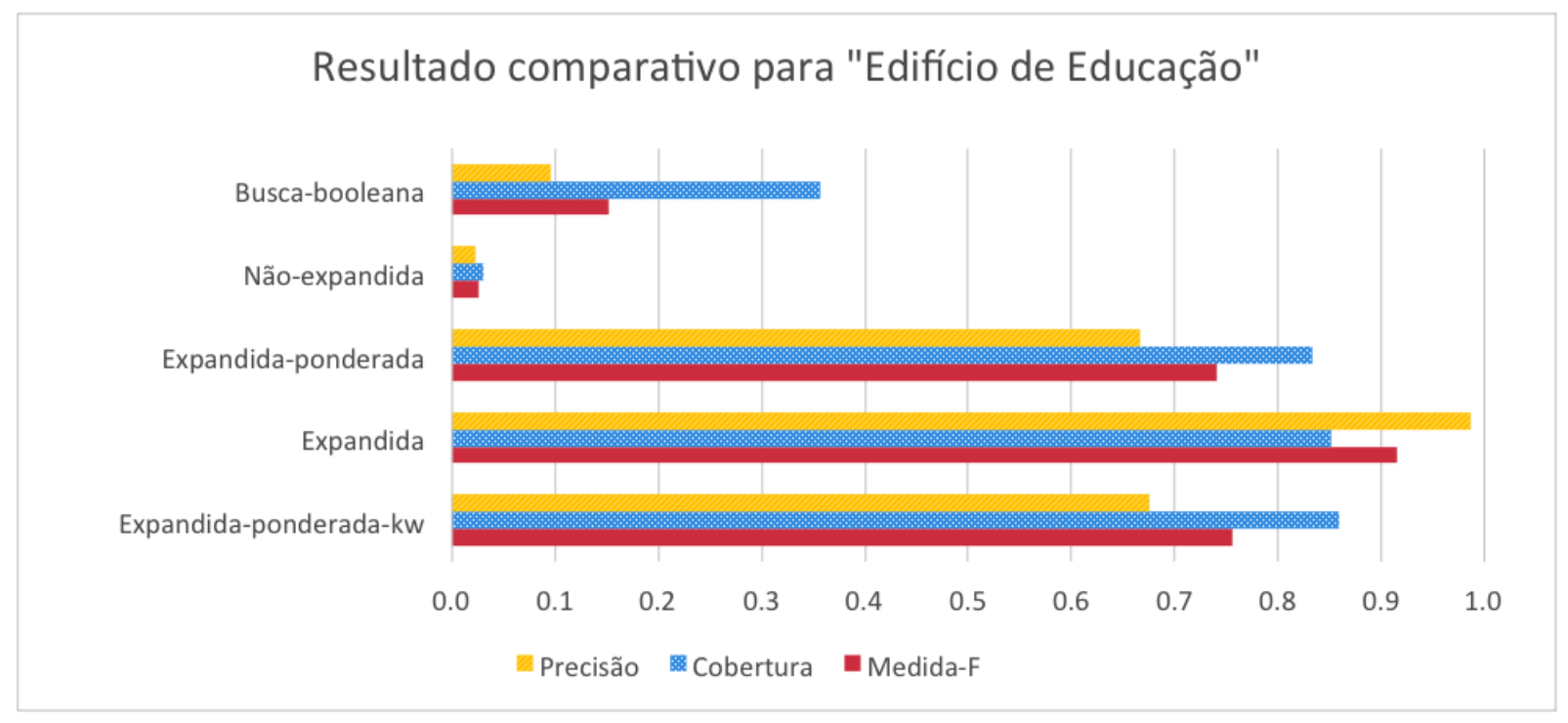

Figura 4.8: Resultado comparativo para "Edifícios de educação".

- Para a consulta "Residência do arquiteto Joaquim Guedes", conforme podemos observar na Figura 4.9, os resultados para as técnicas "Expandida-ponderada" e "Expandidaponderada-kw" alcançam uma medida-F de $60.4 \%$ e $47.7 \%$ respectivamente.

Ambas técnicas utilizam a ontologia e os resultados delas foram maiores do que as técnicas "Não-expandida", "Expandida" e "Busca-booleana", pois o valor da medida-F destas últimas técnicas são de $39.4 \%$, 19.2\% e 7.57\% respectivamente.

A melhoria dos resultados das técnicas "Expandida-ponderada" e "Expandidaponderada-kw" é devida a duas situações: a primeira é pela ocorrência dos termos "Joaquim Guedes", os quais existem na ontologia como uma instância da classe autor_da_obra; a segunda é pela ponderação do peso do termo residência, isto ocorre, porque o termo residência está associada à classe edifício residencial e pertence à hierarquia principal. Assim, ao executar a consulta, para o termo "Joaquim Guedes" são adicionadas as construções que estão relacionadas a este arquiteto. Após, este procedimento temos a consulta expandida, para logo ser utilizada com o modelo vetorial para recuperar os documentos(das imagens) relacionados aos termos da consulta.

Contudo, quando utilizamos as técnicas "Não-expandida", "Expandida" e "Buscabooleana" conseguem recuperar todos os documentos relacionados aos termos da consulta, porém o valor da precisão destas técnicas é menor em comparação com as técnicas que usam a ontologia.

Para o caso da técnica "Não-expandida" obteve-se o valor de $24.5 \%$ para a precisão e o valor de $100 \%$ para a cobertura, com o valor de $39.4 \%$ para sua medida-F.

Quanto à "Expandida" obteve o valor de $11.5 \%$ para a precisão e o valor de $57.1 \%$ para a cobertura, com o valor de $19.2 \%$ para sua medida-F, os resultados para esta técnica 
foram baixos mesmo ela utilizando a ontologia. Isto ocorre, porque vários termos foram adicionados à consulta inicial, causando que o vetor da consulta seja grande e com isso o valor de similaridade seja muito pequeno, menor ao limiar 0.07 .

E para a "Busca-booleana", obteve-se o valor de 3.9\% para a precisão e o valor de $100 \%$ para a cobertura, com o valor de $7.5 \%$ para sua medida-F. Esta última técnica teve uma precisão muito baixa, pois ela usou o operador OR para recuperar todos os documentos relacionados a cada termo da consulta, e muitos deles não são relevantes para a consulta.

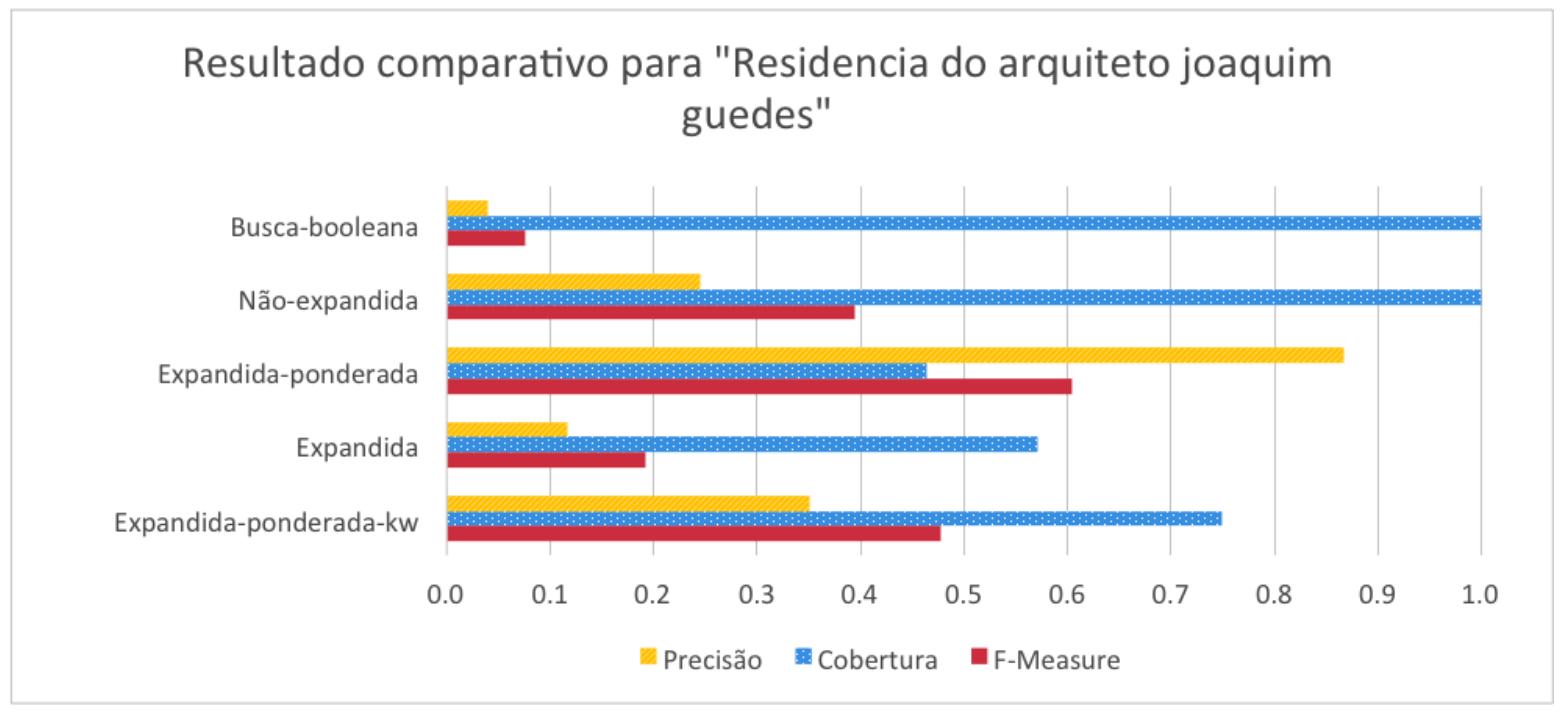

Figura 4.9: Resultado comparativo para "Residência do arquiteto Joaquim Guedes".

\subsection{Discussão}

Como temos visto ao longo deste trabalho, nossa abordagem apoia-se sobretudo na representação do conhecimento criado na ontologia, a qual introduz relações semânticas entre os termos da consulta no processo de recuperação, à diferença das técnicas tradicionais, como é a busca booleana.

Na seção anterior (avaliação dos resultados da abordagem), utilizamos as questões de competência e as consultas extraídas dos logs de busca do Analytics de Arquigrafia para avaliar se o uso da ontologia integrado ao sistema de recuperação aprimorava a recuperação dos documentos.

Como parâmetro de verificação, utilizamos as métricas de precisão, cobertura e medida-F. Assim, pelos resultados obtidos nos experimentos, nos casos em que usamos as questões de competência como consulta, observamos que a ontologia integrada ao sistema de recuperação obteve um comportamento distinto em cada consulta. Isso ocorre porque existem diferentes tipos de consulta, os quais podem ser divididos em três subgrupos.

O primeiro subgrupo de consultas é composto pelos termos: "quem", "autor" e "projetou" - os quais referem-se aos termos relacionados a uma dada edificação (ou instância). Como exemplo de 
consulta desse caso, temos: "Quem é o autor do projeto da Praça do Relógio?", ou ainda, "Quem projetou a Rodoviária de Jaú?".

Em nossa abordagem, alcançamos um valor de precisão entre $69 \%$ e 100\%, um valor de cobertura de $100 \%$ e uma medida-F entre $82 \%$ e $100 \%$ ao passo que na busca booleana encontramos um valor de precisão menor que $0.43 \%$, um valor de cobertura de $100 \%$ e um valor de medida-F menor ou igual a $60 \%$.

Pela avaliação dos resultados, concluímos que, no caso da nossa abordagem, os resultados são mais favoráveis; isto é, o uso da propriedade ou relação semântica "tem_autor" permite a adição de novos termos relacionados aos autores dessas edificações. Assim, obtivemos uma consulta expandida que, ao ser utilizada no processo de recuperação, foi capaz de recuperar os documentos mais relevantes para a consulta.

O segundo subgrupo de consultas é composto pelos termos relacionados a uma edificação genérica (subclasse), termos relacionados ao "material" ou "sistema construtivo" e os termos relacionados a lugar; como por exemplo: "Onde encontro casas de madeira no Para?".

Para essa consulta, nossa abordagem obteve uma medida-F de $51 \%$, ao passo que na busca booleana encontramos uma medida-F de $0.09 \%$. Isto se deve ao uso da propriedade "eh_material", que permite a adição de termos que pertencem às edificações (instâncias) constituídas desse material - no nosso exemplo, isso equivale às edificações construídas em madeira.

Como as edificações são numerosas, há um limite de adição de termos obtido empiricamente. Esse valor limita-se a cerca de 15 elementos. Em seguida, obtivemos a consulta expandida que compreende os novos termos de edificações específicas, facilitando, assim, o processo de recuperação de documentos relevantes.

No entanto, nos experimentos realizados, notamos que, se os termos relacionados a uma dada edificação pertencerem a uma classe muito genérica, como nos casos das classes "construcao_arquitetônica" e "construcao", isso pode afetar os resultados.

Tal é observado com a consulta "Existem edifícios em vidro construídos no Brasil?", o qual, ainda que tenha obtido uma precisão elevada (88\%), apresentou, contudo, uma cobertura e medida-F muito baixas $(0.02 \%$ e $0.03 \%$, respectivamente).

Isso ocorre, pois nas classes mencionadas, o nível de hierarquia é mais profundo que o de outras classes e o de uma grande quantidade de subclasses. Assim, ao adicionar novos termos relacionados a essas mesmas classes, a consulta expandida obterá um número grande de termos.

Consecutivamente, ao calcular a similaridade entre a consulta expandida e os documentos, os valores de similaridade aproximam-se de zero. E, como consideramos o valor de similaridade mínimo como sendo maior que 0.03 (limiar), documentos com valor de similaridade menor que o limiar não serão retornados.

O terceiro subgrupo de consultas é composto pelos termos relacionados a uma edificação genérica (classe), os termos relacionados ao nome de autor (instância) e os termos relacionados a 
lugar; como por exemplo: "Quais os edifícios projetados por Macedo Silvio Soares em São Paulo?". Para esse tipo de consulta, nossa abordagem obteve uma medida-F entre $93 \%$ e $100 \%$, ao passo que na busca booleana encontramos uma medida-F menor que $0.08 \%$. Consideramos que os primeiros resultados, mais favoráveis, devem-se ao uso, em nossa abordagem, da propriedade ou relação semântica "eh_autor", a qual permite a adição de novos termos relacionados às edificações projetadas pelos autores específicos.

Desse modo, também obtivemos uma consulta expandida que contribuiu para o processo de recuperação de documentos relevantes.

Nos experimentos realizados, observamos que o uso de ontologias como ferramenta de apoio na recuperação de informação, quando comparado à recuperação tradicional, baseada em palavraschave ou busca booleana, é mais eficiente. Isso se deve ao uso que a ontologia faz da hierarquia e das relações semânticas para a adição de novos termos à consulta original, criando uma consulta expandida que, quando utilizada no processo de recuperação, permite retornar mais documentos relevantes à consulta do usuário. 


\section{Capítulo 5}

\section{Conclusões}

O propósito deste trabalho é contribuir para a melhoria da recuperação de informação em sistemas colaborativos no domínio da Arquitetura que não possuem conteúdos controlados devido à livre inserção de títulos e tags. Com este fim, construímos a ontologia OntoArq utilizando o Vocabulário Controlado da área de Arquitetura, o Tesauro Experimental de Arquitetura e os dados do sistema Arquigrafia.

Os registros do sistema Arquigrafia apresentam termos relevantes, como por exemplo: títulos, descrições e tags. Procurou-se as relações existentes entre os títulos e as tags, e as descrições e as tags com a finalidade de dar um maior significado às tags. No entanto, não foi possível encontrar as relações nos casos em que as tags não pertenciam ao domínio da Arquitetura, como por exemplo, nos termos: "bandeira", "açúcar", "base", "mar". Ainda que estes termos não estejam associados a nenhuma classe ou instância da ontologia, contudo, eles ainda serão utilizados no processo de recuperação. Isso ocorre pois, no processo de indexação, tais termos estão indexados a um documento.

Nossa abordagem foi realizada em quatro fases. A primeira consistiu na construção da ontologia OntoArq. O objetivo de tal procedimento era a criação de conceitos relacionados aos termos arquitetônicos e mapeamento dos termos genéricos das tags pelo emprego dos conceitos estruturados da ontologia, a fim de obtermos um significado mais preciso para as tags, possibilitando, assim, a sua recuperação, dentro do domínio da Arquitetura.

Para a construção da ontologia nos foi necessário empregar uma metodologia. No entanto, como não há até o momento uma metodologia padrão, tomamos a liberdade de selecionar uma que consideramos mais apropriada ao nosso trabalho. Optamos pela de Falbo et. al. descrita na seção 2.5, pois ela reúne os passos basilares para a construção de uma ontologia, tais como: identificação do propósito e especificação dos requisitos; captura da ontologia seguida de formalização e integração com as ontologias pré-existentes; e, por fim, avaliação e documentação da ontologia.

Além disso, identificamos uma constante interação entre alguns desses passos, como por exemplo: entre a construção da ontologia formal e a avaliação e documentação; e entre o propósito da construção e a avaliação e documentação. Isso permitiu a construção da ontologia de modo iterativo, resultando que, a cada iteração ou versão da ontologia construída, ela fosse reavaliada. Tal avaliação consiste em realizar consultas relacionadas às questões de competência e às quais a 
ontologia deve responder corretamente. Quando isso não acontece, é necessário "corrigir" a ontologia por meio da criação de uma nova iteração; um processo que se repete continuamente até que a ontologia realize o propósito para o qual foi criada.

Dentre os vários procedimentos desta fase, na captura da ontologia (visto na seção 3.3.2) desenvolvemos uma série de passos para a criação de classes, instâncias, propriedades e relações; sendo, ainda, que cada termo a ser criado para os nomes das classes, instâncias e propriedades dependeu do uso e propósito da ontologia. Desse modo, visto que parte de nossa abordagem tratou do modo como a ontologia se integra ao sistema de recuperação, foi necessário analisarmos quais termos seriam criados para o nome das classes, das propriedades e das instâncias. Utilizamos, para isso, os termos arquitetônicos existentes no vocabulário controlado da USP e no tesauro experimental. Porém, pela observação dos experimentos realizados, verificamos que os termos utilizados no processo não foram suficientes para recuperar os documentos de imagens relevantes. Isso ocorreu, pois as consultas relacionadas às questões de competência e aos logs de busca dos usuários continham termos arquitetônicos não existentes tanto no vocabulário controlado da USP quanto no tesauro experimental.

Por esse motivo, foi necessário criar classes, instâncias e propriedades equivalentes. Dessa forma, a maioria dos termos pertencentes à consulta puderam ser encontrados na ontologia, facilitando assim o seu processo de recuperação.

Por outro lado, para as fases relacionadas ao sistema de recuperação que desenvolvemos, foi utilizado o modelo de espaço vetorial. Já para a fase de indexação e pré-processamento, foi utilizada a indexação de palavras contidas em cada documento da coleção. A partir da observação dos experimentos, verificamos que a expansão dos termos pertencentes às tags, aos títulos e às descrições são úteis para a ampliação do significado semântico dos termos; por exemplo, para a tag "madeira", foi adicionado o termo "material" - os novos termos foram também indexados aos documentos (como vimos na seção 3.4). Dessa forma, quando a consulta contiver o termo "material", poderão ser recuperados todos os documentos que possuírem o termo madeira.

Na fase de processamento e similaridade de termos, o uso da ontologia nos permitiu calcular quão similares podem ser dois termos (o termo do índice invertido e o termo da ontologia) baseados na hierarquia e nas propriedades existentes na ontologia. Assim, se um termo similar a outro pertencer à consulta, este poderá ser utilizado na expansão da mesma.

Na fase de expansão da consulta e de recuperação de imagens, foram adicionados novos termos extraídos da hierarquia de classes, da relação semântica (ambas presentes na ontologia) e da estrutura de similaridade dos termos. Para isso, foi necessário considerar o limite de adição de novos termos e calcular, empiricamente, os pesos apropriados a cada termo adicionado. Assim, ao alterarmos qualquer um desses valores, o resultado do valor de similaridade dos documentos era alterado. 


\subsection{Análise dos resultados}

Para a análise dos resultados, realizamos 20 consultas a título de experimento. Entre essas, 11 se referiam às questões de competência e 9 aos logs de busca do Analytics do Arquigrafia.

Como resultado, obtivemos diferentes valores para as métricas de precisão, cobertura e medida$\mathrm{F}$, tanto nas técnicas que usam a ontologia, como para as que não a utilizam.

Pelos experimentos executados, atribuindo diferentes valores para o limiar de mínima similaridade, e utilizando o conjunto de consultas que contem as questões de competência, obtivemos resultados com um valor de precisão superior a $69 \%$, e valor de cobertura superior a $70 \%$ e um valor de medida-F superior a $81 \%$ que consideramos como "bom". E para resultados com uma precisão superior a $50 \%$, cobertura igual ou superior a $50 \%$ e medida-F superior a $50 \%$, consideramos como "aceitável". Os resultados obtidos devem-se ao o grau de complexidade da recuperação dos dados, contudo, pela nossa abordagem, conseguimos recuperar a maioria dos documentos relevantes em cada consulta.

Na tabela 5.1 mostra-se as consultas relacionadas às questões de competência e os valores obtidos das métricas de precisão $(P)$, cobertura $(C)$ e medida-F $(M-F)$ para todas as técnicas empregadas. Para leitura dos resultados completos de todas as questões de competência e técnicas empregadas, consultar tabela A.4 no apêndice A.

Para a técnica "Expandida-ponderada", que usa a ontologia, obtivemos, em sete consultas relacionadas às questões de competência, precisão mínima e máxima de 53\% e 100\%; cobertura, $50 \%$ e 100\%; e medida-F, $51 \%$ e 100\%. Entretanto, nas 4 questões de competência restantes, obtivemos resultados abaixo dos valores mínimos, sendo os valores da medida-F abaixo de $28 \%$. Estes resultados podem ser observados na tabela 5.1.

Para a técnica "Expandida", que usa a ontologia, obtivemos, em quatro consultas relacionadas às questões de competência, precisão mínima e máxima de $72 \%$ e 100\%; cobertura, $98 \%$ e 100\%; e medida-F, $84 \%$ e $100 \%$. Porém, nas 7 questões de competência restantes, obtivemos resultados abaixo dos valores mínimos, sendo os valores de precisão e medida-F abaixo de $45.28 \%$ e62.34\%, respectivamente. Estes resultados podem ser observados na tabela 5.1.

Os resultados da medida-F de ambas as técnicas acima mencionadas devem-se à utilização da ontologia para expandir os termos novos na consulta. De modo geral, tal procedimento permitiu recuperar documentos relevantes à consulta com precisão superior a 50\%. Contudo, a existência de consultas com valores de precisão e medida-F abaixo de $50 \%$, deve-se à complexidade de tais consultas, à existência de poucos termos nos documentos indexados e à dificuldade de associar os termos genéricos presentes nas tags e que não pertencem à área de arquitetura, nem existem como instância ou classe na ontologia construída.

Para a técnica "Expandida-ponderada-kw", que combina as técnicas de "Expandida-ponderada" e "Não-expandida", obtivemos, em cinco consultas relacionadas às questões de competência, precisão mínima e máxima de $72.06 \%$ e 100\%; cobertura, $66.67 \%$ e $100 \%$; e medida-F, $74.87 \%$ e $100 \%$. Entretanto, nas 6 questões de competência restantes, obtivemos resultados abaixo dos valores mínimos, sendo os valores da medida-F abaixo de 34.04\%. Estes resultados podem ser observados 


\begin{tabular}{|c|c|c|c|c|c|c|c|c|c|c|c|c|c|c|c|}
\hline \multirow[b]{2}{*}{ Consultas } & \multicolumn{3}{|c|}{$\begin{array}{l}\text { Expandida- } \\
\text { ponderada }\end{array}$} & \multicolumn{3}{|c|}{ Expandida } & \multicolumn{3}{|c|}{$\begin{array}{l}\text { Expandida- } \\
\text { ponderada- } \\
\text { kw }\end{array}$} & \multicolumn{3}{|c|}{$\begin{array}{l}\text { Não ex- } \\
\text { pandida }\end{array}$} & \multicolumn{3}{|c|}{$\begin{array}{l}\text { Busca- } \\
\text { boolena }\end{array}$} \\
\hline & $\mathrm{P}$ & $\mathrm{C}$ & $\begin{array}{l}\text { M- } \\
\text { F }\end{array}$ & $\mathrm{P}$ & $\mathrm{C}$ & $\begin{array}{l}\text { M- } \\
\text { F }\end{array}$ & $\mathrm{P}$ & $\mathrm{C}$ & $\begin{array}{l}\text { M- } \\
\text { F }\end{array}$ & $\mathrm{P}$ & $\mathrm{C}$ & $\begin{array}{l}\text { M- } \\
\text { F }\end{array}$ & $\mathrm{P}$ & $\mathrm{C}$ & $\begin{array}{l}\text { M- } \\
\text { F }\end{array}$ \\
\hline $\begin{array}{llr}\text { Quem é } & \text { o au- } \\
\text { tor do projeto } \\
\text { da Praça } & \text { do } \\
\text { Relógio? } & \end{array}$ & 0.72 & 1.00 & 0.84 & 0.72 & 1.00 & 0.84 & 0.73 & 1.00 & 0.84 & 0.77 & 1.00 & 0.87 & 0.03 & 1.00 & 0.06 \\
\hline $\begin{array}{l}\text { Existem edifícios } \\
\text { em vidro cons- } \\
\text { truídos no Brasil? }\end{array}$ & 0.88 & 0.02 & 0.03 & 0.88 & 0.02 & 0.03 & 0.84 & 0.02 & 0.05 & 0.82 & 0.11 & 0.20 & 0.99 & 1.00 & 1.00 \\
\hline \begin{tabular}{lr}
\multicolumn{3}{l}{ Quais os edifícios } \\
projetados & por \\
Macedo & Silvio \\
Soares em & São \\
Paulo? &
\end{tabular} & 0.88 & 0.98 & 0.93 & 0.88 & 0.98 & 0.93 & 0.85 & 0.67 & 0.75 & 0.14 & 0.17 & 0.15 & 0.04 & 1.00 & 0.08 \\
\hline $\begin{array}{l}\text { Existem edifícios } \\
\text { projetados por } \\
\text { Plinio Croce no } \\
\text { interior do estado } \\
\text { de São Paulo? }\end{array}$ & 1.00 & 1.00 & 1.00 & 0.45 & 1.00 & 0.62 & 0.21 & 1.00 & 0.34 & 0.06 & 1.00 & 0.11 & 0.01 & 1.00 & 0.02 \\
\hline $\begin{array}{l}\text { Quem projetou a } \\
\text { Biblioteca Brasi- } \\
\text { liana? }\end{array}$ & 1.00 & 1.00 & 1.00 & 1.00 & 1.00 & 1.00 & 1.00 & 1.00 & 1.00 & 0.06 & 1.00 & 0.11 & 0.07 & 1.00 & 0.13 \\
\hline $\begin{array}{l}\text { Onde encontro } \\
\text { casas de madeira } \\
\text { no Pará? }\end{array}$ & 0.53 & 0.50 & 0.51 & 0.43 & 0.50 & 0.46 & 0.24 & 0.25 & 0.25 & 0.00 & 0.00 & - & 0.05 & 1.00 & 0.09 \\
\hline \begin{tabular}{lr} 
As & \multicolumn{2}{c}{ palafitas } \\
típicas da ha- \\
bitação ribeiri- \\
nha no Norte do \\
Brasil, podem \\
ser vistas em \\
que lugares da \\
Amazônia?
\end{tabular} & 0.77 & 1.00 & 0.87 & 0.77 & 1.00 & 0.87 & 0.77 & 1.00 & 0.87 & 0.22 & 1.00 & 0.36 & 0.01 & 1.00 & 0.02 \\
\hline $\begin{array}{l}\text { Quem projetou } \\
\text { a Rodoviária de } \\
\text { Jaú? }\end{array}$ & 0.69 & 1.00 & 0.82 & 0.43 & 1.00 & 0.60 & 0.72 & 1.00 & 0.84 & 0.56 & 1.00 & 0.72 & 0.43 & 1.00 & 0.60 \\
\hline
\end{tabular}

Tabela 5.1: Resultados das métricas para consultas relacionadas às questões de competência.

na tabela 5.1.

Para a técnica "Não-expandida", a qual não usa a ontologia mas utiliza o modelo de espaço vetorial, obtivemos, em dois consultas relacionadas às questões de competência, uma precisão mínima e máxima de $56.32 \%$ e $76.64 \%$; cobertura de $100 \%$; e medida-F entre $72.06 \%$ e $86.78 \%$. Porém, nas 9 questões de competência restantes, obtivemos resultados abaixo dos valores mínimos, sendo os valores de precisão e medida-F abaixo de $43.33 \%$ e $53.28 \%$, respectivamente. Estas duas consultas foram Quem é o autor do projeto da Praça do Relógio? e Quem projetou a Rodoviária de Jaú?, para as quais também obteve-se resultados aceitáveis empregando as técnicas que utilizaram a ontologia. Estes resultados podem ser observados na tabela 5.1.

Para a técnica "Busca-booleana", a qual não usa a ontologia, obtivemos, em 1 consulta relacio- 
nada às questões de competência, precisão de $99 \%$; cobertura de 100\%; e medida-F de 99\%. Porém, nas 10 questões de competência restantes, obtivemos resultados abaixo dos valores mínimos, sendo os valores de precisão e medida-F abaixo de $42 \%$ e $60.12 \%$, respectivamente. Esta consulta foi Existem edifícios em vidro construídos no Brasil?, para a qual não obtivemos resultados aceitáveis empregando as técnicas que utilizaram a ontologia. Estes resultados podem ser observados na tabela 5.1.

Pelos resultados acima descritos, podemos observar que as técnicas que não usaram a ontologia recuperaram um número de documentos relevantes menor do que as técnicas que a utilizaram. Isso ocorre, pois as técnicas que não a utilizam só recuperam documentos que contenham os exatos termos da consulta, seja utilizando os pesos dos termos da consulta (técnica "Não expandida"), seja utilizando os operadores booleanos em combinação com os termos ("Busca booleana").

Assim, concluímos que as técnicas que utilizam a ontologia alcançam resultados mais satisfatórios do que as técnicas que não as utilizam.

\subsection{Contribuições do trabalho}

- A principal contribuição deste trabalho consiste na construção de uma ontologia para a área da Arquitetura Brasileira, a partir do emprego do Tesauro Experimental de Arquitetura e do vocabulário controlado da área da arquitetura do SIBi/USP. Para validar a ontologia construída, realizamos consultas na linguagem SPARQL para as questões de competência.

- Implementação de um sistema de recuperação de informação de imagens, para consultas realizadas em linguagem "natural". O sistema utilizou a ontologia como base de conhecimento para a expansão das consultas, permitindo assim que a busca não fosse feita apenas pelo uso de palavras-chave.

- Verificações de consultas para observar o comportamento das ontologias como ferramenta de apoio na recuperação de dados e imagens em sistemas colaborativos, como é o caso do sistema Arquigrafia.

\subsection{Trabalhos futuros}

- A população da ontologia foi realizada por meio da análise dos dados existentes no sistema Arquigrafia. Tal processo apresentou certa dificuldade no momento de classificarmos o conteúdo dos registros mais genéricos do banco de dados e associá-los a conceitos ou instâncias da ontologia. Decorrente disso, a população de dados teve de ser realizada manualmente, exigindo maior tempo para isso. Uma alternativa para solucionar este problema é usar o paradigma OBDA (Ontology Based Data Acess), na qual é possível recuperar informação a partir do banco de dados ao invés de instâncias existentes na ontologia. Para isso, é necessário criar os mapeamentos entre os conceitos e relações da ontologia e o banco de dados [27].

- Para automatização do processo de população da ontologia, seria recomendada a utilização de um algoritmo de aprendizado para a classificação de termos. Tal procedimento permitiria a 
inserção de mais dados, influindo positivamente nos resultados das consultas realizadas pelos usuários.

- Para a construção da ontologia, demos ênfase apenas aos termos relacionados à "arquitetura", deixando em segundo plano os termos relacionados a "urbanismo". Para ampliação da ontologia, portanto, seria recomendada também a inclusão desses termos à mesma, com o apoio de um especialista de domínio o que influenciaria diretamente em melhorias na obtenção de resultados.

- A recuperação de documentos em consultas complexas, realizadas em linguagem natural, pode ser aprimorada utilizando técnicas que permitam identificar o conteúdo semântico da consulta e transformá-las automaticamente em consultas SPARQL. Esta abordagem foi iniciada na dissertação "Consulta a Ontologias utilizando Linguagem Natural Controlada" [31]. A utilização da linguagem SPARQL permite que as consultas sejam respondidas diretamente pela ontologia, levando à recuperação de documentos relevantes e, portanto, a um retorno mais amplo dos resultados. 


\section{Apêndice A}

\section{Fonte de dados associadas}

\section{A.1 Dicionário de termos arquitetônicos}

O dicionário contém a descrição dos termos pertencentes ao área da arquitetura utilizados na criação das classes da ontologia.

Na tabela A.1 mostra-se as descrições das classes, subclasses e instâncias pertencentes à ontologia.

Na tabela A.2 são descritas as propriedades de objeto e as relações derivadas pela utilização destas propriedades.

Na tabela A.3 descreveremos as propriedades de dados.

Na tabela A.4 mostra-se os resultados para as métricas de precisão $(P)$, cobertura $(C)$ e medidaF $(M-F)$ das técnicas empregadas para as as questões de competência, consultas obtidas do $L o g$ do Analytics e consultas adicionais.

\begin{tabular}{|c|c|c|c|c|c|c|c|c|c|c|c|c|c|c|c|}
\hline & \multicolumn{3}{|c|}{$\begin{array}{l}\text { Expandida- } \\
\text { ponderada }\end{array}$} & \multicolumn{3}{|c|}{ Expandida } & \multicolumn{3}{|c|}{$\begin{array}{l}\text { Expandida- } \\
\text { ponderada- } \\
\text { kw }\end{array}$} & \multicolumn{3}{|c|}{$\begin{array}{l}\text { Não ex- } \\
\text { pandida }\end{array}$} & \multicolumn{3}{|c|}{$\begin{array}{l}\text { Busca- } \\
\text { boolena }\end{array}$} \\
\hline Consultas & $\mathrm{P}$ & $\mathrm{C}$ & $\begin{array}{l}\text { M- } \\
\text { F }\end{array}$ & $\mathrm{P}$ & $\mathrm{C}$ & $\begin{array}{l}\text { M- } \\
\text { F }\end{array}$ & $\mathrm{P}$ & $\mathrm{C}$ & $\begin{array}{l}\text { M- } \\
\text { F }\end{array}$ & $\mathrm{P}$ & $\mathrm{C}$ & $\begin{array}{l}\text { M- } \\
\text { F }\end{array}$ & $\mathrm{P}$ & $\mathrm{C}$ & $\begin{array}{l}\text { M- } \\
\text { F }\end{array}$ \\
\hline $\begin{array}{l}\text { Quem é o au- } \\
\text { tor do projeto } \\
\text { da Praça do } \\
\text { Relógio }\end{array}$ & 0.72 & 1.00 & 0.84 & 0.72 & 1.00 & 0.84 & 0.73 & 1.00 & 0.84 & 0.77 & 1.00 & 0.87 & 0.03 & 1.00 & 0.06 \\
\hline $\begin{array}{lr}\text { Existem } & \\
\text { edifícios } & \text { em } \\
\text { vidro } & \text { cons- } \\
\text { truídos } & \text { no } \\
\text { Brasil } & \end{array}$ & 0.88 & 0.02 & 0.03 & 0.88 & 0.02 & 0.03 & 0.84 & 0.02 & 0.05 & 0.82 & 0.11 & 0.20 & 0.99 & 1.00 & 1.00 \\
\hline
\end{tabular}




\begin{tabular}{|c|c|c|c|c|c|c|c|c|c|c|c|c|c|c|c|}
\hline $\begin{array}{lr}\text { Quais } & \text { os } \\
\text { edifícios } & \text { pro- } \\
\text { jetados } & \text { por } \\
\text { Macedo } & \text { Silvio } \\
\text { Soares em São } & \\
\text { Paulo } & \\
\end{array}$ & 0.88 & 0.98 & 0.93 & 0.88 & 0.98 & 0.93 & 0.85 & 0.67 & 0.75 & 0.14 & 0.17 & 0.15 & 0.04 & 1.00 & 0.08 \\
\hline $\begin{array}{lr}\text { Existem } & \\
\text { edifícios } & \text { pro- } \\
\text { jetados } & \text { por } \\
\text { Plinio Croce } & \\
\text { no interior do } \\
\text { estado de São } \\
\text { Paulo }\end{array}$ & 1.00 & 1.00 & 1.00 & 0.45 & 1.00 & 0.62 & 0.21 & 1.00 & 0.34 & 0.06 & 1.00 & 0.11 & 0.01 & 1.00 & 0.02 \\
\hline $\begin{array}{l}\text { Quem proje- } \\
\text { tou a Biblio- } \\
\text { teca Brasiliana }\end{array}$ & 1.00 & 1.00 & 1.00 & 1.00 & 1.00 & 1.00 & 1.00 & 1.00 & 1.00 & 0.06 & 1.00 & 0.11 & 0.07 & 1.00 & 0.13 \\
\hline $\begin{array}{lr}\text { Quais } & \text { edifícios } \\
\text { foram } & \text { pro- } \\
\text { jetados } & \text { por } \\
\text { Gian } & \text { Carlo } \\
\text { Gasperini no } & \text { nosil } \\
\text { Bras }\end{array}$ & 0.80 & 0.04 & 0.08 & 0.80 & 0.04 & 0.08 & 0.67 & 0.04 & 0.08 & 0.43 & 0.69 & 0.53 & 0.19 & 1.00 & 0.31 \\
\hline $\begin{array}{l}\text { Onde encontro } \\
\text { casas de ma- } \\
\text { deira no Pará }\end{array}$ & 0.53 & 0.50 & 0.51 & 0.43 & 0.50 & 0.46 & 0.24 & 0.25 & 0.25 & 0.00 & 0.00 & - & 0.05 & 1.00 & 0.09 \\
\hline $\begin{array}{l}\text { As palafitas } \\
\text { típicas da } \\
\text { habitação } \\
\text { ribeirinha } \\
\text { no Norte do } \\
\text { Brasil, podem } \\
\text { ser vistas em } \\
\text { que lugares da } \\
\text { Amazônia }\end{array}$ & 0.77 & 1.00 & 0.87 & 0.77 & 1.00 & 0.87 & 0.77 & 1.00 & 0.87 & 0.22 & 1.00 & 0.36 & 0.01 & 1.00 & 0.02 \\
\hline
\end{tabular}




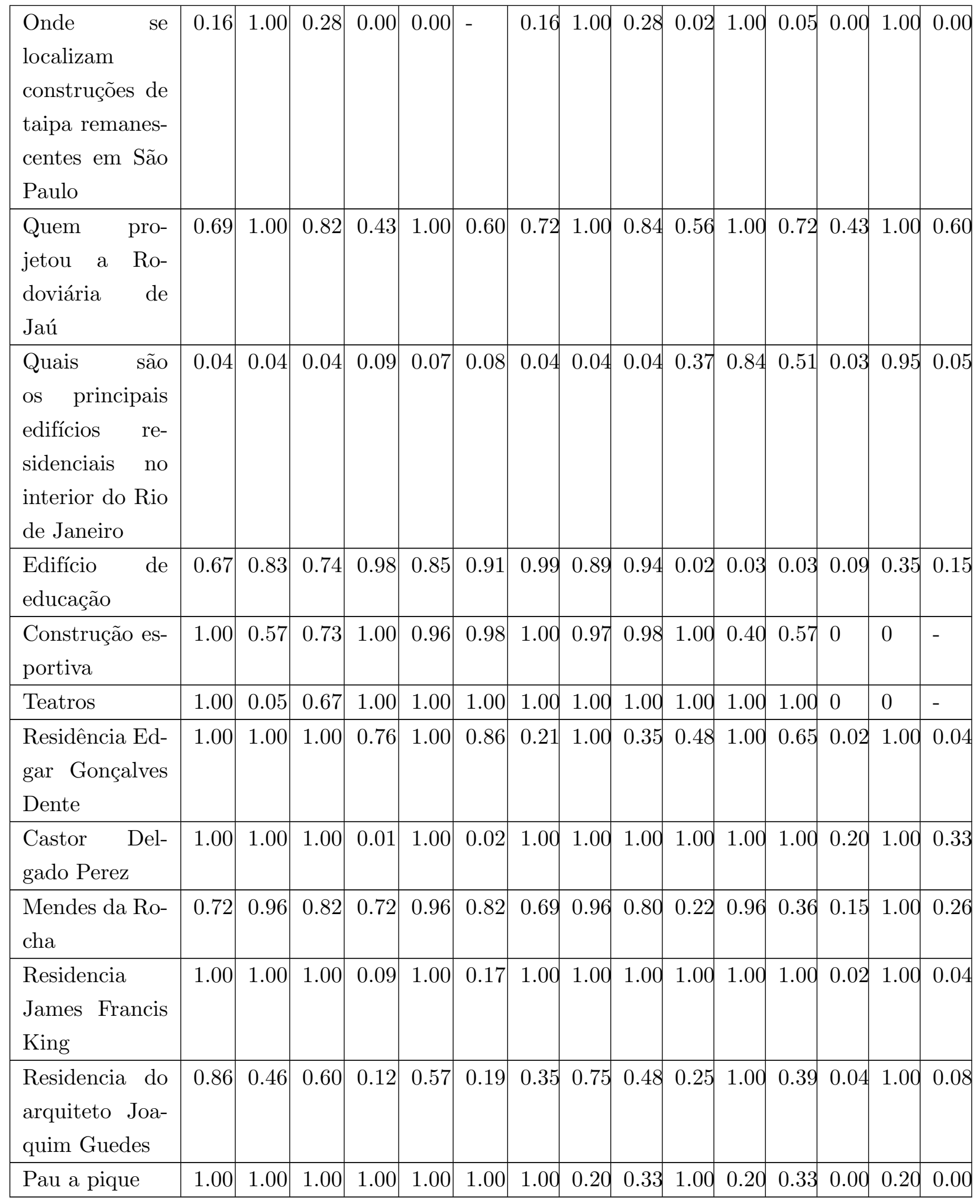

Tabela A.4: Resultados das métricas para consultas relacionadas às questões de competência. 


\begin{tabular}{|c|c|}
\hline Classes & Comentários e indivíduos \\
\hline Elemento_abertura. & $\begin{array}{l}\text { é um elemento de estrutura de vão (uma abertura na construção) que } \\
\text { são utilizados para complementar essa abertura, por exemplo o grade, } \\
\text { a persiana que pode ser utilizado junto com uma janela ou porta. }\end{array}$ \\
\hline Estrutura_abertura. & $\begin{array}{l}\text { são elementos que permitem a passagem do ar, da luz, do sol de } \\
\text { pessoas ou coisas, um exemplo disso são as janelas e as portas. }\end{array}$ \\
\hline Elemento_balanceado. & $\begin{array}{l}\text { é um elemento cuja proteção horizontal está fora do perímetro deter- } \\
\text { minado pelos componentes de sustentação da estrutura de uma obra, } \\
\text { um exemplo de estes elementos são balaustre, sacada entre outros. }\end{array}$ \\
\hline Elemento_elevado. & $\begin{array}{l}\text { é uma estrutura de elemento elevado que é localizado num plano su- } \\
\text { perior, por exemplo os elementos torre, campanário entre outros. }\end{array}$ \\
\hline Elemento_ornamental. & $\begin{array}{l}\text { ou estrutura do elemento ornamental, que é toda peça ou forma } \\
\text { acessória que se acrescenta a outro elemento com o objetivo de em- } \\
\text { belezá-lo, existindo uma relação entre a construção e a disposição do } \\
\text { elemento ornamental, como exemplo temos o elemento pináculo, vo- } \\
\text { luta entre outros. }\end{array}$ \\
\hline Elemento_sustentante. & $\begin{array}{l}\text { é uma estrutura do elemento sustentante, o qual é o elemento que } \\
\text { fornece o apoio a uma determinada carga, exemplo de estos elementos } \\
\text { são: coluna, muro, entre outros. }\end{array}$ \\
\hline Elemento_sustentado. & $\begin{array}{l}\text { é uma estrutura do elemento sustentado, na qual o elemento ou com- } \\
\text { ponente da construção apoia-se por cima de outro, temos por exemplo } \\
\text { a os tipos de arco, e os elementos de entablamento. }\end{array}$ \\
\hline Elemento_decorativo. & $\begin{array}{l}\text { recursos utilizados para complementar o ambiente arquitetônico. Por } \\
\text { exemplo elementos como cor, luminária, mobiliário. }\end{array}$ \\
\hline Sistema_construtivo. & $\begin{array}{l}\text { é uma estrutura de sistema construtivo, que tem diferentes estruturas } \\
\text { de materiais e técnicas que são utilizados numa construção particular. }\end{array}$ \\
\hline Sociologia_da_habitacao. & $\begin{array}{l}\text { é o tipo de habitação e sua relação com a sociedade, um exemplo são } \\
\text { as casas de padrão subnormal. }\end{array}$ \\
\hline Autor_da_obra. & é o responsável de uma construção específica. \\
\hline Estilo_arquitetonico. & $\begin{array}{l}\text { expressão utilizada na arquitetura no período da historia baseado nas } \\
\text { características formais, técnicas e materiais. Tem como indivíduos } \\
\text { estilo barroco, neoclássico, entre outros. }\end{array}$ \\
\hline Material_construcao. & $\begin{array}{l}\text { são produtos empregados na construção arquitetura. Por exemplo } \\
\text { cimento, ferro, gesso, madeira, entre outros. }\end{array}$ \\
\hline Objeto_geográfico. & $\begin{array}{l}\text { é o localização de alguma construção. Tem subclasses como cidade, } \\
\text { continente, estado, país. }\end{array}$ \\
\hline Construcao_arquitetonica. & $\begin{array}{l}\text { também conhecida como construção, tem várias subclasses, tais como } \\
\text { construcao_esportiva, construcao_espaco_verde, edificios_comerciais, } \\
\text { edificio_educacao, edificio_cultura, edificio_comunicacao, entre outros. }\end{array}$ \\
\hline Edifício_religioso. & $\begin{array}{l}\text { tem também subclasses como igreja, capela, catedral. Os indivíduos } \\
\text { para estas classes são os nomes de cada edifício. }\end{array}$ \\
\hline
\end{tabular}

Tabela A.1: Esta tabela mostra o dicionário de classes e subclasses e algumas instâncias de exemplo pertencentes à ontologia 


\begin{tabular}{|c|c|c|}
\hline $\begin{array}{l}\text { Propriedades } \\
\text { objeto }\end{array}$ & Comentários & Exemplos \\
\hline Contem & 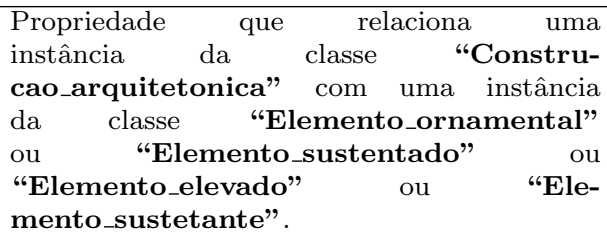 & $\begin{array}{l}\text { Catedral São Francisco Xavier con- } \\
\text { tem abóboda. }\end{array}$ \\
\hline Situado_em & $\begin{array}{l}\text { Propriedade que relaciona uma instância da } \\
\text { subclasse de "Construcao_arquitetonica" } \\
\text { com uma instância da classe "Ob- } \\
\text { jeto_geografico" }\end{array}$ & $\begin{array}{l}\text { Hospital Sul América situado_em Rio } \\
\text { de Janeiro. }\end{array}$ \\
\hline Tem_autor_da_obra & $\begin{array}{l}\text { Propriedade que relaciona uma instância } \\
\text { de uma subclasse da classe "Constru- } \\
\text { cao_arquitetonica" com uma instância da } \\
\text { classe "Autor_da_obra". }\end{array}$ & \begin{tabular}{ll} 
Biblioteca & \multicolumn{2}{c}{ Brasiliana } \\
tem_autor_da_obra & Eduardo de \\
Almeida. &
\end{tabular} \\
\hline Eh_material & $\begin{array}{l}\text { Propriedade que relaciona uma instância da } \\
\text { classe "Material_construcao" com uma } \\
\text { instância de alguma subclasse "Constru- } \\
\text { cao_arquitetonica". }\end{array}$ & $\begin{array}{l}\text { Ferro eh_material Museu de arte mo- } \\
\text { derna. }\end{array}$ \\
\hline Feito_de & $\begin{array}{l}\text { Propriedade que relaciona uma instância } \\
\text { da subclasse da classe "Constru- } \\
\text { cao_arquitetonica" com uma instância } \\
\text { da classe "Material_construcao". }\end{array}$ & $\begin{array}{l}\text { O estádio Jornalista Mario Filho Ma- } \\
\text { racanã feito_de ferro. }\end{array}$ \\
\hline Parte_de & $\begin{array}{l}\text { Propriedade que relaciona uma instância da } \\
\text { classe "Dependencia_habitacao" com uma } \\
\text { instância da subclasse da classe "Constru- } \\
\text { cao_arquitetonica". }\end{array}$ & $\begin{array}{l}\text { Rampa tparte_de Praça Dom José } \\
\text { Gaspar. }\end{array}$ \\
\hline
\end{tabular}

Tabela A.2: Esta tabela mostra as descrições das propriedades de objeto utilizadas na OntoArq.

\begin{tabular}{|c|c|c|}
\hline Propriedades de dados & Comentários & Exemplos \\
\hline tem_data_da_obra & $\begin{array}{l}\text { Esta propriedade registra a data de } \\
\text { construção de uma construção ar- } \\
\text { quitetônica. A propriedade é utili- } \\
\text { zada para relacionar uma instância da } \\
\text { classe "Construcao_arquitetonica" } \\
\text { com um literal como "dateTime" }\end{array}$ & 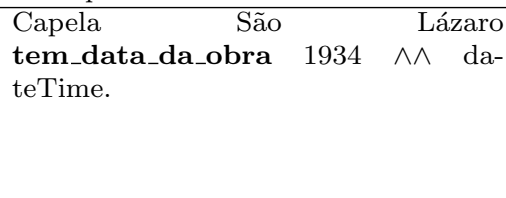 \\
\hline
\end{tabular}

Tabela A.3: Esta tabela mostra a descrição da propriedade de tipo de dado utilizada na ontologia. 


\section{Apêndice B}

\section{Sistema OntoArq}

Para nossa abordagem implementou-se uma API baseada nas 4 fases (seção 3.2). Também implementou-se um sistema web OntoArq, que utiliza a API mencionada para realizar diversas consultas de construções arquitetônicas que foram extraídas do sistema Arquigrafia. A ontologia construída e utilizada pelo sistema OntoArq, encontra-se disponível em :

$$
\text { https://www.ime.usp.br/ msolis/ontologies/ontoArq.owl }
$$

E a implementação e configuração do sistema encontra-se disponível em:

https://www.ime.usp.br/ msolis/projeto.php

A seguir exibimos algumas captura de tela do sistema implementado. 


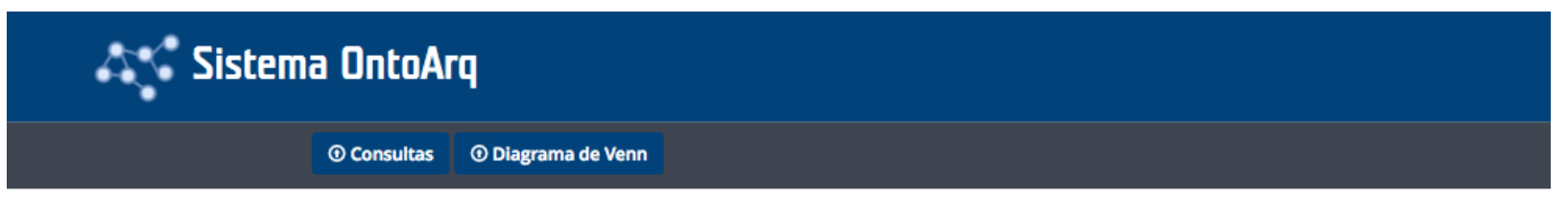

Sistema OntoArq / Consulta

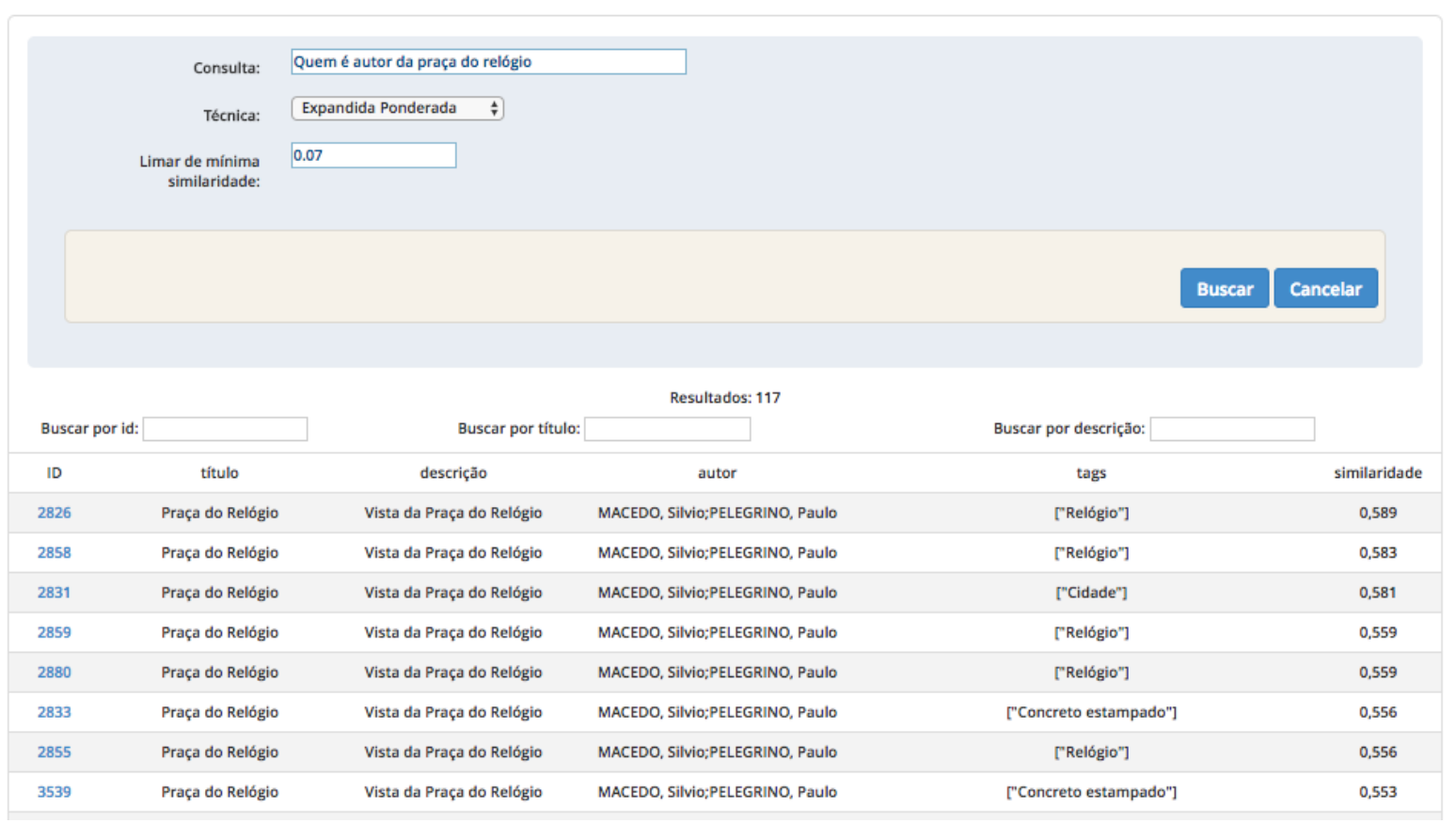

Figura B.1: Resultados para a consulta "Quem é autor da praça do relógio". 


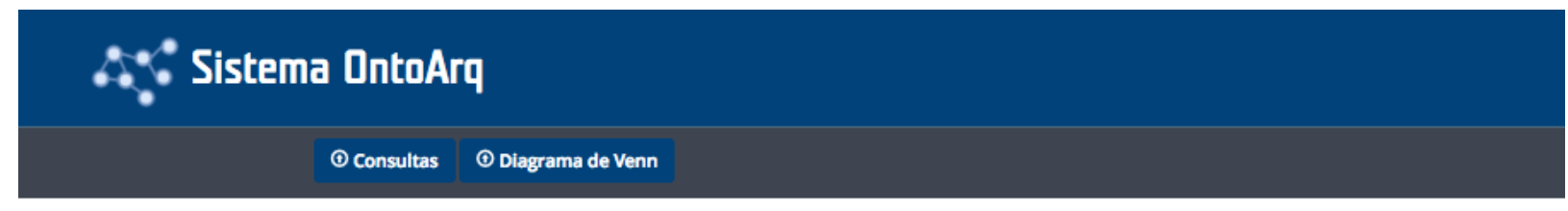

Sistema OntoArq / Consulta

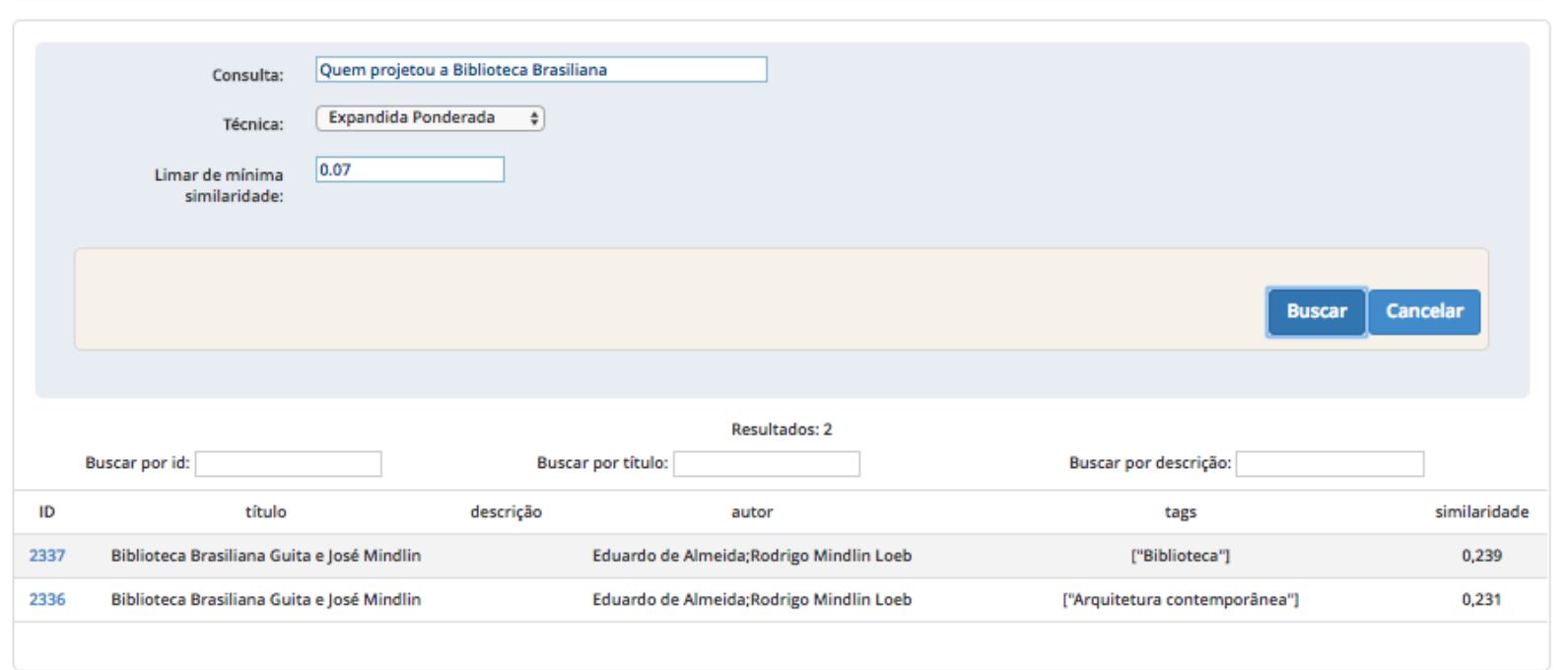

Marisol SY - Universidade de São Paulo - Brasil.

Figura B.2: Resultados para a consulta "Quem projetou a biblioteca brasiliana". 


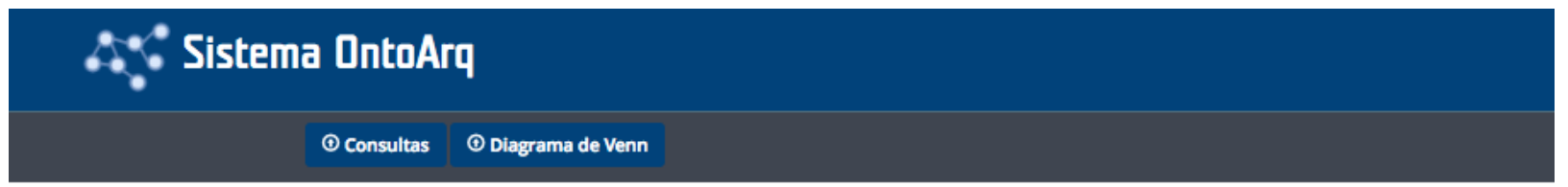

Sistema OntaArq / Consulta

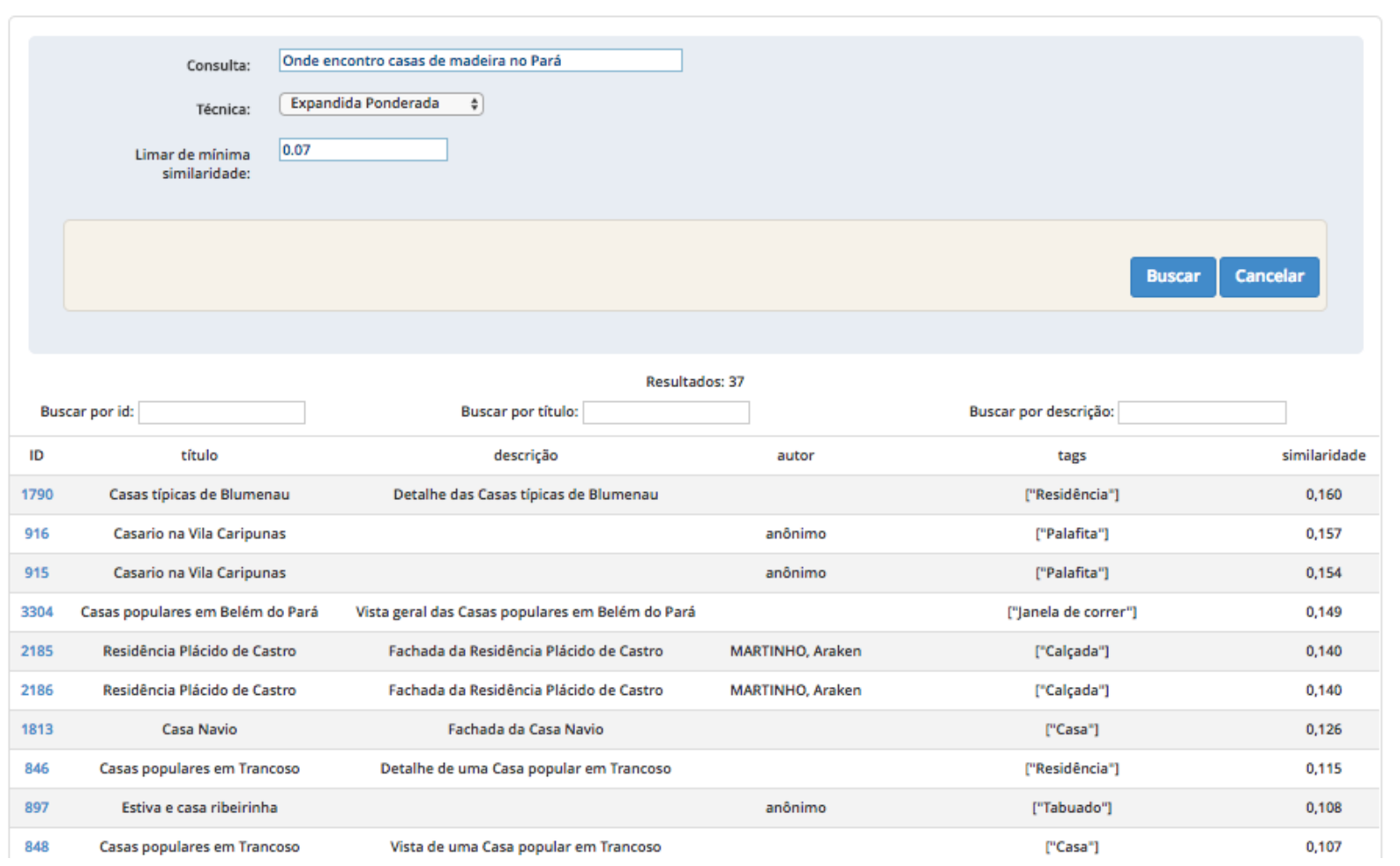

Figura B.3: Resultados para a consulta "Onde encontro casas de madeira no Pará". 


\section{Referências Bibliográficas}

[1] Vocabulario controlado da SIBi/USP, http://143.107.154.62/Vocab/Sibix652.dll/, Accesado: 01 março, 2016. 36

[2] Sunitha Abburu and G. Suresh Babu, Survey on ontology construction tools, International Journal of Scientific \& Engineering Research, IV (2013), 1748-1752. 14, 15

[3] Priyansh Arora, A novel approach for accurate retrieval of video using semantic annotations, Ph.D. thesis, THAPAR UNIVERSITY PATIALA, 2013. 31, 33

[4] R. Baeza-Yates, B. de Araujo Ribeiro-Neto, and B. Ribeiro-Neto, Modern information retrieval, ACM Press books, ACM Press, 1999. 1, 19, 24, 28, 63

[5] Fabiano Duarte Beppler et al., Um modelo para recuperação e busca de informação baseado em ontologia e no círculo hermenêutico, (2008). 32, 33

[6] Jagdev Bhogal, Andy Macfarlane, and Peter Smith, A review of ontology based query expansion, Information processing \& management 43 (2007), no. 4, 866-886. 66

[7] Willem Nico Borst, Construction of engineering ontologies for knowledge sharing and reuse, Ph.D. thesis, Universiteit Twente, September 1997. 7

[8] S. Ceri, A. Bozzon, M. Brambilla, E.D. Valle, P. Fraternali, and S. Quarteroni, Web information retrieval, Data-Centric Systems and Applications, Springer Berlin Heidelberg, 2013. 29

[9] Rashmi Chauhan, Rayan Goudar, Robin Sharma, and Atul Chauhan, Domain ontology based semantic search for efficient information retrieval through automatic query expansion, Intelligent Systems and Signal Processing (ISSP), 2013 International Conference on, IEEE, 2013, pp. 397-402. 2, 32, 33

[10] Stijn Christiaens, Metadata mechanisms: From ontology to folksonomy... and back, On the Move to Meaningful Internet Systems 2006: OTM 2006 Workshops, Springer, 2006, pp. 199207. 19

[11] Eduardo Corona and Carlos Alberto Cerqueira Lemos, Dicionário da arquitetura brasileira, Edart-São Paulo Livraria Editora, 1972. 36, 53

[12] Eunice R. Costa and Tatiana Douchkin, Thesaurus experimental de arquitetura, Tech. report, Fundação para a Pesquisa Ambiental, Universidade de São Paulo, 1982. 36

[13] Márcio Bezerra da Silva, A aplicação da folksonomia em sistemas de informação, $4^{\circ}$ Congresso Brasileiro de Arquitetura da Informação, São Paulo, 2010. 1 
[14] Ricardo de Almeida Falbo, Credine Silva de Menezes, and Ana Regina C da Rocha, A systematic approach for building ontologies, Ibero-American Conference on Artificial Intelligence, Springer, 1998, pp. 349-360. 15, 16, 34

[15] Jairo Francisco de Souza, Arquivos invertidos, http://www.ufjf.br/jairo_souza/files/ 2012/11/9-Indexa\%C3\%A7\%C3\%A3o-invertida.pdf, 2015, Acessado Novembro, 2015. ix, 21

[16] Ribeiro Costa Eucine and Douchkin Tatiana, Thesaurus experimental de arquitetura, FAUUSP, 1982. ix, 18, 19, 71

[17] Ricardo de Almeida Falbo, Giancarlo Guizzardi, and Katia Cristina Duarte, An ontological approach to domain engineering, Proceedings of the 14th international conference on Software engineering and knowledge engineering, ACM, 2002, pp. 351-358. 16

[18] Miriam Fernández, Iván Cantador, Vanesa López, David Vallet, Pablo Castells, and Enrico Motta, Semantically enhanced information retrieval: an ontology-based approach, Web Semantics: Science, Services and Agents on the World Wide Web 9 (2011), no. 4, 434-452. 32, 33, 75

[19] Thomas R Gruber, A translation approach to portable ontology specifications, Knowledge acquisition 5 (1993), no. 2, 199-220. 7, 8

[20] Michael Grüninger and Mark S Fox, Methodology for the design and evaluation of ontologies, International Joint Conference on Artificial Inteligence (IJCAI95), Workshop on Basic Ontological Issues in Knowledge Sharing, 1995. 15, 34

[21] Nicola Guarino, Understanding, building and using ontologies, International Journal of HumanComputer Studies 46 (1997), no. 2, 293-310. 8

[22] Nicola Guarino, Formal ontology and information systems, Proceedings of FOIS, vol. 98, 1998, pp. 81-97. ix, 7, 8

[23] Nicola Guarino, Daniel Oberle, and Steffen Staab, Handbook on ontologies, ch. What Is an Ontology?, pp. 1-17, Springer Berlin Heidelberg, Berlin, Heidelberg, 2009. 7, 8

[24] Giancarlo Guizzardi, Desenvolvimento para e com reuso: Um estudo de caso no domínio de vídeo sob demanda, Master's thesis, Universidade Federal do Espírito Santo, Brasil, 2000. 8

[25] Joana Hois, Mehul Bhatt, and Oliver Kutz, Modular ontologies for architectural design., FOMI, 2009, pp. 66-77. 51

[26] Matthew Horridge, Holger Knublauch, Alan Rector, Robert Stevens, and Chris Wroe, A practical guide to building OWL ontologies using the Protégé-OWL plugin and CO-ODE tools edition 1.0, University of Manchester (2004). 12

[27] Roman Kontchakov, Mariano Rodríguez-Muro, and Michael Zakharyaschev, Ontology-based data access with databases: A short course, Reasoning Web. Semantic Technologies for Intelligent Data Access, Springer, 2013, pp. 194-229. 93

[28] Dekang Lin, An information-theoretic definition of similarity., ICML-International Conference on Machine Learning, vol. 98, 1998, pp. 296-304. 23, 66 
[29] Yong Liu, Congfu Xu, Qiong Zhang, and Yunhe Pan, Ontology based semantic modeling for Chinese ancient architectures, Proceedings of the national conference on artificial intelligence, vol. 21, Menlo Park, CA; Cambridge, MA; London; AAAI Press; MIT Press; 1999, 2006, p. 1808.51

[30] Phillip Lord, Components of an ontology, http://ontogenesis.knowledgeblog.org/514, 2010, Acessado Abril, 2016. 11

[31] Fabiano Ferreira Luz, Consulta a ontologias utilizando linguagem natural controlada, Master's thesis, Universidade de São Paulo, 2013. 94

[32] George Macgregor and Emma McCulloch, Collaborative tagging as a knowledge organisation and resource discovery tool, Library review $\mathbf{5 5}$ (2006), no. 5, 291-300. 1

[33] Christopher D. Manning, Prabhakar Raghavan, and Hinrich Schütze, Introduction to information retrieval, Cambridge University Press, New York, NY, USA, 2008. 20, 21, 24

[34] Jacinto Mata, Mariano Crespo, and Manuel J Maña, Using MeSH to expand queries in medical image retrieval, MICCAI International Workshop on Medical Content-Based Retrieval for Clinical Decision Support, Springer, 2011, pp. 36-46. 2, 32

[35] Brian McBride, The resource description framework (RDF) and its vocabulary description language RDFS, Handbook on ontologies, Springer, 2004, pp. 51-65. 9

[36] Edison Andrade Martins Morais and Ana Paula L Ambrósio, Ontologias: conceitos, usos, tipos, metodologias, ferramentas e linguagens, Tech. report, Universidade Federal de Goiás, 2007, http://www.inf.ufg.br/sites/default/files/uploads/ relatorios-tecnicos/RT-INF_001-07.pdf. 16

[37] Boris Motik, Peter F Patel-Schneider, Bijan Parsia, Conrad Bock, Achille Fokoue, Peter Haase, Rinke Hoekstra, Ian Horrocks, Alan Ruttenberg, Uli Sattler, et al., OWL2 Web Ontology Language: Structural specification and functional-style syntax, W3C recommendation 27 (2009), no. $65,159.11,12,13$

[38] Viviane Orengo and Christian Huyck, A stemming algorithmm for the portuguese language, spire, IEEE, 2001, p. 0186. 22

[39] National Information Standards Organization, ANSI/NISO z39.19 - guidelines for the construction, format, and management of monolingual controlled vocabularies, National information standards series, NISO Press, 2005. 17

[40] Maria Elisa Valentim Pickler, Web semântica: ontologias como ferramentas de representação do conhecimento, Perspectivas em Ciência da Informação 12 (2007), no. 1, 65-83. 1

[41] Gerard Salton, Anita Wong, and Chung-Shu Yang, A vector space model for automatic indexing, Communications of the ACM 18 (1975), no. 11, 613-620. 24

[42] Vincent Schickel-Zuber and Boi Faltings, OSS: A semantic similarity function based on hierarchical ontologies., IJCAI, vol. 7, 2007, pp. 551-556. 22, 23

[43] Nigel Shadbolt, Wendy Hall, and Tim Berners-Lee, The semantic web revisited, Intelligent Systems, IEEE 21 (2006), no. 3, 96-101. 18 
[44] Jéssica Câmara Siqueira, A noção de folksonomia: uma abordagem terminológica, Tradterm 20 (2012), 129-145. 18

[45] Thabet Slimani, Ontology development: A comparing study on tools, languages and formalisms, Indian Journal of Science and Technology 8 (2015), no. 24. 14, 15

[46] Christian Danniel Paz Trillo, Recuperação de vídeos indexados por conceitos, Master's thesis, Instituto de Matemática e Estatística da Universidade de São Paulo, 21/03/2005., 2005. 2, 22, $33,63,64,66$

[47] Michael Uschold and Martin King, Towards a methodology for building ontologies, Citeseer, 1995. 34

[48] R. Baeza Yates and B. Ribeiro Neto, Recuperação de informação: Conceitos e tecnologia das máquinas de busca. 2ed., Bookman, Porto Alegre, 2013. 1, 19, 20 